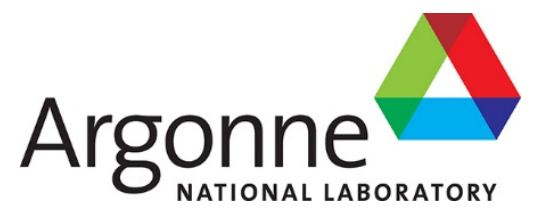

\title{
Draft Rules for Alloy 617 Creep-Fatigue Design using an EPP+SMT Approach
}

Applied Materials Division 


\section{About Argonne National Laboratory}

Argonne is a U.S. Department of Energy laboratory managed by UChicago Argonne, LLC under contract DE-AC02-06CH11357. The Laboratory's main facility is outside Chicago, at 9700 South Cass Avenue, Argonne, Illinois 60439. For information about Argonne and its pioneering science and technology programs, see www.anl.gov.

\section{DOCUMENT AVAILABILITY}

Online Access: U.S. Department of Energy (DOE) reports produced after 1991 and a growing number of pre-1991 documents are available free at OSTI.GOV (http://www.osti.gov/), a service of the US Dept. of Energy's Office of Scientific and Technical Information.

Reports not in digital format may be purchased by the public from the National Technical Information Service (NTIS):

U.S. Department of Commerce

National Technical Information Service

5301 Shawnee Rd

Alexandria, VA 22312

www.ntis.gov

Phone: (800) 553-NTIS (6847) or (703) 605-6000

Fax: (703) 605-6900

Email: orders@ntis.gov

Reports not in digital format are available to DOE and DOE contractors from the Office of Scientific and Technical Information (OSTI):

U.S. Department of Energy

Office of Scientific and Technical Information

P.O. Box 62

Oak Ridge, TN 37831-0062

www.osti.gov

Phone: (865) 576-8401

Fax: (865) 576-5728

Email: reports@osti.gov

\section{Disclaimer}

This report was prepared as an account of work sponsored by an agency of the United States Government. Neither the United States Government nor any agency thereof, nor UChicago Argonne, LLC, nor any of their employees or officers, makes any warranty, express or implied, or assumes any legal liability or responsibility for the accuracy, completeness, or usefulness of any information, apparatus, product, or process disclosed, or represents that its use would not infringe privately owned rights. Reference herein to any specific commercial product, process, or service by trade name, trademark, manufacturer, or otherwise, does not necessarily constitute or imply its endorsement, recommendation, or favoring by the United States Government or any agency thereof. The views and opinions of document authors expressed herein do not necessarily state or reflect those of the United States Government or any agency thereof, Argonne National Laboratory, or UChicago Argonne, LLC. 


\section{Draft Rules for Alloy 617 Creep-Fatigue Design using an EPP+SMT Approach}

Applied Materials Division

Argonne National Laboratory

September 2021

Prepared by

B. Barua, Argonne National Laboratory

M. C. Messner, Argonne National Laboratory

Y. Wang, Oak Ridge National Laboratory

T.-L. Sham, Idaho National Laboratory

R. I. Jetter, R. I. Jetter Consulting 



\section{ABSTRACT}

The report describes an improved new creep-fatigue design method for structural components in high temperature nuclear service. The new method uses an integrated elastic-perfectly plastic (EPP) analysis and Simplified Model Test (SMT) approach that greatly simplifies the design process by avoiding the separate evaluation of creep and fatigue damages and eliminating the requirement of stress classification. The report includes draft design rules, presented in a format compatible with an ASME nuclear Code Case, as well as a commentary on the rules and the validation of the rules using pressurized SMT (p-SMT) test data. Areas of potential improvement have been identified for further evaluation. The report also develops EPP+SMT design charts for Alloy 617 at temperatures between $800^{\circ} \mathrm{C}$ and $950^{\circ} \mathrm{C}$ by extrapolating high strain range, short hold test data to low strain range and long hold times, typical for structural components in high temperature nuclear service. The design charts are currently limited to 10,000 cycles to avoid excessive extrapolation outside the test database. More robust alternate extrapolation procedures will be considered in future work. The report includes several verification problems comparing the new EPP+SMT design method with current ASME creep-fatigue design methods. The comparison demonstrates that the EPP+SMT method significantly reduces the over-conservatism in current methods. Finally, the report includes a fully-documented sample problem with multiple load cases detailing the application of proposed EPP+SMT design rules. 



\section{TABLE OF CONTENTS}

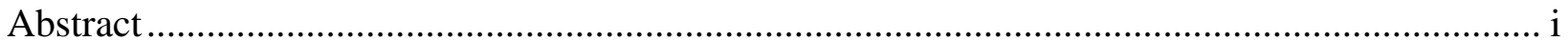

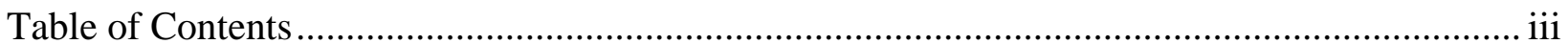

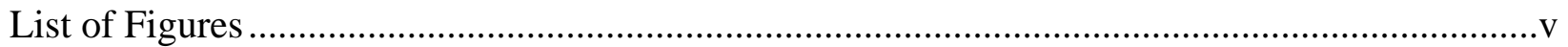

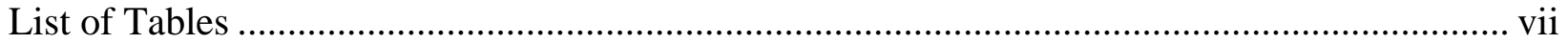

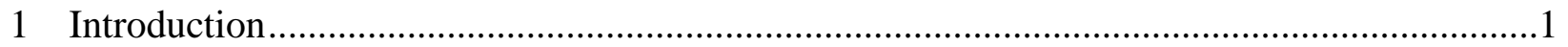

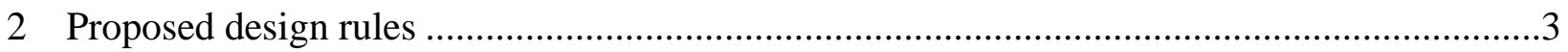

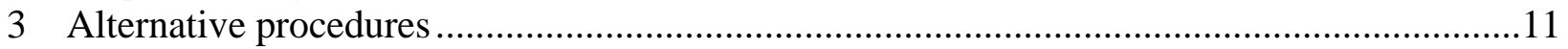

3.1 Composite cycle definition .......................................................................................

3.2 Creep-fatigue damage calculation ...........................................................................11

3.3 Allowable cycle design charts ................................................................................12

3.4 Cycle counting procedure ................................................................................................13

4 Commentary on the draft design rules and options selected for this report.............................15

4.1 Analysis method ...................................................................................................15

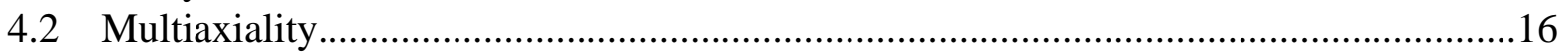

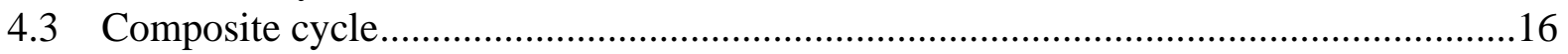

4.4 Creep-fatigue damage calculation ............................................................................18

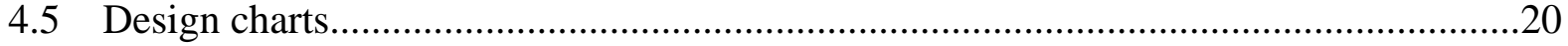

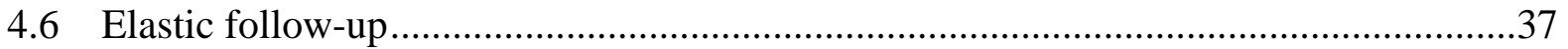

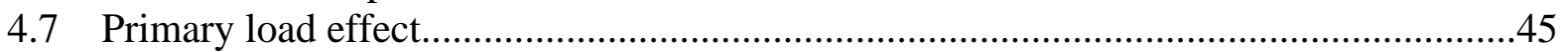

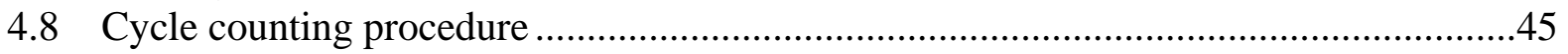

4.9 Validation with p-SMT tests........................................................................................48

5 Comparison with current ASME methods ............................................................................53

5.1 Sample problem-1: A flat head vessel ........................................................................53

5.2 Sample problem-2: A hot gas duct ………………...................................................56

5.3 Sample problem-3: STP-PT-070 Heat recovery steam generator outlet header..............58

6 Walk-through sample problem with multiple load cycles ..........................................................63

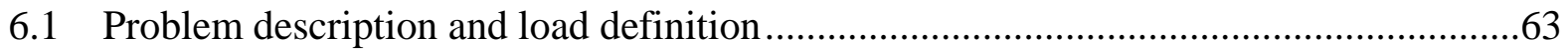

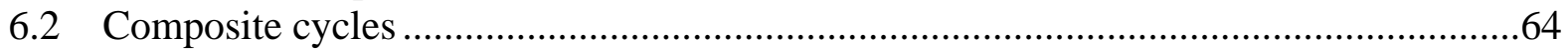

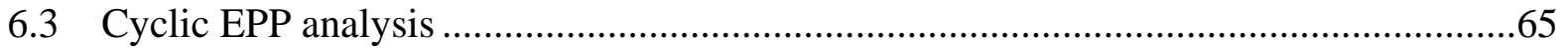

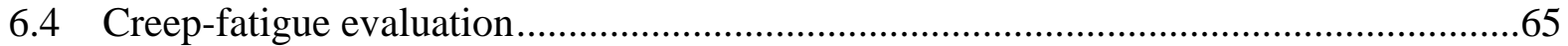

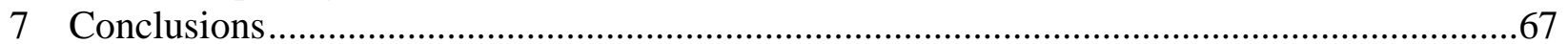

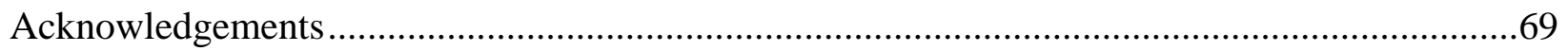

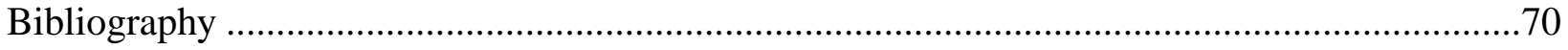





\section{LIST OF FIGURES}

Figure 4.1: Schematic demonstrating two different approaches for extrapolating high strain range, short hold time experimental data to low strain range, long hold time conditions...

Figure 4.2: Curve fit to the experimental fatigue and creep-fatigue data in the high strain range regime for Alloy 617 at different temperatures using the modified Coffin-shift model. Test data come from [14]

Figure 4.3: Nominal fatigue curves fit to fatigue test data at $800^{\circ} \mathrm{C}, 850^{\circ} \mathrm{C}$, and $950^{\circ} \mathrm{C}$. Fatigue test data come from [14].

Figure 4.4: Nominal EPP+SMT curves compared with creep-fatigue experimental data for Alloy 617 at $950^{\circ} \mathrm{C}$ with different hold times. Test data come from [14].

Figure 4.5: Nominal EPP+SMT curves compared with creep-fatigue experimental data for Alloy 617 at $950^{\circ} \mathrm{C}$ with different hold times. Creep-fatigue test data come from [14] . .......................... 27

Figure 4.6: Nominal EPP+SMT curves compared with creep-fatigue experimental data for Alloy 617 at $850^{\circ} \mathrm{C}$ with different hold times. Creep-fatigue test data come from [14] ......................... 28

Figure 4.7: Nominal EPP+SMT curves compared with creep-fatigue experimental data for Alloy 617 at $800^{\circ} \mathrm{C}$ with different hold times. Creep-fatigue test data come from [14].

Figure 4.8: Nominal EPP+SMT curves compared with creep-fatigue experimental data for Grade 91 at $600^{\circ} \mathrm{C}$ with different hold times. Creep-fatigue test data come from [12, 30].

Figure 4.9: Nominal EPP+SMT curves compared with creep-fatigue experimental data for Grade 91 at $550^{\circ} \mathrm{C}$ with different hold times. Creep-fatigue test data come from [30].

Figure 4.10: Nominal EPP+SMT curves compared with creep-fatigue experimental data for Grade 91 at $500^{\circ} \mathrm{C}$ with different hold times. Creep-fatigue test data come from [30].................... 32

Figure 4.11: Nominal EPP+SMT curves compared with creep-fatigue experimental data for $316 \mathrm{H}$ at different temperatures and hold times. Creep-fatigue test data come from [31, 32] .............. 33

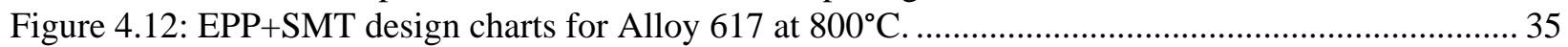

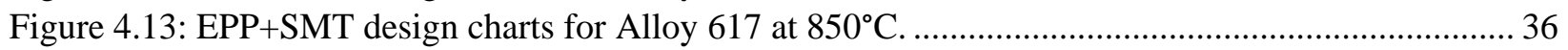

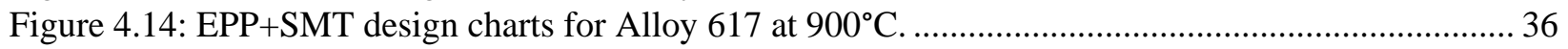

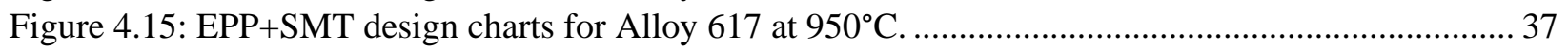

Figure 4.16: Axisymmetric finite element models for Type-1 and Type-2 SMT specimens. .................... 39

Figure 4.17: Example SMT test simulation results showing the contour plots of elastic follow up factor, Q during hold (determined from inelastic simulation) and steady cyclic equivalent strain range (determined from EPP cyclic analysis). Figures show half of the specimen....... 41

Figure 4.18: Alloy 617 SMT test results (considering $Q=Q \max$ and $\Delta \varepsilon=\Delta$ ceqmax) compared with average approach nominal curves $(Q=1)$ and creep-fatigue test data. SMT test data come from [14].

Figure 4.19: Alloy 617 SMT test results (considering $Q=$ Qavg and $\Delta \varepsilon=\Delta$ czzavg) compared with average approach nominal curves $(Q=1)$ and creep-fatigue test data. SMT test data come from [14].

Figure 4.20: Alloy 617 SMT test results (considering $\mathrm{Q}=1$ and $\Delta \varepsilon=\Delta \varepsilon$ eqmax) compared with average approach nominal curves $(Q=1)$ and creep-fatigue test data. SMT test data come from [14].

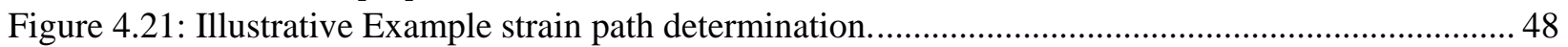

Figure 4.22: Axisymmetric finite element model for p-SMT tests. ........................................................ 49

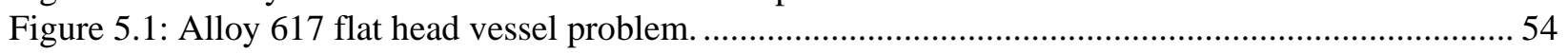

Figure 5.2: Alloy 617 hot gas duct problem. ……............................................................................. 56

Figure 5.3: Metal temperature at different through thickness locations of the inner tube (a) under normal operating conditions and (b) during an accidental incident as a result of broken thermal insulation between the liner and inner tubes. 
Figure 5.4: HRSG outlet header model. The model is half symmetric both out of the page (tube) and for the header (larger pipe section). 58

Figure 5.5: Design EPP+SMT chart for Grade 91 at $550^{\circ} \mathrm{C}$, based on ORNL test data. 59

Figure 5.6: Loading conditions for the sample problem.

Figure 6.1: Alloy 617 flat head vessel.

Figure 6.2: He temperature profiles under different composite cycles. (a) composite cycle type-1, (b) composite cycle type-2, and (c) composite cycle type-3. 


\section{LIST OF TABLES}

Table 4.1: Parameters for the modified Coffin-shift model for Alloy 617 at different temperatures......... 22

Table 4.2: Parameters for the modified Coffin-shift model for Alloy 617 at different temperatures......... 23

Table 4.3: Values of constants to be used in equations for constructing EPP+SMT design charts for Alloy 617 at temperatures between $800^{\circ} \mathrm{C}$ and $950^{\circ} \mathrm{C}$.

Table 4.4: Steady cyclic equivalent strain range from EPP analysis of Alloy 617 p-SMT tests under different loading conditions. p-SMT test data come from $[8,10]$.

Table 4.5: Best estimate creep-fatigue life using EPP+SMT method and inelastic analysis method compared with experimental life for Alloy 617 p-SMT tests. p-SMT test data come from $[8,10]$.

Table 4.6: Creep-fatigue design life compared between design by elastic analysis, design by inelastic analysis, and EPP+SMT method for Alloy 617 p-SMT tests. p-SMT test data come from $[8,10]$.

Table 5.1: Creep-fatigue design life of the A617 flat head vessel under different loading conditions compared for different design methods.

Table 5.2: Allowable accidental incidents for the hot gas duct problem compared for different design methods.

Table 5.3: Allowable design cycles for the three different creep-fatigue design methods.

Table 5.4: Allowable design life for design by inelastic analysis for different values of $\mathrm{K}^{\prime}$.

Table 6.1: He temperature, $T$ inside the vessel under different loading condition.

Table 6.2: Service loads and their repetitions considered in composite cycles.

Table 6.3: Summary of creep-fatigue evaluation at a critical location of the flat head vessel. 


\section{Introduction}

This report describes the development of a new creep-fatigue design method for high temperature nuclear structural components based on an integrated elastic-perfectly plastic (EPP) analysis and Simplified Model Test (SMT) approach [1-2]. The new method aims to overcome several limitations of current creep-fatigue design methods. Currently, Section III, Division 5 of the ASME Boiler and Pressure Vessel Code [3] and an associated nuclear Code Case [4] include three methods for evaluating creep-fatigue damage in high temperature structural components - design by elastic analysis, design by inelastic analysis, and design by EPP analysis. All three methods calculate creep and fatigue damage fractions separately and then compare those with a creep-fatigue damage interaction diagram, also known as D-diagram. These approaches are generally conservative relative to both other design methods and the creep-fatigue data itself. Because of large scatter in creep-fatigue data, the D-diagram is typically a generally conservative representation the nominal response. The new EPP+SMT method uses an integrated creep-fatigue damage evaluation approach that avoids the use of the D-diagram [1-2] with its artificial separation of creep and fatigue damage and the associated conservatism in their recombination for design evaluation. The method directly compares the strain range determined from an EPP analysis with design charts, conceptually developed directly from creep-fatigue and SMT tests, to determine the creep-fatigue damage.

A second advantage of the EPP+SMT method is its much simpler design evaluation process compared to current methods. The EPP analysis approach eliminates the need for stress classification and stress linearization used in the design by elastic analysis method. The process of selecting stress linearization location is always challenging especially for new component types versus conventional thin-walled pressure vessels. The strain range estimated through EPP analysis at any point of the structure approximately accounts for creep and plasticity [5] directly, without requiring additional input from the designer.

A third advantage of the EPP+SMT method is it explicitly accounts for the effect of elastic follow up in the creep-fatigue design procedure. It uses the results of SMT tests, developed through extensive research and development work [2, 6-13], to evaluate the elastic follow up on cyclic creepfatigue life. Elastic follow up is a reduction in the rate of stress relaxation, compared to fullystrain controlled relaxation, caused by stored elastic energy elsewhere in the mechanical system that tends to increase the development of creep-fatigue damage and decrease the component cyclic life. Accounting for elastic follow up is critical in developing an effective creep-fatigue design method. The new EPP+SMT method described here provides a more accurate simplified description of elastic follow than the current ASME design by elastic analysis rules. 
Chapter 2 of this report provides proposed draft EPP+SMT design rules in a format compatible with an ASME Code Case. These design rules do not present a complete, step by step method as several alterative options are available for several key design steps. Chapter 3 then discusses these alternatives by providing a high-level description of the different options. Chapter 4 then implements one potential complete procedure by detailing one choice for each alternative, including an executable step-by-step procedure. This chapter is also a commentary describing the rationale behind the design rules. For some elements of the design method the commentary summarizes the development work from past research [5, 14-16]. This chapter also discusses a procedure for generating the design charts in detail. The discussion includes investigation of several approaches for extrapolating high strain range, short hold time test data to low strain range and long hold times, typically experienced by structural components in high temperature nuclear service. The commentary then discusses the effect of elastic-follow up on creep-fatigue damage evaluation using the SMT test results. In the end, the commentary validates the overall design method using the pressurized SMT (p-SMT) test data.

Chapter 5 compares the version of the EPP+SMT method implemented in Chapter 4 with current design methods by analyzing several representative nuclear reactor components. Chapter 6 provides a worked sample problem with multiple load cases detailing the application of the rules to high temperature nuclear service. Finally, Chapter 7 summarizes the work presented in this report and discusses potential future improvements as well as the extension of the method to the other ASME Class A materials. 


\section{Proposed design rules}

This chapter provides draft rules for creep-fatigue assessment of Alloy 617 components using a design methodology based on combining the features of Elastic-Perfectly Plastic (EPP) analysis to determine structural response of a component and the Simplified Model Test (SMT) methodology for evaluation of the creep-fatigue damage accrued in the component as a result of that response. There are elements of the proposed draft that consideration of potential alternate approaches might lead to simpler, more readily implementable evaluation methods that might, however, potentially not be as accurate. In those cases, instead of delineating the initial approach in the draft rules, the details of the initial proposal are provided in Chapter 4 for use in the example problems. Further, the basic concept of these initial elements is briefly highlighted in Chapter 3 on "Alternative Approaches" along with a brief outline of the alternative being proposed for additional consideration.

Tables and figures are deliberately numbered as internal to the proposed design rules and not included in the global table and figure numbering scheme nor in the list of tables and figures for this report.

\section{GENERAL REQUIREMENTS}

Except as identified herein, all requirements of Section III, Division 5, Subsection HB, Subpart B apply to components designed in accordance with these rules.

The design methodology employed here for the evaluation of the creep-fatigue criteria is based on cyclic analyses using a small strain theory and an elastic-perfectly plastic material model with elastic and thermal properties defined in Nonmandatory Appendix II and a pseudo-yield stress selected to bound the actual steady state strain range at each location in the component. Guidance on cyclic elastic-perfectly plastic analysis is provided in Mandatory Appendix I.

The combination of Levels A, B, and C Service Loadings shall be evaluated for accumulated creep-fatigue damage, including hold time and strain rate effects. The criteria for a design to be acceptable is $D \leq 1$, where $D$ is the total accumulated creep-fatigue damage. The acceptance criteria must be met at all points in the structure.

(a) This design methodology is not applicable to structures where geometrical nonlinearities exist, e.g., canopy and omega seals.

(b) The stamping and data reports shall indicate the Case number and applicable revision.

\section{LOAD DEFINITION}

Define all applicable loads and load cases per Section III, Division 5, HBB-3113.2, Service Loadings.

\subsection{COMPOSITE CYCLE DEFINITION}


A composite cycle takes the Service Load definitions available to the design in the Owner's Design Specification and combines them into one or more analysis cycles. The objective of the composite cycle definition is to avoid requiring the designer to analyze each repetition of each individual Service Load to execute the creep-fatigue analysis. Chapter 3 discusses several alternative options and Chapter 4 details the option selected for the sample problem analyses in this report.

\section{NUMERICAL MODEL}

Develop a numerical model of the component, including all relevant geometric characteristics. The model used for the analysis shall be selected to accurately represent the component geometry, boundary conditions, and applied loads. The model must also be accurate for small details, such as small holes, fillets, corner radii, and other stress risers. The local temperature history shall be determined from a thermal transient analysis based on the thermal boundary conditions determined from the loading conditions defined in 2.

\section{CALCULATION OF CREEP-FATIGUE DAMAGE}

The creep-fatigue damage calculation procedure takes the composite cycle(s) defined in 2.1, runs a strain analysis on each cycle, and then uses the results of the strain analysis in conjunction with the design charts defined in Mandatory Appendix II to calculate the creep-fatigue damage fraction $D$. Chapter 3 describes alternative damage calculation procedures and Chapter 4 details the particular procedure used in the sample problems here.

\section{WELDMENTS}

Implementation of the evaluation of creep-fatigue damage in 4 above for weldments requires additional consideration.

\subsection{WELD REGION MODEL BOUNDARIES}

Figure 1 shows a full penetration butt weld as an example of the definition of a weld region. As shown, $w_{1}$ and $w_{2}$ are needed to define the weld region for use in this Code Case and are approximations consistent with the specified weld configuration and parameters. The specified weld region must include applicable stress concentrations in accordance with the requirements for analysis of geometry, HBB-T-1714, unless ground flush.

The weld shown in Figure 1 represents a full penetration butt weld in a shell. Other weld configurations may be needed for construction of an elevated temperature service component in accordance with Section III, Division 5, Subsection HB, Subpart B. Section III, Division 5, HBB4200 refers to various Section III, Division 1, Article NB-4000 paragraphs for weld configurations and requirements. These NB-4000 weld configurations are represented by the shaded region.

\subsection{ALLOWABLE CYCLES}


The number of allowable cycles in the weld region is one-half the number of allowable cycles from Mandatory Appendix-II for base metal.

\subsection{REQUIREMENTS}

The requirements for analysis of geometry of HBB-T-1714 are applicable for satisfaction of the requirements of this Code Case.

\subsection{PROPERTIES}

The thermal/physical properties of weldments shall be assumed to be the same as the corresponding base metal for the base metal-weld combinations listed in Nonmandatory Appendix-II.

\subsection{DISSIMILAR METAL WELDS}

The requirements for dissimilar metal welds are in the course of preparation.

Figure 1 Weld Region Model Boundaries

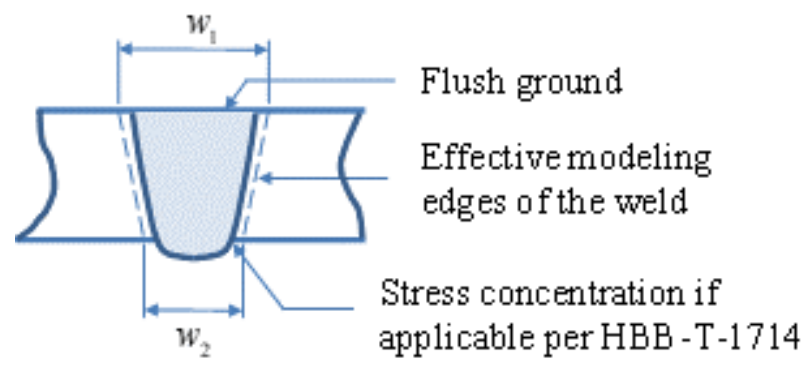




\section{MANDATORY APPENDIX-I}

\section{CYCLIC ELASTIC-PERFECTLY PLASTIC ANALYSIS}

Perform an elastic-perfectly plastic analysis to determine the stable strain range for use in the creep-fatigue evaluation.

(a) Define Composite Cycle Load Time-Histories and Step(s).

(1) Composite cycle load may consist of histories of mechanical loads, pressure loads, displacements, temperatures and thermal boundary conditions.

(2) Time-independent parts of the cycle may be truncated because the elastic-perfectly plastic analysis is not time dependent.

(3) The cycle should not have discontinuities. Discontinuities arising from the selection of the specified cycles to form a composite cycle should be eliminated by a simple and reasonable transition from one state to the next.

(4) Subject to the requirements in (b) the composite cycle time does not affect the result of the shakedown analysis.

(5) Temperatures, thermal boundary conditions, boundary displacements and mechanical loads over a cycle should be cyclic; that is, begin and end at the same value.

(6) A single analysis step may represent one cycle. Dividing a single cycle into more than one step to facilitate definition of the load cycle, and to ensure that maximum loads are analyzed, is often helpful.

(b) Define Analysis Types. A sequentially coupled thermal-mechanical analysis of the composite cycle may be performed. First a thermal analysis is performed to generate temperature histories. Next the mechanical analyses are performed using these temperature histories as inputs. Care must be taken that times in the mechanical analysis step and in the previous thermal analysis are the same or do not conflict, depending on the requirements of the analysis software.

Alternatively, a coupled thermal-mechanical analysis may be performed. The composite temperature history to be used in the mechanical analysis should be cyclic, that is the beginning and end temperature distributions should be the same.

(c) Define Material Properties. Perform an elastic-plastic cyclic mechanical and thermal stress analysis.

(1) For thermal analyses, density, temperature dependent specific heat, and conductivity will generally be required.

(2) For the mechanical analyses, the temperature-dependent properties required are elastic modulus, Poisson's ratio, and mean expansion coefficient. Density may also be required.

(d) Perform Analyses. Perform an elastic-plastic cyclic mechanical and thermal stress analysis using the temperature dependent pseudoyield stress defined above. Repeat the composite cycle until the structure achieves a stable strain range at all locations of the structure.

Care must be taken to ensure that the analysis deals with all the changes within a cycle. Elastic-plastic routines increase increment size where possible, and may miss a detail in the loading. A conservative limit to maximum increment size can address this problem, or division of the 
cycle into more than one step as in paragraph (a)(3) of this Appendix.

(e) Detect Constant Cyclic Strain Range Over Cycles.

(1) Repeat the composite cycle loading for $N$ cycles, where a good starting value of $N$ is typically 5.

(2) For each point in the structure calculate the strain difference from the beginning of repetition $N$ to the end of repetition $N$. Call this strain difference $\Delta \epsilon_{N}$.

(3) For each point in the structure calculate the strain difference from the beginning of repetition $N-1$ to the end of repetition $N-1$. Call this strain difference $\Delta \epsilon_{N-1}$.

(4) If $\Delta \epsilon_{N}=\Delta \epsilon_{N-1}$ everywhere in the component, then stop. No additional repetitions of the composite cycle are required and structure has reached a steady cyclic condition.

(5) If not, repeat the composite loading cycle for an additional repetition and repeat this procedure with repetitions $N+1$ and $N$. Continue until the structure achieves the steady cyclic condition defined in (4). All structures will eventually achieve this steady cyclic condition for the elastic-perfectly plastic material models used in the analysis. 


\section{MANDATORY APPENDIX-II \\ DESIGN CHARTS FOR CREEP-FATIGUE DAMAGE EVALUATION}

Chapter 3 discusses alternative methods for constructing the design charts based on the available creep-fatigue and SMT test data. Preliminary design charts are provided in Chapter 4 of this report. Final design charts are to be determined. 


\section{NONMANDATORY APPENDIX-I}

CYCLE COUNTING PROCEDURE

A cycle counting procedure takes the results of the composite cycle analysis, essentially a steady-cyclic temperature/strain history for all locations in the component, and converts the analysis results into the information required by the creep-fatigue damage procedure, a number of distinct load cycles, each defined by a temperature, strain range, hold time, and number of repetitions. Chapter 3 discusses several alternative approaches and Chapter 4 describes the approach used in the sample problems in detail. 


\section{NONMANDATORY APPENDIX-II}

PROPERTIES OF Alloy 617 (UNS N06617)

Mechanical and thermal properties for Alloy 617 are needed to complete the EPP analysis. These properties can be found in ASME Code Case N-898 as follows:

(1) Yield strength values are provided in Code Case N-898 Table HBB-I-14.5

(2) Isochronous stress-strain relations are provided in Code Case N-898 Table HBB-T-1800

(3) Thermal expansion values are provided in Code Case N-898 Table TE-4 and Table TE-4M

(4) Nominal coefficient of thermal Conductivity and thermal diffusivity values are provided in Code Case N-898 Table TCD

(5) Modulus of elasticity values are provided in Code Case N-898 Table TM-4 and Table TM$4 \mathrm{M}$

A final, complete Code Case will need to insert these properties directly into the ASME proposal, as Section III nuclear Code Cases cannot cross-references other Code Cases. 


\section{Alternative procedures}

The draft design rules in Chapter 2 do not fully detail the composite cycle, creep-fatigue damage summation, and allowable cycle design chart subprocedures. This report describes a complete, executable design procedure by implementing one option for each of these key subprocedures. Chapter 4 describes this implementation, which is then demonstrated in the sample problems in Chapters 5 and 6.

However, alternative approaches to the methods detailed in Chapter 4 are possible. These alternative approaches may be simpler and easier to execute. Additional work, including component testing, could be used to justify the selection from the alternative options.

\subsection{Composite cycle definition}

The design method avoids requiring the designer to analyze each repetition of each Service Load by using a composite cycle. The composite cycle captures the interaction of the individual Service Load transients on the resulting component strain range, while avoiding a full transient analysis.

The reference method in Chapter 4 modifies the current composite cycle construction approach in Code Cases N-861 and N-862 by allowing the designer to use multiple composite load cycles to better-represent expected plant operating conditions and by removing the exemption provided in $\mathrm{N}-862$, which allows the designer to include only a single Service Level C transient in the creepfatigue evaluation (and repeating the evaluation procedure for multiple composite cycles to capture the effect of each Service Level C Load).

Alternative options are available, for example, the Service Level C exemption could be retained in the new design approach. As structured in Code Cases N-861 and N-862, this permits the damage from the unexpected Level $\mathrm{C}$ events that require shutdown and evaluation for repair to be evaluated separately from the Service Level A and B events where the damage limits permit continued operation without further evaluation. For this approach, the allowable damage evaluation for the Service Level A and B events is D $\leq 1.0$ and the separate limit for Service Level C events is an additional $\mathrm{D} \leq 1.0$.

Going further, there are potential simplifications to the creep-fatigue damage evaluation if the Service Level A and B events are limited to a single composite cycle, thus avoiding the requirement to track the different composite cycle damage evaluations to ensure that their sum is $\leq 1.0$.

\subsection{Creep-fatigue damage calculation}

Calculating creep-fatigue damage is a critical part of the proposed design procedure. The process takes as input the composite cycle(s), performs a strain analysis of each cycle, and uses the analysis results in conjunction with the EPP+SMT design charts to calculate the creep-fatigue damage fraction. 
Chapter 4 describes a creep-fatigue damage calculation procedure based on current best-practices for calculating high temperature, strain-based, fatigue damage. The strain analysis uses an elastic perfectly-plastic constitutive model developed to bound the actual strain range in components in high temperature service, a cycle counting procedure to identify strain-based cycles from the results (see below), and Miner's rule to sum damage for all the identified cycles and (if used) multiple composite load cycles.

The advantage of the elastic perfectly plastic analysis is that, with an appropriate pseudo yield stress, it inherently approximates the strain redistribution due to plasticity and creep. In the reference approach, this comes with the expense of tracking cyclic hold time, strain ranges and sequence effects. Because it relatively accurately tracks strain redistribution there is no need for stress classification procedures. The original SMT based on elastic analysis likewise did not require stress classification for creep-fatigue damage evaluation since the redistribution is accounted in the configuration of the SMT specimen. However, explicit limits on stress concentrations in combination with elastic follow-up were required to achieve stable solutions. These explicit limitations are not required for the EPP methodology, which makes it more widely applicable. However, it may be advantageous to retain the elastic analysis approach to take advantage of its inherent simplicity. This will require additional study to see if the projected advantages are real for actual components and loadings

\subsection{Allowable cycle design charts}

Chapter 4 describes the basic problem of constructing design charts providing the allowable number of cycles for a given strain range, temperature, and hold time given fatigue, creep-fatigue, and SMT test data. The challenge is that the available data does not cover the strain ranges and hold times experienced by operating components and so the available data must be extrapolated to cover these conditions.

Chapter 4 describes the development of the extrapolation approach used in this report based on averaging two empirical approaches to extrapolating creep-fatigue data. While the chapter justifies the method both in reference to the currently available data and by limiting the application of the design charts to keep their application mostly in interpolating, rather than extrapolating, the data, an improved process would apply a less ad hoc method for extrapolating the test data. One possibility is using a mechanics based model to provide a more solid technical rational for the extrapolation outside the dataset.

The main difficulty is in estimating the effect of creep on high cycle fatigue. A direct experimental test would be a creep-fatigue experiment with a small strain range and a long hold time. These tests combine a large number of cycles to failure (strain range) with a comparatively long cycle period (hold time), meaning they take a very long time to cause failure. Direct tests data is therefore unavailable, necessitating the development of a means to extrapolate from higher strain range and shorter hold time data.

Many models for extrapolating creep-fatigue tests data have been proposed (c.f. [44]), but workbased methods have become comparatively popular [15, 45-48]. The basic idea of these approaches is that the material fails when the accumulated inelastic (dissipated) work 


$$
W=\int \boldsymbol{\sigma}: d \boldsymbol{\varepsilon}_{\text {in }}
$$

with $\boldsymbol{\sigma}$ the stress and $\boldsymbol{\varepsilon}_{\text {in }}$ the inelastic strain, reaches a critical value

$$
W=W_{\text {crit }}
$$

The challenge is that experimental data suggests the critical work-to-failure varies with the loading rate, naturally expressed in this model as the work rate. For a hypothetical test at a constant work rate the model could be expressed simply as failure occurs when:

where

$$
W=W_{\text {crit }}(\dot{W})
$$

$$
\dot{W}=\boldsymbol{\sigma}: \dot{\varepsilon}_{i n}
$$

However, no standard test actually takes place at a constant work rate. Moreover, creep-fatigue tests combine deformation at a fast work rate (loading) with deformation at a very slow work rate (holding). The work rate during the hold decreases asymptotically to zero for a fully-strain controlled test. For real tests then reformulating the model into a damage mechanics representation provides a means to capture the effect of time-dependent work rates on the failure predictions. This reformulation tracks the damage variable

$$
D=\int \frac{\dot{W}}{W_{\text {crit }}(\dot{W})} d t
$$

and predicts value when $D=1$.

Given the function $W_{\text {crit }}(\dot{W})$ and a suitable inelastic constitutive model this damage model can be used to develop nominal and design EPP+SMT curves. For any combination of temperature, $T$, strain range, $\Delta \varepsilon$, and hold time $t_{\text {hold }}$, the process is simple: simulate a test under the relevant conditions using the inelastic constitutive model and track the evolution of the damage variable $D$. When $D=1$ stop the simulation and record the number of cycles. Repeat this process for different temperatures, strain ranges, and hold times to generate the nominal curves. These nominal curves can then be factored to develop the EPP-SMT design curves. Thorough, validation is required before such an approach could be relied upon to construct the design curves.

\subsection{Cycle counting procedure}

A cycle counting procedure takes the results of the composite cycle analysis and identifies creepfatigue cycles - load reversals characterized by a strain range, temperature, hold time, and number of repetitions. A cycle counting procedure has two, somewhat contradictory goals: to account for the increase in strain range caused by the interaction of individual loading transients and to retain a connection to the number and frequency of the original Service Loadings.

Chapter 4 describes a cycle counting procedure based on the Wang-Brown method [49-50] for strain-based fatigue cycle counting, extended by recent work to provide a complete method for strain-based fatigue damage calculation for high temperature nuclear components [27]. 
The advantage of the Wang-Brown method is that it demonstrably accounts for the variables cited above when it is not possible to identify a cyclic maximum or minimum as required to implement the current cycle definition and counting procedures in HBB-T-1413 and HBB-T-1414. However, the proposed Wang-Brown method is still under ASME code committee review and approval (RC 20-661). Also, although comprehensive, its implementation is somewhat complex and tends to compromise the goal of simplicity and accessibility for the majority of ASME Code users.

Accordingly, it is recommended that the draft EPP-SMT code case for ASME consideration only reference the cycle counting procedures in HBB-T-1413 and HBB-T-1414 until RC 20-661 is fully approved. Further, a parallel effort should be initiated to see if a less comprehensive but simpler approach can be identified that would be consistent with uncertainties in load definition and as built properties and configuration associated with real components, loading and the other approximations in the EPP-SMT methodology. 


\section{Commentary on the draft design rules and options selected for this report}

The purpose of the design rules provided in Chapter 2 is to provide an EPP+SMT design method for creep-fatigue evaluation of Alloy 617 components in high temperature nuclear service. This chapter provides a commentary describing the rationale behind the proposed design rules. For some elements of the design method, as discussed below, the commentary summarizes the development work while referring to previous ART sponsored work [5, 14-16] for details. The commentary provides detailed discussion on the recent works including the procedure for generating the design charts, the effect of elastic-follow up on creep-fatigue damage evaluation, and finally, validating the overall design method through comparing with failure data from p-SMT tests.

\subsection{Analysis method}

As in the Section III, Division 5 design methodologies, the EPP+SMT creep-fatigue design method is also based on a design-by-analysis approach with two components: a method of analysis and design checks on the analysis results to guard against creep-fatigue damage. The analysis method EPP+SMT methodology uses is based on a cyclic analysis using an elastic-perfectly plastic material model using a pseudo yield stress not necessary equal to the actual material yield stress and small strain theory. The analysis method is defined as EPP analysis.

The EPP analysis method typically retains the elastic and thermal properties of the material but approximates the creep and plasticity using a pseudoyield stress, which is not necessarily the actual material yield stress. The theory behind these approximations has been developed over the past four decades [17-20]. Currently, ASME B\&PV Code allows the use of EPP methods for designing high temperature nuclear components through two Code Cases: N-861 [21] for limiting ratcheting strain accumulation and N-862 [4] for evaluating creep-fatigue damage. An in-progress [22] Code Case will provide a method for assessing long-term creep rupture, i.e. primary load design. Each of these methods uses a different definition for pseudoyield stress to bound the relevant quantities in EPP analysis.

The EPP+SMT methodology uses the EPP analysis to determine a steady cyclic strain range which can be directly compared to the design charts for creep-fatigue damage evaluation. This requires defining a pseudoyield stress to be used in EPP analysis so that the steady cyclic strain range determined from analysis properly accounts for the creep-fatigue damage. Messner et al. [5] determined this pseudoyield stress to be the lesser of the material yield strength and the $0.2 \%$ offset stress from the material isochronous stress-strain curve for a time equal to the composite cycle period. The rationale behind this definition of the pseudoyield stress along with several validation tests can be found in [5]. 
Note there is also a significant analysis change between this EPP+SMT approach and the current EPP Code Cases: N-861 and N-862. The EPP+SMT approach does not require establishing a shakedown in the EPP analysis, while the current EPP Code Cases [4, 31] require the designer to demonstrate plastic shakedown (N-861) to bound the ratcheting strain accumulation or elastic shakedown $(\mathrm{N}-862)$ before using the analysis results to calculate the creep-fatigue damage. The stabilized cyclic solution from EPP analysis is sufficient purely for the sake of finding a strain range to use in a design method, which is all the EPP+SMT approach requires. As guaranteed by the Frederick-Armstrong theorem [23], the EPP cyclic analysis eventually reaches a stable strain range everywhere in the component. However, this stabilized cyclic solution may have non-zero ratcheting. This type of solution, with or without ratcheting, is sufficient for a strain range based creep-fatigue life assessment like EPP+SMT, but not to bound the strain accumulation or creep damage in the current Code Cases. Note there is an exception for the eventual stable cyclic solution in an EPP analysis. As discussed in Section 4.9, a stable cyclic solution may not be reached in EPP analysis when the primary load exceeds the design load limit, due to progressive plastic collapse. However, this does not affect the design method as a component must pass the primary load limit before creep-fatigue evaluation using the proposed design rules.

The guidance in the proposed design rules suggests that five repetitions of the composite cycle may be enough to reach this steady condition. This suggestion is based on our experience with the method, in theory the steady loading condition may only occur asymptotically. The full design procedure directs the designer to continue cycling until stable strain ranges occur.

\subsection{Multiaxiality}

Structural components are often subjected to a multiaxial state of stress resulting from the type of loading or from geometric or thermal constraints. For example, stresses are biaxial even in simple vessel structures. Realistic components, e.g. nozzles, experience triaxial stress state near structural discontinuities. Past research [24, 25] have shown that the multiaxial stress field strongly influences the creep rupture life. The EPP+SMT design method, therefore, must account for the effect of stress multiaxiality on cyclic creep-fatigue cyclic life. The effect of stress multiaxiality is traditionally handled by developing a scaler effective stress measure, a map from a general state of stress to a scaler, that correlates the available multiaxial rupture data to the uniaxial data. Messner et al. [16] adopted this general approach but, as the EPP+SMT approach uses strain ranges instead of stress, defined a scalar effective strain range that incorporates the effect of multiaxiality. They discussed several methods based on the Huddleston model [26] for calculating the effective strain range from EPP analysis. Their recommendation is to retain the current ASME definition of effective strain range until the development of multiaxial SMT tests.

$$
\Delta \varepsilon_{e q}=\frac{\sqrt{2}}{3} \sqrt{\left(\Delta \varepsilon_{x}-\Delta \varepsilon_{y}\right)^{2}+\left(\Delta \varepsilon_{y}-\Delta \varepsilon_{z}\right)^{2}+\left(\Delta \varepsilon_{z}-\Delta \varepsilon_{x}\right)^{2}+\frac{3}{2}\left(\Delta \gamma_{x y}^{2}+\Delta \gamma_{y z}^{2}+\Delta \gamma_{z x}^{2}\right)}
$$

\subsection{Composite cycle}

A composite cycle combines the Service Loadings defined in the Owner's Design Specification into a single analysis load cycle for strain analysis. As described in Chapter 2, several alternative procedure are available. The following provides one step-by-step procedure, justified in Section 4.3.2 below. 


\subsubsection{Composite cycle procedure used in this report}

(a) Generate one or more composite cycles by composing together one or more of individual Service Loads into a single cycle. The number of composite cycles and the ordering of each individual Service Load within a composite cycle should be guided by any information about the expected ordering of Service Loads in actual operation. In the absence of such information, distributing transients uniformly throughout the component design life typically produces reasonable composite cycles.

(b) A composite cycle must be periodic; that is, it must start and end at the same pressures, mechanical loads, and temperature and/or thermal boundary conditions. This may require postulating new loads that are not defined in the Design Specification.

(c) Determine the number of repetitions of each composite cycle and refer it as $n^{i}$, where $i$ is the composite cycle type. For each type of Service Load in the Design Specification, the following relation must be satisfied.

where

$$
\sum_{i=1}^{p} n^{i} * n_{a}^{i}=n_{a}
$$

$p=$ total number of composite cycle types

$n^{i}=$ number of repetitions of composite cycle, $i$

$n_{a}^{i}=$ number of Service Load $a$ considered in the composite cycle $i$

$n_{a}=$ total number of Service Load $a$ in the Design specification

\subsubsection{Commentary on the composite cycle procedure}

As in the current Code Cases $(\mathrm{N}-861, \mathrm{~N}-862)$ the EPP+SMT method also requires the designer to define composite cycle for EPP cyclic analysis. However, there is a change in the definition of the composite cycles for EPP+SMT compared to the current Codes Cases. The Code Cases requires the designer to define an overall composite cycle that includes all relevant features from the individual Level A, B, and C Service Loadings. The Code Cases allow multiple composite cycles only when Service Level C Loadings are included with Service Level A and B Loadings for separate evaluation. In both cases, the Code Cases only require the total time the component will be at temperature above the negligible creep temperature to determine the pseudoyield stress. The Code Cases do not keep track of the repetitions of different type of Loadings in the design specification.

In the EPP+SMT method, on the other hand, designers must keep track of all the Service Loadings and the corresponding number of repetitions in the design specification. The designer may use as many composite cycles as required to include all the Loadings in the design calculation. Each composite cycle may contain several different types of Service Loading transients or can use just a single Service Loading. The EPP+SMT method uses the total time contained in each composite cycle as a key parameter in the EPP analysis. 
For each composite cycle, a creep-fatigue damage fraction is calculated using the cyclic stabilized strain range(s) determined from the EPP analysis and the design charts. The design passes if the sum of the creep-fatigue damage fractions, following the Miner's rule, from all composite cycles along with their repetitions is less than 1 . This requires ensuring all Loadings in the design specification to be included in the composite cycles so that the creep-fatigue damage from each Loading is included in the total creep-fatigue damage calculation. The relation expressed in Eq. 4.2, therefore, must be satisfied for each type of Service Loading when generating the composite cycles.

Note a composite cycle must be periodic, i.e. it must start and end at the same pressures, mechanical loads, and temperature and/or thermal boundary conditions. To meet this requirement the draft rules allow postulating new loads that are not defined in the design specification. However, the time of the postulated load should not be counted toward the cycle period of the composite cycle. As discussed in Section 4.1, the composite cycle period is required to determine the pseudoyield stress for EPP cyclic analysis.

\subsection{Creep-fatigue damage calculation}

The creep-fatigue damage calculation process takes the composite cycles, executes a strain analysis, and calculates a creep-fatigue damage fraction accounting for all the Service Loads in the design specification based on those analysis results and the SMT design charts. The following details the damage calculation procedure adopted in the remainder of this report.

\subsubsection{Creep-fatigue damage calculation approach used in this report}

Step-1. Determine the cycle period corresponding to each composite cycle defined in 2.1 (in draft rules provided in Chapter 2) and refer the cycle period as $t^{i}$, where $i$ is the composite cycle type. The cycle period, $t^{i}$ is the total time of the Service Loads assigned to composite cycle, $i$, accounting only for the individual Service Load within the composite cycle and not the total time duration during the design life of the component. The fictitious loads used to enforce periodicity in composite cycle shall be assigned a zero time in this calculation.

Step-2. For each composite cycle determine the temperature dependent pseudoyield stress, $S_{\varepsilon}^{i}(T)$. The pseudo-yield stress is equal to the lesser of the quantities defined in (a) and (b) below.

(a) The yield strength, $S_{y}$, given in Nonmandatory Appendix-II (in draft rules provided in Chapter 2).

(b) Stress determined from the isochronous stress-strain curves in Nonmandatory Appendix-II (in draft rules provided in Chapter 2) for a $0.2 \%$ offset in strain from the elastic slope at temperature, $T$ and for time, $t^{i}$.

Step-3. Perform a cyclic elastic-perfectly plastic analysis, following the guidance provided in Mandatory Appendix I (in draft rules provided in Chapter 2), for each composite cycle with the temperature dependent pseudoyield stress, $S_{\varepsilon}^{i}(T)$ determined in Step 2.

Step-4. From the steady cyclic condition achieved in the analysis performed in Step 3, determine all the total, elastic plus plastic, strain components $\left(\varepsilon_{x}, \varepsilon_{y}, \varepsilon_{z}, \gamma_{x y}, \gamma_{y z}, \gamma_{x z}\right)$ and temperature, $T$ for each composite cycle at each point of interest in the structure. 
Step-5. From the strain and temperature history determined in Step 4, calculate the strain ranges, $\Delta \epsilon_{j}^{i}$, temperatures $T_{j}^{i}$, and corresponding number of cycles $N_{j}^{i}$ for each composite cycle using the procedure in Nonmandatory Appendix-I (in draft rules provided in Chapter 2), HBB-T1413 or HBB-T-1414 with $v^{*}=0.5$.

Step-6. A time must be assigned to each individual full or half cycle determined in Step 5 to index to the corresponding number of allowable cycles from the design charts in Mandatory Appendix II. Refer this time as $t_{j, k}^{i}$. Designers must use engineering judgement and a conservative approach for assigning these times. The assigned times must satisfy the following relation for all composite cycles.

where

$$
\sum_{j=1}^{q} \sum_{k=1}^{N_{j}^{i}} N_{j, k}^{i} * t_{j, k}^{i} \geq t^{i}
$$

$q=$ total number of cycle types determined in Step-5 for composite cycle, $i$

$N_{j, k}^{i}=1$ for a full cycle and 0.5 for a half cycle

An example of a conservative approach of assigning times to cycles would be identifying two half cycles with the largest strain ranges from the list of cycles determined in Step 5 and assign the cycle period of the respective composite cycle to these two half cycles. Then, the rest of the cycles within that composite cycle may be assigned a zero time.

Step-7. For each $\left(\Delta \epsilon_{j}^{i}, T_{j}^{i}, t_{j, k}^{i}\right)$ determine the allowable number of cycle, $N_{d}\left(\Delta \epsilon_{j}^{i}, T_{j}^{i}, t_{j, k}^{i}\right)$ from the design charts in Mandatory Appendix-II.

Step-8. Calculate the total accumulated creep-fatigue damage using Eq. 4.4. Additional requirement for welds are found in 5 (in draft rules provided in Chapter 2).

$$
D=\sum_{i=1}^{p} \sum_{j=1}^{q} \sum_{k=1}^{N_{j}^{i}} \frac{Q * n_{i} * N_{j, k}^{i}}{N_{d}\left(\Delta \epsilon_{j}^{i}, T_{j}^{i}, t_{j, k}^{i}\right)}
$$

where the designer shall determine an appropriate value of the elastic follow up factor, $Q$, for piping systems and may use $Q=2$ for other components.

\subsubsection{Commentary on the creep-fatigue damage method}

The EPP+SMT approach is an integrated creep-fatigue damage evaluation approach that avoids the separate evaluation of creep and fatigue damage and the use of D-diagram. Similar to the fatigue damage calculation in current design methods, the EPP+SMT approach uses strain range vs allowable cycles design charts for creep-fatigue damage calculation. For each composite cycle type, $i$, the strain and temperature history are first extracted from the EPP analysis after achieving the steady cyclic condition. The steady cyclic strain and temperature history is then used to determine sets of strain range, $\Delta \epsilon_{j}^{i}$, temperature, $T_{j}^{i}$, and corresponding number of cycles, $N_{j}^{i}$, using the procedures in Section III, Division 5, Nonmandatory Appendix HBB-T-1413 or HBB-T-1414, or Nonmandatory Appendix I in the draft design rules provided in Chapter 2. The Nonmandatory Appendix I is a new cycle counting procedure recently developed by Rovinelli et al. [27] and currently being balloted to be included in the Code. 
While the fatigue design curves are only temperature dependent, the EPP+SMT design charts also depend on time. The time dependence of the EPP+SMT design charts accounts for the creep damage in addition to the fatigue damage. This requires keeping track of the time during the strain range calculation and correctly assigning a time to each individual full or half cycle to index to the corresponding number of allowable cycles from the EPP+SMT design charts. However, a procedure is not currently available for this. While a complete guidance must await further development, the draft design rules recommend applying engineering judgement and a conservative approach. The total of the assigned times must be equal to or greater than the cycle period of the composite cycle following Eq. 4.3.

The procedure above describes one conservative approach. This approach essentially identifies two half cycles with the largest strain ranges and assign the cycle period of the respective composite cycle to these two half cycles. Then, the rest of the cycles within that composite cycle may be assigned a zero time.

Similar to fatigue damage calculation in current design methods, the EPP+SMT approach uses Miner's rule to determine the total creep-fatigue damage following Eq. 4.4. The rationale for the value of $Q$ to use in Eq. 4.4 is discussed in Section 4.6.

\subsection{Design charts}

The EPP+SMT design method uses allowable cycle design charts to calculate the creep-fatigue damage fraction. These design charts are essentially modified fatigue design curves plotting an effective strain range versus the expected number of cycles to failure. In addition to the effect of strain range and temperature, as in the conventional fatigue design curves, the EPP+SMT design charts must account for the effect of hold time and elastic follow up. The SMT test methodology was developed to experimentally control all four variables. However, like the conventional creepfatigue tests, performing the SMT tests at low strain ranges with long holds, typical for structural components under operating conditions, is not practically possible. Although both types of tests are conceptually possible they would take very long time to complete. Therefore, a procedure must be developed to extrapolate the high strain range, short hold test results to low strain ranges and long hold times. This section develops such procedures by investigating several different extrapolation approaches. The effect of elastic follow up is discussed in Section 4.6 by comparing the SMT test data with the nominal curves developed in this section.

\subsubsection{Extrapolation approaches}

\subsubsection{Direct extrapolation}

This approach directly extrapolates the results of fatigue and creep-fatigue tests with short hold time and high strain range to low strain range regime and long hold times. Figure 4.1 provides a schematic description of the direct extrapolation approach along with the classical approach discussed below. The creep-fatigue trendline is first determined using high strain range, short hold test data that is then extrapolated to realistic long hold times and low strain ranges using an appropriate model. 
The direct extrapolation approach uses a modified Coffin-shift model to determine the cycles to failure given a strain range and hold time. The modified Coffin-shit model was developed in [15] through modifying the base Coffin-shift model to capture the hold time effect on the saturation of the creep damage accumulation. Development of the modified Coffin-shift model is briefly discussed below.

The base Coffin-shift model originates from the frequency-modified fatigue equations proposed by Coffin [28] for time-dependent fatigue. It is essentially the standard fatigue equation in the high strain range multiplied with a factor to account for the hold time:

$$
N^{c f}=\frac{C}{\Delta \varepsilon^{n}}\left(\frac{1}{1+t_{h}}\right)^{p}
$$

where $N$ is the cycles to failure under creep-fatigue load, $\Delta \varepsilon$ is the strain range, $t_{h}$ is the hold time, and $C, p, n$ are some temperature dependent constants. Note the change in Eq. 4.5 from previous work [14] where the value of $n$ was assumed to be 1, i.e. a linear correlation with fixed slope of 1 between cycles to failure and strain range in the log-log space for experimental test data in the high strain range regime. However, further investigation indicates that the high strain range regime fatigue and creep-fatigue test data can be better described if the slope is not considered to be constant, i.e. a variable $n$ in Eq. 4.5 .

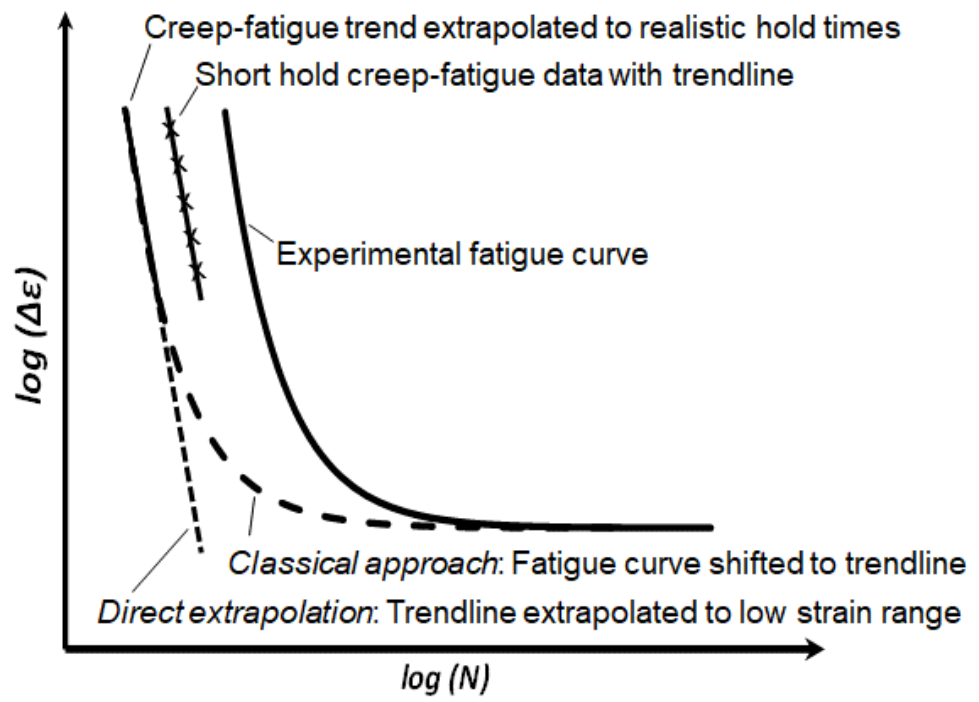

Figure 4.1: Schematic demonstrating two different approaches for extrapolating high strain range, short hold time experimental data to low strain range, long hold time conditions.

Messner et al. [15] demonstrated that the base Coffin-shift model exaggerates the effect of hold time on cyclic life when compared with Alloy 617 creep-fatigue tests. Stress relaxes during the hold portion of a creep-fatigue experiment and for a long hold will essentially reach a point where it accumulates negligible creep damage. The base Coffin-shift model does not reflect this saturation of creep damage accumulation as it postulates zero cyclic life for an infinite hold time. To capture the effect of hold time on creep damage saturation the base Coffin-shift model is modified to: 


$$
N^{c f}=\frac{C}{\Delta \varepsilon^{n}} \frac{\left(\frac{1}{1+t_{h}}\right)^{p}+D}{1+D}
$$

where $D$ is an additional temperature dependent constant. As discussed in Section 4.5.2, the modified Coffin-shift model is found to reasonably capture the trend of creep-fatigue test data in high strain range regime. The constants in Eq. 4.6 are determined from available high strain range fatigue and creep-fatigue tests at different temperatures. Table 4.1 provides the values of the constants and Figure 4.2 show the curve fits to the experimental data. For the direct extrapolation approach Eq. 4.6 can be rewritten for nominal curves as:

$$
N_{\text {nominal }}^{c f, \text { direct }}=\frac{C}{\Delta \varepsilon^{n}} \frac{\left(\frac{1}{1+t_{h}}\right)^{p}+D}{1+D}
$$

\begin{tabular}{ccccc}
\hline$T$ & $C(T)$ & $p(T)$ & $D(T)$ & $n(T)$ \\
\hline $800^{\circ} \mathrm{C}$ & 0.1339 & 4.459588 & 0.233113 & 1.8556 \\
$850^{\circ} \mathrm{C}$ & 0.1339 & 2.459588 & 0.233113 & 1.8556 \\
$950^{\circ} \mathrm{C}$ & 0.1937 & 3.173761 & 0.615903 & 1.7220 \\
\hline
\end{tabular}

Table 4.1: Parameters for the modified Coffin-shift model for Alloy 617 at different temperatures.
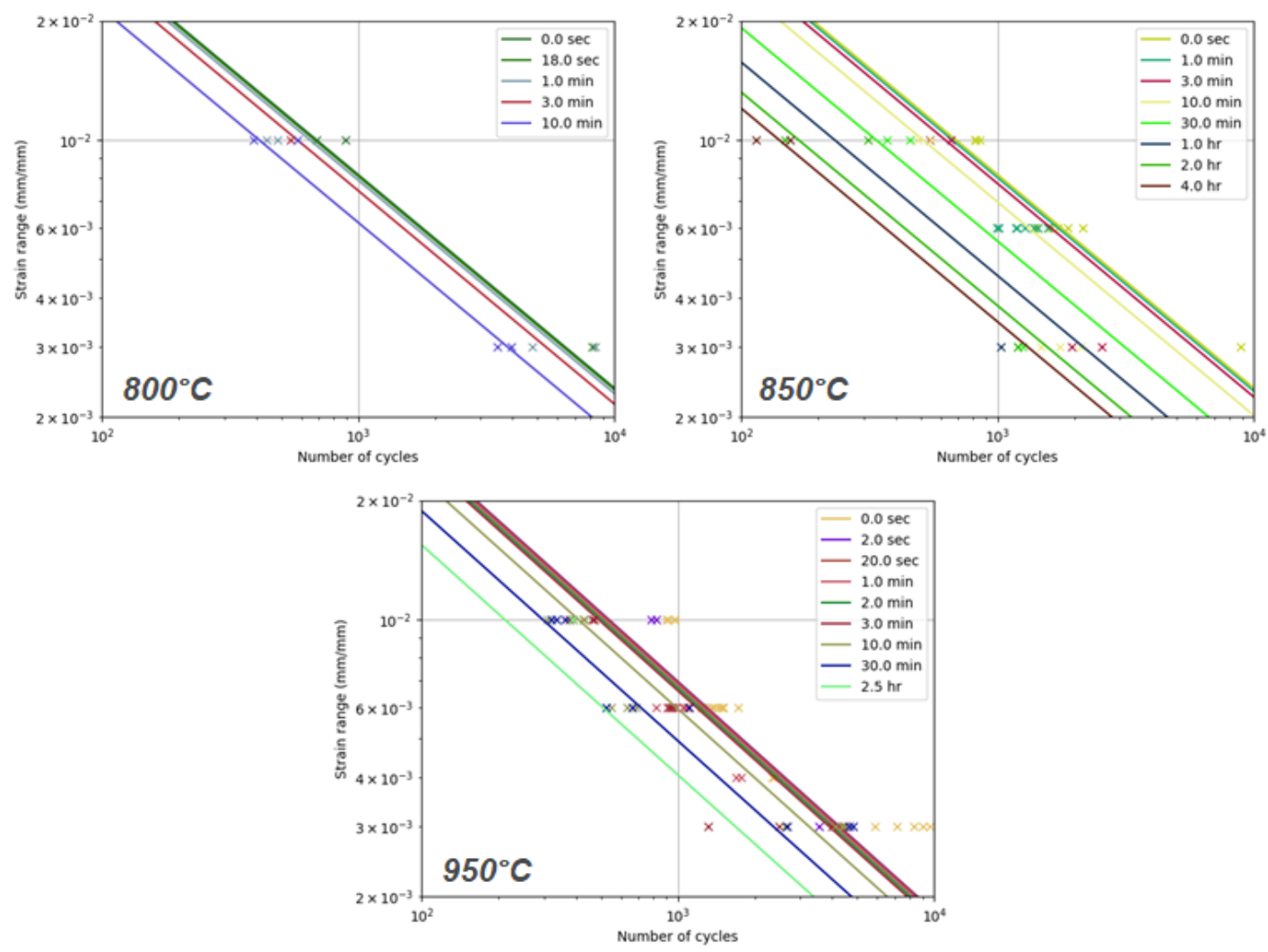

Figure 4.2: Curve fit to the experimental fatigue and creep-fatigue data in the high strain range regime for Alloy 617 at different temperatures using the modified Coffin-shift model. Test data come from [14]. 


\subsubsection{Classical approach}

The standard fatigue equation, $N^{f}=\frac{C}{\Delta \varepsilon^{n}}$, used in the Coffin-shift model cannot capture the behavior of the material in the low strain range regime. Therefore, an alternate to the direct extrapolation approach could be just shifting the experimental fatigue curve based on the shift parameters determined using the modified Coffin-shift model. This approach is defined as the classical approach. It is still based on the modified Coffin-shift approach but shifts the nominal fatigue curve instead of the trendline determined using high strain range data. Figure 4.1 sketches a schematic illustration of the approach. The equation for nominal curve using classical approach is then:

$$
N_{\text {nominal }}^{\text {cf,classical }}=N_{\text {nominal }}^{f}\left\{\frac{\left(\frac{1}{1+t_{h}}\right)^{p}+D}{1+D}\right\}
$$

where $N_{\text {nominal }}^{f}$ represents the cycles to failure under fatigue load and its values directly come from the nominal fatigue curves as a function of strain range, $\Delta \varepsilon$. The shift factor, $\frac{\left(\frac{1}{1+t_{h}}\right)^{p}+D}{1+D}$, is determined using the temperature dependent constants $p$ and $D$ from Table 3.1 and $t_{h}$. This shift factor is then used to shift the nominal fatigue curve to the realistic long hold times. The temperature dependent nominal fatigue curves are generated using:

$$
\Delta \varepsilon=a_{1}(T) * N_{\text {nominal }}^{f} b_{1}(T)+a_{2}(T) * N_{\text {nominal }}^{f} b_{2}(T)
$$

where $a$ 's and $b$ 's are temperature dependent constants for Alloy 617. Table 4.2 provides the values of the constants for Alloy 617 at $800^{\circ} \mathrm{C}, 850^{\circ} \mathrm{C}$, and $950^{\circ} \mathrm{C}$. Figure 4.3 shows the nominal fatigue curves along with the fatigue test data.

Note the Alloy 617 Code Case [29] includes fatigue design curves at $427^{\circ} \mathrm{C}, 704^{\circ} \mathrm{C}, 871^{\circ} \mathrm{C}$, and $954^{\circ} \mathrm{C}$, while the creep-fatigue test to construct the EPP+SMT design charts are available at $800^{\circ} \mathrm{C}$, $850^{\circ} \mathrm{C}$, and $950^{\circ} \mathrm{C}$. We, therefore, constructed the $800^{\circ} \mathrm{C}, 850^{\circ} \mathrm{C}$, and $950^{\circ} \mathrm{C}$ fatigue curves basing on the temperature dependent trends in the Code fatigue curves and the available fatigue test data at these temperatures. Figure 4.3 indicates that there are enough fatigue test data at $950^{\circ} \mathrm{C}$ and therefore good agreement between the test data and the model curve. There are only a few fatigue test data at $800^{\circ} \mathrm{C}$ and $850^{\circ} \mathrm{C}$ to make a proper comparison between experiment and model curves. The nominal fatigue curves at these two temperatures are therefore based on the interpolation between the fatigue curves provided in the Code Case.

\begin{tabular}{lcccc}
\hline$T$ & $a_{1}(T)$ & $b_{1}(T)$ & $a_{2}(T)$ & $b_{2}(T)$ \\
\hline $800^{\circ} \mathrm{C}$ & 0.879951 & -0.74747 & 0.007539 & -0.08785 \\
$850^{\circ} \mathrm{C}$ & 1.104091 & -0.7916 & 0.006743 & -0.08693 \\
$950^{\circ} \mathrm{C}$ & 1.086107 & -0.78928 & 0.003383 & -0.06287 \\
\hline
\end{tabular}

Table 4.2: Parameters for the modified Coffin-shift model for Alloy 617 at different temperatures. 


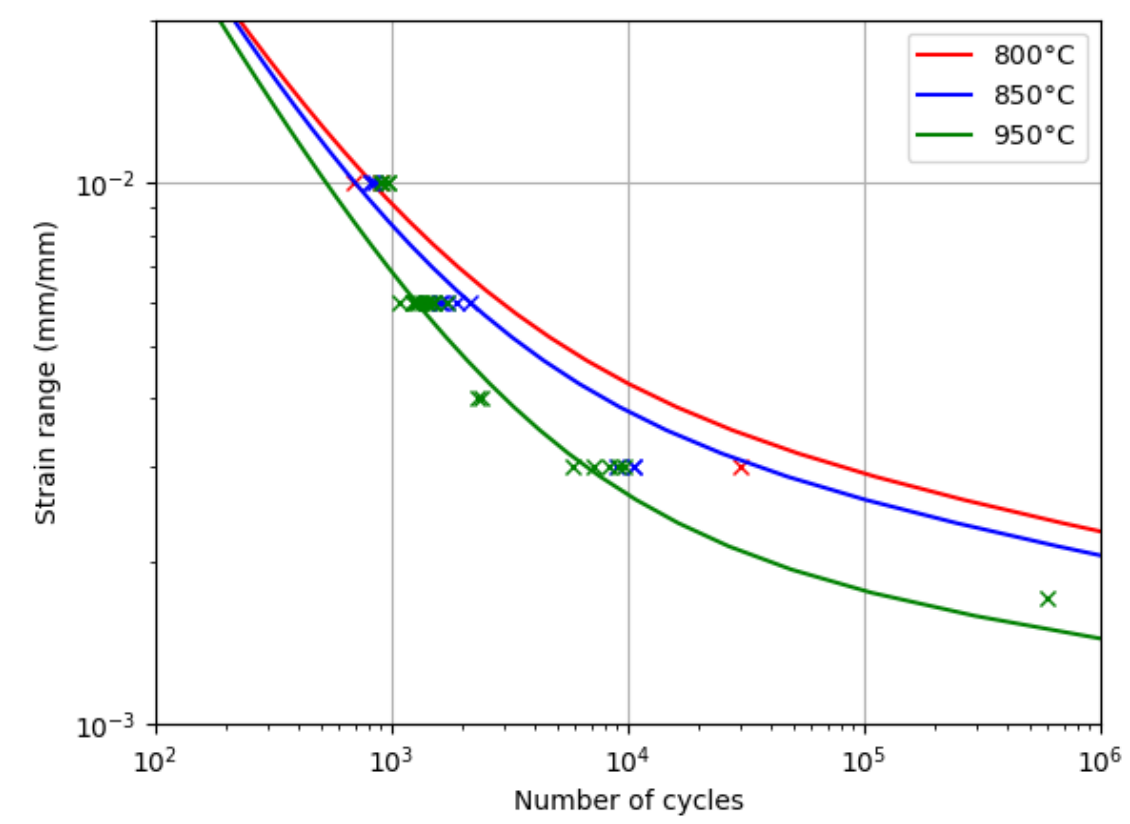

Figure 4.3: Nominal fatigue curves fit to fatigue test data at $800^{\circ} \mathrm{C}, 850^{\circ} \mathrm{C}$, and $950^{\circ} \mathrm{C}$. Fatigue test data come from [14].

\subsubsection{Average approach}

As discussed in Section 4.5.2, both the direct extrapolation and classical approaches predict the creep-fatigue test results in the high strain range with reasonable accuracy. In the low strain range regime, however, the direct extrapolation approach seems to be overly conservative and the classical approach appears to over predict the cyclic life. As a compromise, therefore, we also investigate an average approach by taking the algebraic average of the strain ranges from the direct extrapolation and classical approaches as a function of cycles to failure.

$$
\Delta \varepsilon_{\text {nominal }}^{c f, \text { average }}(N)=\frac{\Delta \varepsilon_{\text {nominal }}^{c f, \text { direct }}(N)+\Delta \varepsilon_{\text {nominal }}^{c f, \text { classical }}(N)}{2}
$$

\subsubsection{Comparison of extrapolation approaches}

Three approaches are discussed above for constructing the EPP+SMT curves through extrapolating fatigue and creep-fatigue test results to low strain range regime and long hold times. This section investigates the competing extrapolation approaches for Alloy 617 by comparing the available creep-fatigue test data with the predicted nominal EPP+SMT curves. The section also examines the extrapolation approaches for two other Class A materials - Grade 91 and 316H.

Figure 4.4 to Figure 4.7 plot the EPP+SMT nominal curves constructed using different extrapolation approaches along with the creep-fatigue test data for Alloy 617 at different temperatures and hold times. The figures indicate the predicted curves from all the extrapolation approaches are very similar in the high strain range regime $(\Delta \varepsilon>0.4 \%)$. All the approaches also predict the experimental test data with good accuracy in the high strain range regime for all temperatures and hold times. This indicates the trend of the creep-fatigue test data in the high strain range regime is well captured by all the approaches. 
With decreasing strain range, however, the predicted curves start diverging from each other. The difference between experimental data and the predicted curves also becomes prominent for all the different extrapolation approaches. Therefore, the comparison of different approaches in predicting the creep-fatigue test data in the intermediate to low strain range regime is important for determining the best extrapolation approach for constructing the EPP+SMT curves.

The comparison between predicted curves and the creep-fatigue test data in the intermediate strain range regime $(0.2 \%<\Delta \varepsilon<0.4 \%)$ for Alloy 617 does not point toward one approach that works best at all the temperatures. While only the direct extrapolation approach, as indicated by Figure 4.7, appears to provide reasonable prediction of the intermediate strain range data at $850^{\circ} \mathrm{C}$; all three approaches, as indicated by Figure 4.4 and Figure 4.5 , predict the $950^{\circ} \mathrm{C}$ test data in the intermediate strain range regime with reasonable accuracy. Only a few test data at $800^{\circ} \mathrm{C}$ indicate both direct extrapolation and average approach provide reasonable prediction of the test data in the intermediate strain range regime. This inconsistency could be due to various reasons, for example, not enough test data to reasonably cover the variation in the creep-fatigue tests or a change in creep-fatigue mechanism with temperature. However, note that, due to the limited number of test data, as discussed in Section 4.5.1.2, the fatigue curves at $800^{\circ} \mathrm{C}$ and $850^{\circ} \mathrm{C}$ are constructed based on the Code fatigue design curves provided at $704^{\circ} \mathrm{C}$ and $871^{\circ} \mathrm{C}$. This may have affected the extrapolation approaches to some extent. Future work will further investigate this issue.

An important objective of the extrapolation approaches is to predict the creep-fatigue behavior in the low strain range regime. Creep-fatigue tests in the low strain range regime takes long time to complete. Therefore, only two creep-fatigue test data, close to the upper bound $(0.2 \%)$ of the low strain range regime are available for Alloy 617. The strain range, hold time, and temperature conditions for these tests are $0.165 \%, 20 \mathrm{sec}$, and $950^{\circ} \mathrm{C}$ and $0.18 \%, 2 \mathrm{~min}$, and $950^{\circ} \mathrm{C}$. To give a perspective on the time required to complete creep-fatigue tests in the low strain range regime, the time taken by these two tests are about 18 and 95 days, respectively, which are very long considering the relatively short hold times used in these tests. Plots in Figure 4.4 compare results from these tests with the nominal curves from different extrapolation approaches. The $20 \mathrm{sec}$ hold time test data falls in between the classical and average approach curves, while the 2 min hold time test data falls exactly on the classical approach curve. These comparisons point toward using the average approach for extrapolating the test data into the low strain range regime. The discussion below further investigates the extrapolation approaches for Grade 91 and $316 \mathrm{H}$ to provide supporting evidence. 
Figure 4.8 to Figure 4.10 compare the creep-fatigue test data with nominal EPP+SMT curves constructed using different extrapolation approaches for Grade 91 at different temperatures and hold times. Figure 4.11 compares the same for $316 \mathrm{H}$. Similar to the observation for Alloy 617, all three approaches predict the high strain range test data with good accuracy. This includes a $316 \mathrm{H}$ creepfatigue test with adequately long hold time of $5 \mathrm{hr}$ which again verifies the ability of the modified Coffin-shift model to capture the hold time effect on the creep-fatigue damage accumulation. The comparison for all the intermediate strain range data for both Grade 91 and $316 \mathrm{H}$ suggests the average approach representing the experimental test data better than both the direct extrapolation and classical approaches. Including all the creep-fatigue test data for Grade 91 and $316 \mathrm{H}$, the average approach curve either closely matches with or bounds the experimental data. The same statement about the average approach can be made for Alloy 617 creep-fatigue test data at $950^{\circ} \mathrm{C}$. While the extrapolation approaches need further investigation for Alloy 617 creep-fatigue tests data at $850^{\circ} \mathrm{C}$ and $800^{\circ} \mathrm{C}$, our current recommendation is to use the average approach at all temperatures for Alloy 617. The Alloy 617 design charts provided below are therefore constructed using the average approach.
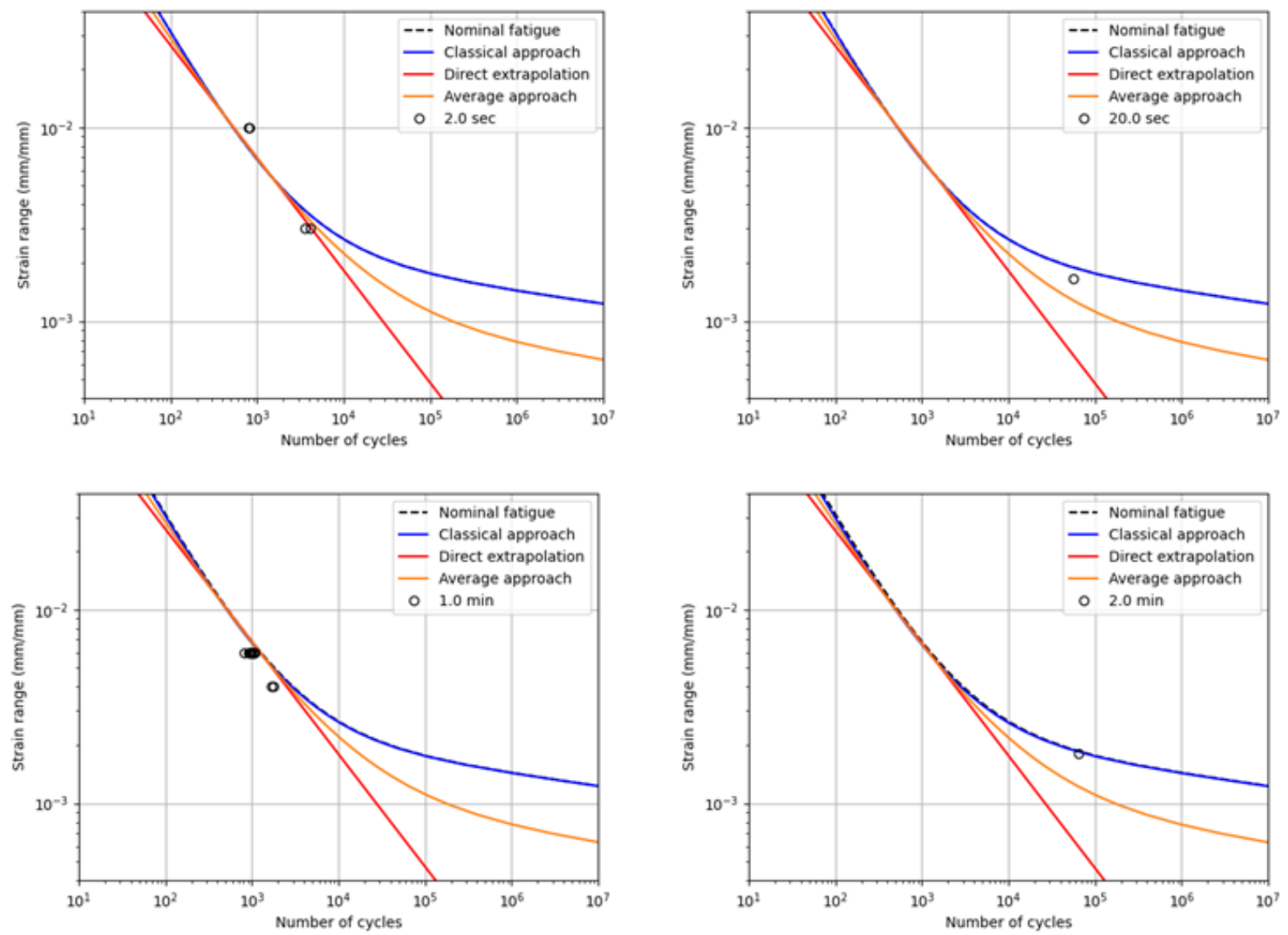

Figure 4.4: Nominal EPP+SMT curves compared with creep-fatigue experimental data for Alloy 617 at $950^{\circ} \mathrm{C}$ with different hold times. Test data come from [14]. 

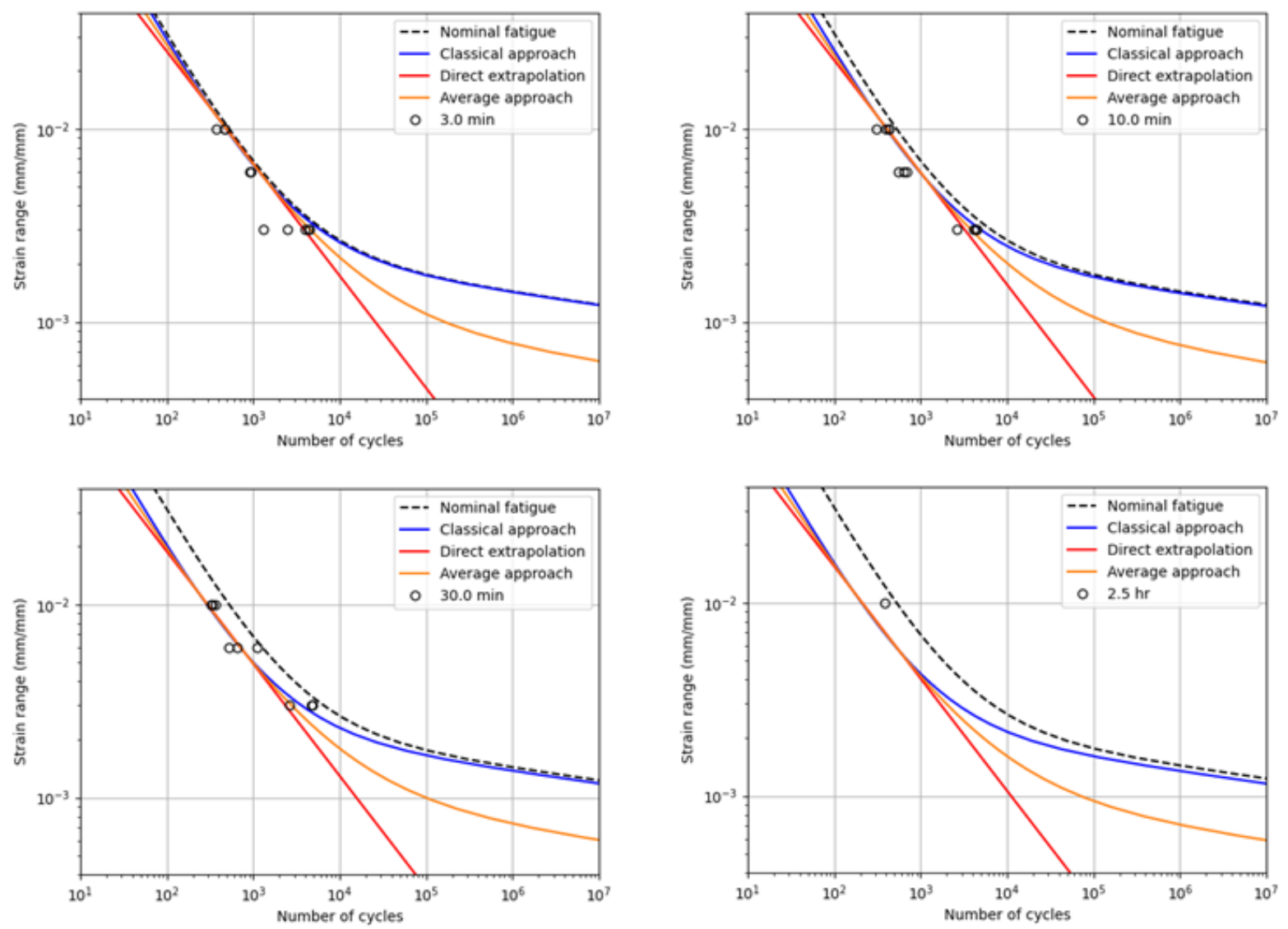

Figure 4.5: Nominal EPP+SMT curves compared with creep-fatigue experimental data for Alloy 617 at $950^{\circ} \mathrm{C}$ with different hold times. Creep-fatigue test data come from [14]. 

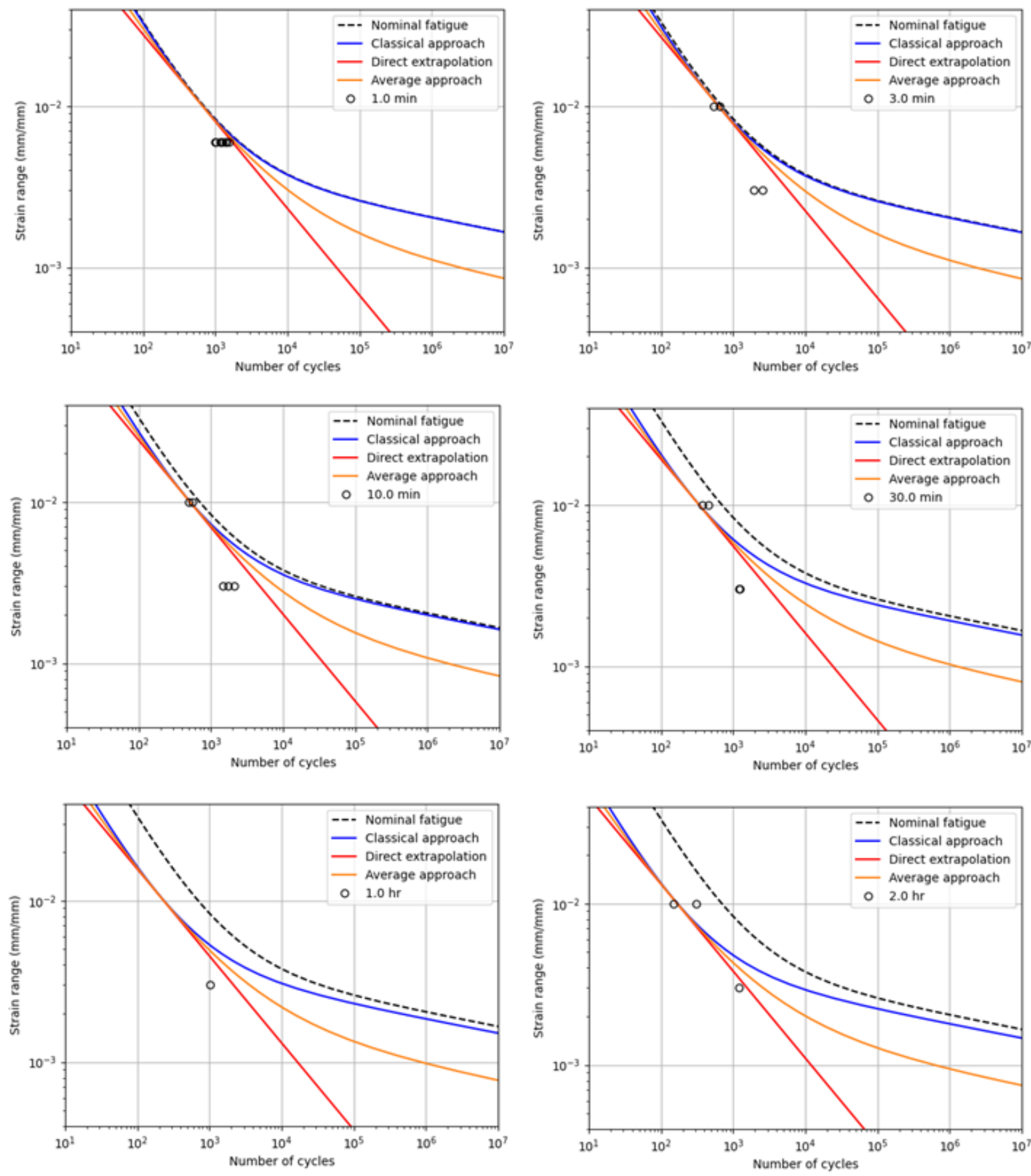

Figure 4.6: Nominal EPP+SMT curves compared with creep-fatigue experimental data for Alloy 617 at $850^{\circ} \mathrm{C}$ with different hold times. Creep-fatigue test data come from [14]. 

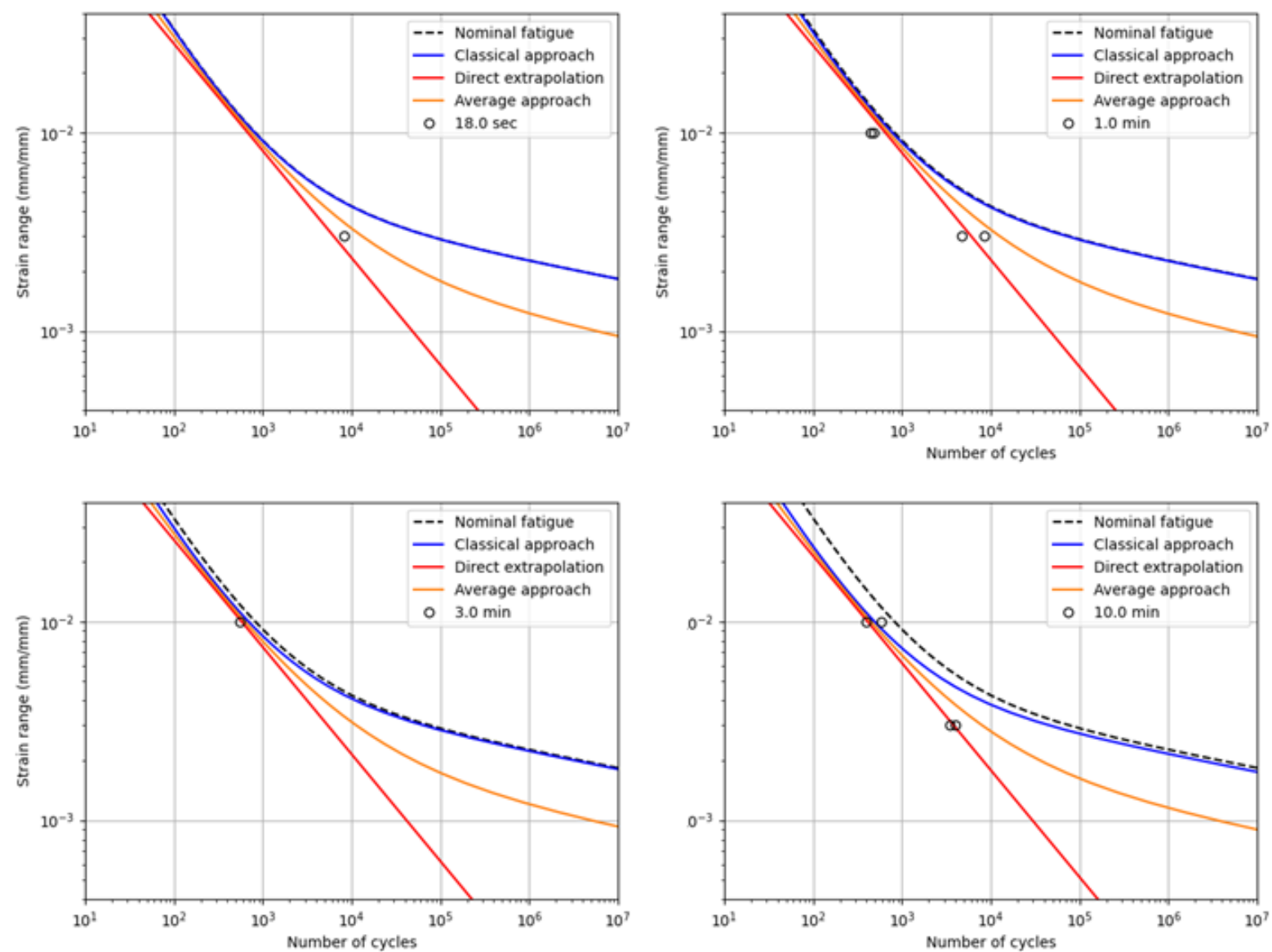

Figure 4.7: Nominal EPP+SMT curves compared with creep-fatigue experimental data for Alloy 617 at $800^{\circ} \mathrm{C}$ with different hold times. Creep-fatigue test data come from [14]. 

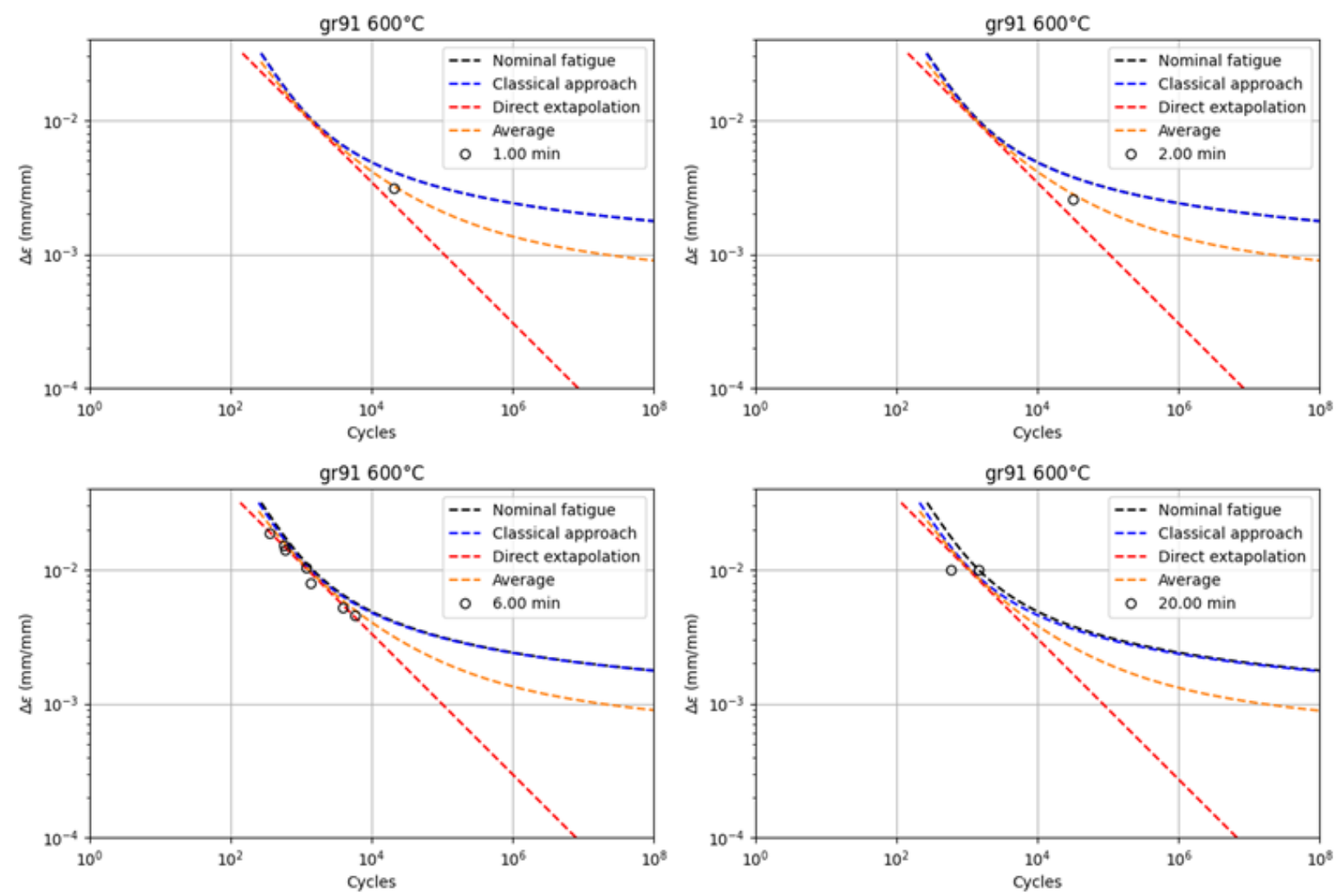

Figure 4.8: Nominal EPP+SMT curves compared with creep-fatigue experimental data for Grade 91 at $600^{\circ} \mathrm{C}$ with different hold times. Creep-fatigue test data come from [12, 30]. 

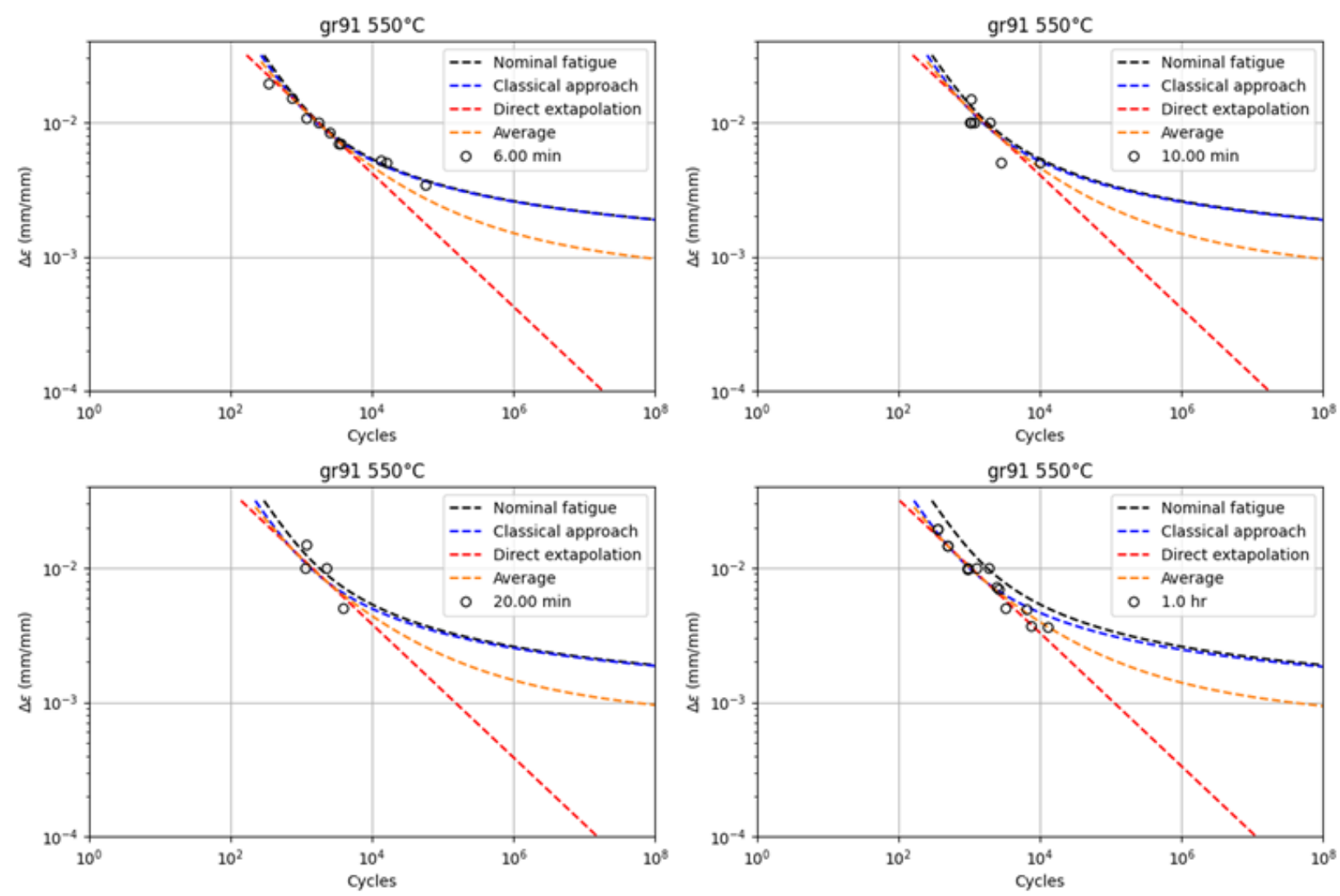

Figure 4.9: Nominal EPP+SMT curves compared with creep-fatigue experimental data for Grade 91 at $550^{\circ} \mathrm{C}$ with different hold times. Creep-fatigue test data come from [30]. 

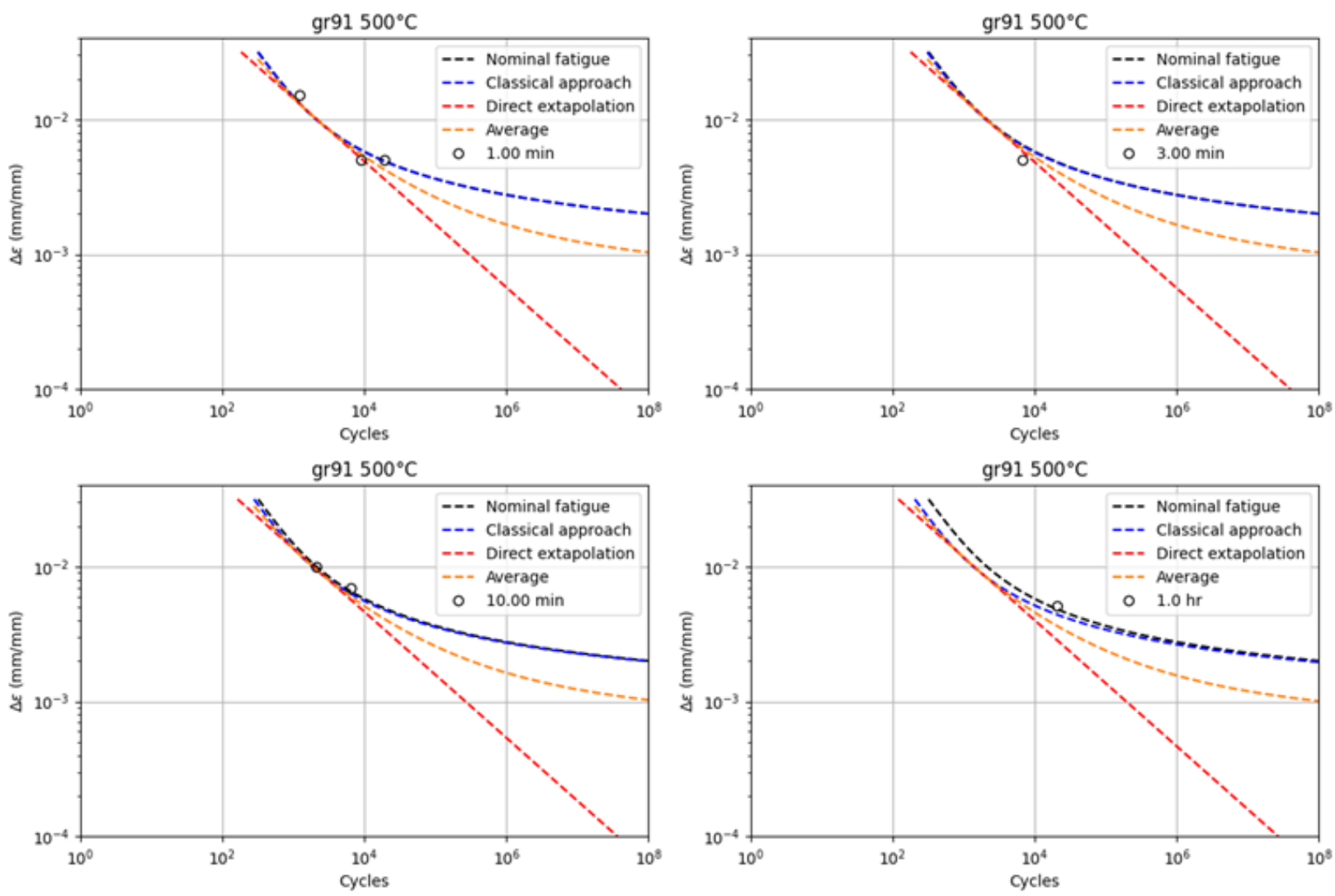

Figure 4.10: Nominal EPP+SMT curves compared with creep-fatigue experimental data for Grade 91 at $500^{\circ} \mathrm{C}$ with different hold times. Creep-fatigue test data come from [30]. 

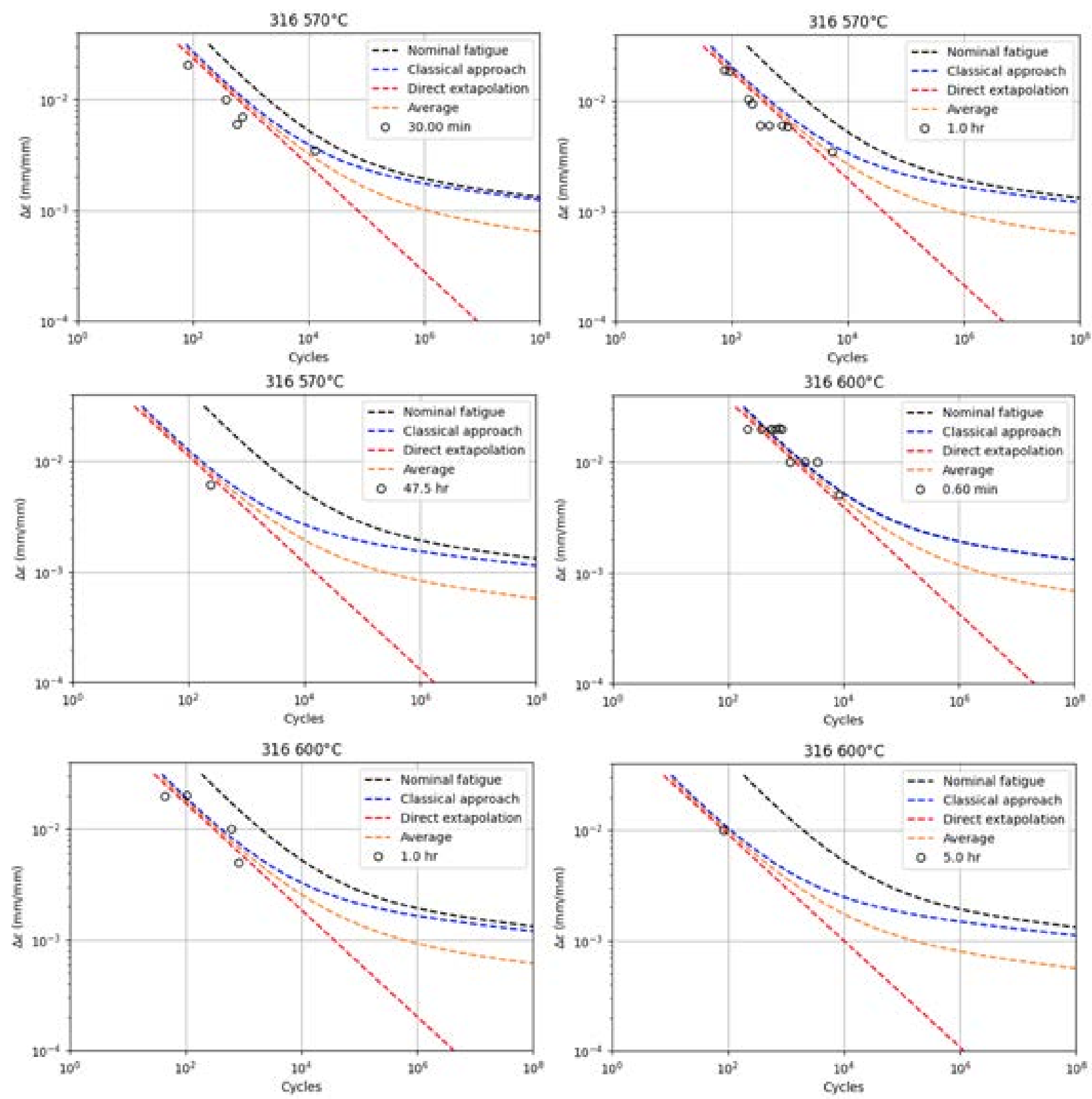

Figure 4.11: Nominal EPP+SMT curves compared with creep-fatigue experimental data for $316 \mathrm{H}$ at different temperatures and hold times. Creep-fatigue test data come from [31, 32].

\subsubsection{Alloy 617 design charts}

The above discussion recommends to use the average approach for extrapolating the high strain range, short hold test data to low strain ranges and long hold times, typically experienced by the structural components in high temperature nuclear service. Although the average approach is entirely empirical, it is recommended because it provides the best prediction of the experimental results among all the approaches investigated here. 
An ideal approach for the test data extrapolation use a mechanics based model to provide a more solid technical rational for the extrapolation outside the dataset. Chapter 3 discusses such a model based on the dissipated work. The basic idea is that the work-based model assumes the material fails when the cumulative dissipated work reach to a critical value. The challenge is then to develop an appropriate model that can predict this critical value under different loading conditions and is also compatible with the deformation model. Future work will investigate the work-based approach for test data extrapolation. Until then this work recommend to use the average approach for constructing the EPP+SMT design charts.

The nominal EPP+SMT curves are based on experimental data, i.e. average material properties, and therefore a design margin must be applied to the nominal curves for constructing the EPP+SMT design charts for creep-fatigue design evaluation. The ASME Code applies a factor of 2 on the strain range and 20 on cycles for constructing the fatigue design curves that are used to calculate the fatigue damage fraction using the strain range determined in the component analysis. The Code also increases the stress relaxation history by a factor of 0.9 in the design by elastic analysis and by a factor of 0.67 in design by inelastic analysis before calculating creep damage fraction using 95\% confidence prediction lower bound rupture properties. The creep and fatigue damage fractions are then compared with the creep-fatigue damage envelope in the creep-fatigue interaction diagram, D-diagram. No additional design margin is applied to the " $\mathrm{D}$ " diagram which is essentially constructed directly from creep-fatigue test data base. On the other hand, the EPP+SMT method is an integrated creep-fatigue damage evaluation method, i.e. no separate evaluation of fatigue and creep damages and no use of D-diagram. Similar to the fatigue damage calculation in current methods, the EPP+SMT method uses the strain range, temperature, and cycle time to determine the allowable creep-fatigue cycles from the design charts. We, therefore, propose to use the similar design margins, as in the current Code fatigue curves, for the EPP+SMT design charts, i.e. a factor of 2 on the strain range and 20 on the cycles to failure. After combining Equations 4.7 to 4.10 and applying the design margins, the equations for the EPP+SMT design charts for Alloy 617 are then:

$$
\Delta \varepsilon(\mathrm{N}, \mathrm{T}, \mathrm{t})=\min \left(\mathrm{f}(20 \mathrm{~N}, \mathrm{~T}, \mathrm{t}), \frac{\mathrm{f}(\mathrm{N}, \mathrm{T}, \mathrm{t})}{2}\right)
$$

where

$\Delta \varepsilon=$ strain range $(\mathrm{mm} / \mathrm{mm})$ as a function of $\mathrm{N}, \mathrm{T}$, and $\mathrm{t}$

$\mathrm{N}=$ number of allowable cycles, not exceeding 10,000

$\mathrm{T}=$ temperature

$\mathrm{t}=$ time

$$
\mathrm{f}(\mathrm{N}, \mathrm{T}, \mathrm{t})= \begin{cases}\mathrm{a}_{1}(\mathrm{~T}) * \mathrm{~N}^{\mathrm{b}_{1}(\mathrm{~T})}+\mathrm{a}_{2}(\mathrm{~T}) * \mathrm{~N}^{\mathrm{b}_{2}(\mathrm{~T})} & ; t=0 \\ \frac{1}{2}\left(\left(\frac{\mathrm{C}(\mathrm{T})}{\mathrm{N}} * \mathrm{SF}(\mathrm{T}, \mathrm{t})\right)^{\frac{1}{\mathrm{n}(\mathrm{T})}}+\left(\mathrm{a}_{1}(\mathrm{~T}) *\left(\frac{\mathrm{N}}{\mathrm{SF}(\mathrm{T}, \mathrm{t})}\right)^{\mathrm{b}_{1}(\mathrm{~T})}+\mathrm{a}_{2}(\mathrm{~T}) *\left(\frac{\mathrm{N}}{\mathrm{SF}(\mathrm{T}, \mathrm{t})}\right)^{\mathrm{b}_{2}(\mathrm{~T})}\right)\right) & ; t>0 \\ \mathrm{SF}(\mathrm{T}, \mathrm{t})=\frac{\left(\frac{1}{1+\mathrm{t}}\right)^{\mathrm{p}(\mathrm{T})}+\mathrm{D}(\mathrm{T})}{(1+\mathrm{D}(\mathrm{T}))}\end{cases}
$$


$a_{1}(T), b_{1}(T), a_{2}(T), b_{2}(T), C(T), p(T), D(T)$, and $n(T)$ are $T$ dependent constants and can be determined from Table 3.3 through linear interpolation. Note the values of the constants provided in Table 4.3 for $900^{\circ} \mathrm{C}$ are just interpolated values between $850^{\circ} \mathrm{C}$ and $950^{\circ} \mathrm{C}$.

\begin{tabular}{ccccccccc}
\hline$T$ & $a_{1}(T)$ & $b_{1}(T)$ & $a_{2}(T)$ & $b_{2}(T)$ & $C(T)$ & $p(T)$ & $D(T)$ & $n(T)$ \\
\hline $800^{\circ} \mathrm{C}$ & 0.879951 & -0.74747 & 0.007539 & -0.08785 & 0.1339 & 4.459588 & 0.233113 & 1.8556 \\
$850^{\circ} \mathrm{C}$ & 1.104091 & -0.7916 & 0.006743 & -0.08693 & 0.1339 & 2.459588 & 0.233113 & 1.8556 \\
$900^{\circ} \mathrm{C}$ & 1.095099 & -0.79044 & 0.005063 & -0.0749 & 0.1638 & 2.816675 & 0.424508 & 1.7888 \\
$950^{\circ} \mathrm{C}$ & 1.086107 & -0.78928 & 0.003383 & -0.06287 & 0.1937 & 3.173761 & 0.615903 & 1.7220 \\
\hline
\end{tabular}

Table 4.3: Values of constants to be used in equations for constructing EPP+SMT design charts for Alloy 617 at temperatures between $800^{\circ} \mathrm{C}$ and $950^{\circ} \mathrm{C}$.

Figure 4.12 to Figure 4.15 plot the design charts for Alloy 617 at different temperatures and hold times. Note the number of allowable cycles in the design charts are limited to 10,000 cycle no matter how small the strain range is. This restriction on the number of allowable cycles limits the design charts to interpolation over the available test data. Validation of the design charts along with the overall EPP+SMT design method is discussed in Section 4.9.

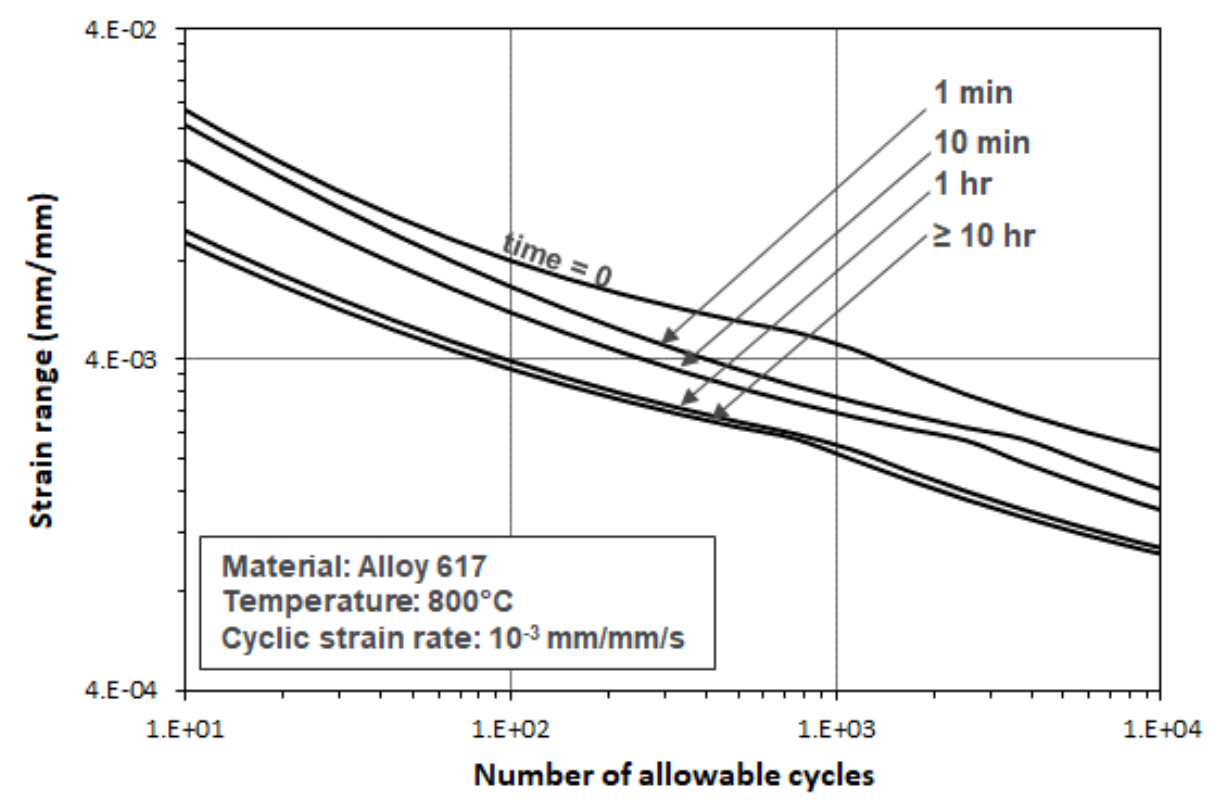

Figure 4.12: EPP+SMT design charts for Alloy 617 at $800^{\circ} \mathrm{C}$. 


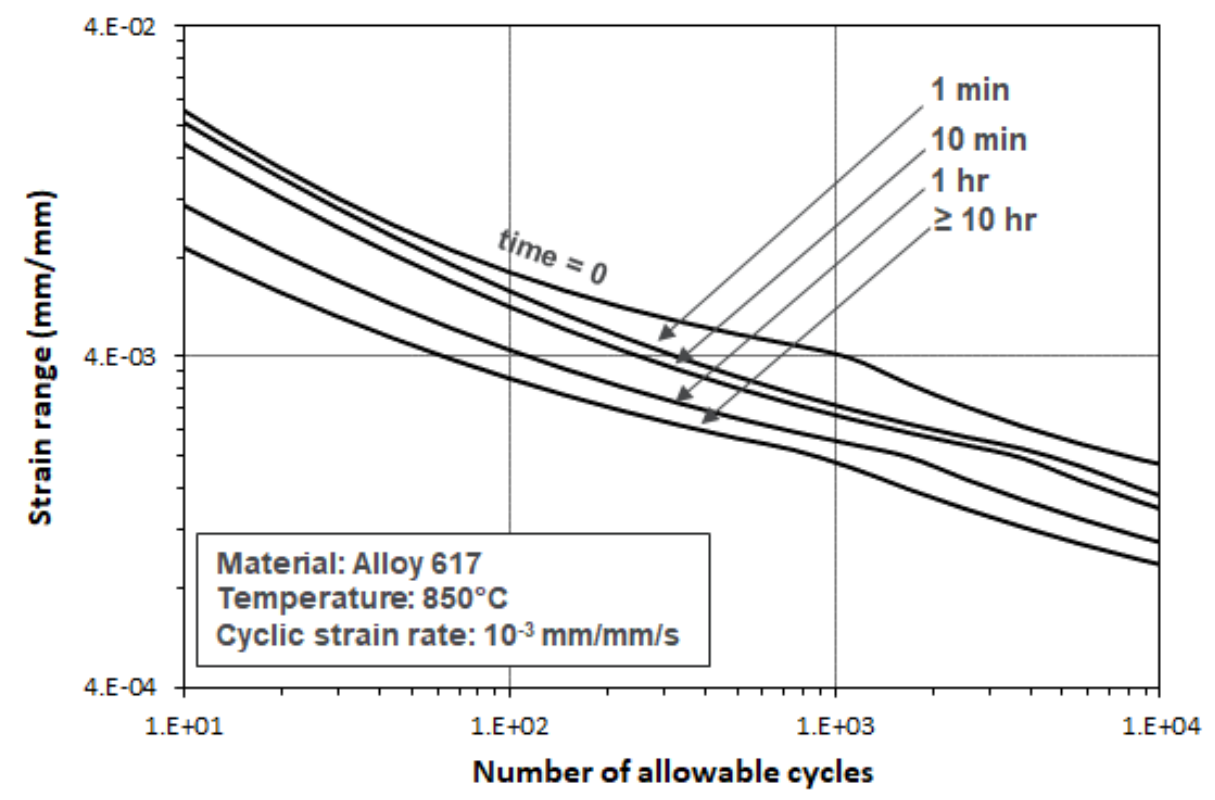

Figure 4.13: EPP+SMT design charts for Alloy 617 at $850^{\circ} \mathrm{C}$.

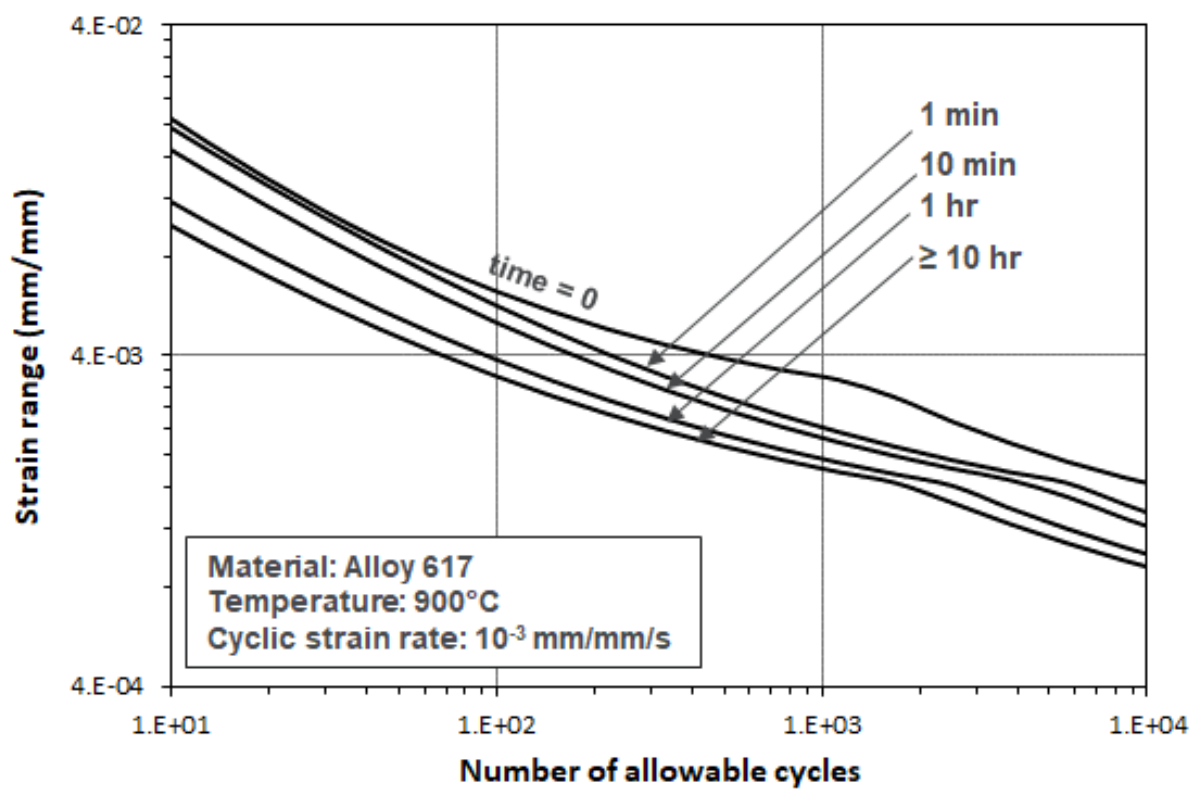

Figure 4.14: EPP+SMT design charts for Alloy 617 at $900^{\circ} \mathrm{C}$. 


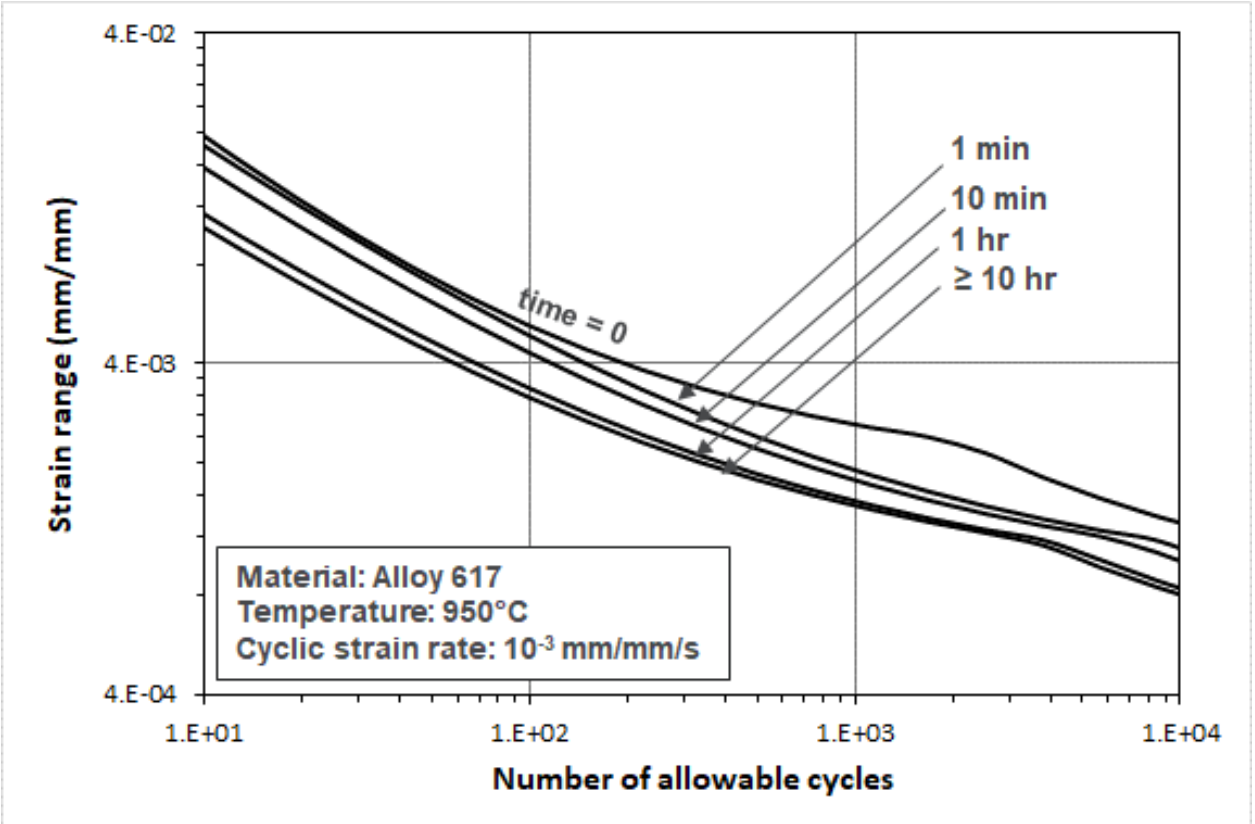

Figure 4.15: EPP+SMT design charts for Alloy 617 at $950^{\circ} \mathrm{C}$.

\subsection{Elastic follow-up}

Elastic follow up can significantly influence the creep-fatigue life of structural components in elevated temperature service. When a structure consisting of components with differing elastic stiffnesses is subjected to a deformation-controlled load, large elastic follow-up can occur, especially in the case that the stiffer region occupies a great portion of structural elements [35-38]. For high temperature structural components the effect of elastic follow up is a reduction in stress relaxation at a material point when compared to stress relaxation under a displacement controlled load. This reduction in stress relaxation causes the material point to undergo higher stresses for longer periods time than a material point relaxing under a pure deformation-controlled load. The material point relaxing with elastic follow up, therefore, tends to accumulate more creep damage when compared to creep damage under pure deformation-controlled load. This is significant for designing high temperature structural components against creep-fatigue damage and the design method must account for the effect of elastic follow up.

The current design by elastic analysis method accounts for the elastic follow up in an indirect and ad hoc manner. Since the elastic analysis cannot account for the stress redistribution that causes the elastic follow up, the Code attempts to account for the elastic follow up in the load classification. The design by elastic analysis rules classifies the secondary stresses with elastic follow up as primary stresses when evaluating structures against strain limits and creep-fatigue damage. An improved creep-fatigue design method might better capture the effect of elastic follow up on creepfatigue life with a direct accounting for elastic follow up, as quantified by the elastic follow up factor, $Q$. 
Previous work [2, 6-12] developed the SMT methodology to quantify the effect follow up effect on creep-fatigue life directly from experiments. Details of several different types of SMT specimens can be found in previous ART sponsored work [6-12]. In summary, the SMT specimens are designed to apply a global elastic follow up to a test section using either a stiffer driver section or an artificial control system while the whole system is subjected to a strain-controlled creep-fatigue loading. The results of SMT tests are cyclic lives as a function of temperature, strain range, hold time and elastic follow up. In standard creep-fatigue tests cyclic lives are quantified as a function of temperature, strain range, and hold time. Therefore, by comparing results from SMT tests with standard creep-fatigue tests the effect of elastic follow up on creep-fatigue life can be quantified.

In our previous work $[14,15]$, we used a simple two bar model, one bar representing the test section in series with another bar representing the driver section, to evaluated the elastic follow up applied to the test section from an inelastic simulation. We used the tangent definition of elastic follow up provided in [33] to determine the elastic follow up from an inelastic simulation. We also performed EPP cyclic analysis to determine the steady cyclic strain range for the test section. Note determination of a steady cyclic strain range from EPP analysis is not required for standard creepfatigue tests as these tests are purely strain controlled. Although a constant strain range is applied, the strain range in the test section of a SMT specimen varies depending on the elastic follow up applied through the stiffer driver section. The EPP analysis of the SMT test computes the bounding steady cyclic strain range in the test section. Note the reason to use the steady cyclic strain range from EPP analysis, instead of the strain range determined in actual SMT tests, is that the EPP+SMT design method uses this strain range to determine the allowable cycles from the design charts.

We then used the elastic follow up and steady cyclic strain range, computed from analyses of the two bar model, to compare the SMT tests results with the results from standard creep-fatigue tests. The comparison followed a general relation:

$$
N^{S M T}\left(\Delta \varepsilon, t_{h}, T, Q\right)=\frac{N^{c f}\left(\Delta \varepsilon, t_{h}, T\right)}{Q}
$$

where $N^{S M T}$ is the cycles to failure from SMT test, $N^{c f}$ is the cycles to failure from creep-fatigue test, i.e. without elastic follow up, and $Q$ is the elastic follow up factor. For a standard creep-fatigue test $Q=1$.

However, because the two bar model is very simple it only represents the average behavior of the test and drivers sections of the SMT specimen. The elastic follow up and EPP steady cyclic strain range computed using the two bar model are, therefore, global behavior of the test section. Since the creep-fatigue damage are evaluated at each material point of a structure, a more detailed analysis of the SMT tests is required to investigate the local behavior of the test section. We therefore performed finite element simulations of the SMT tests using axisymmetric models. 
Figure 4.16 shows the axisymmetric models of Type- 1 and Type-2 SMT specimens. The detailed geometry of the specimens can be found in [9]. These tests apply a deformation controlled cyclic load with either tensile, compressive, or tensile and compressive holds over a length that comprises a thinner test section and two thicker driver sections, one on each side of the test section. Due to the difference in diameter the driver sections act as the stiffer connection for the test section and slows the stress relaxation in the test section. This means the test section undergoes stress relaxation with an elastic follow up.

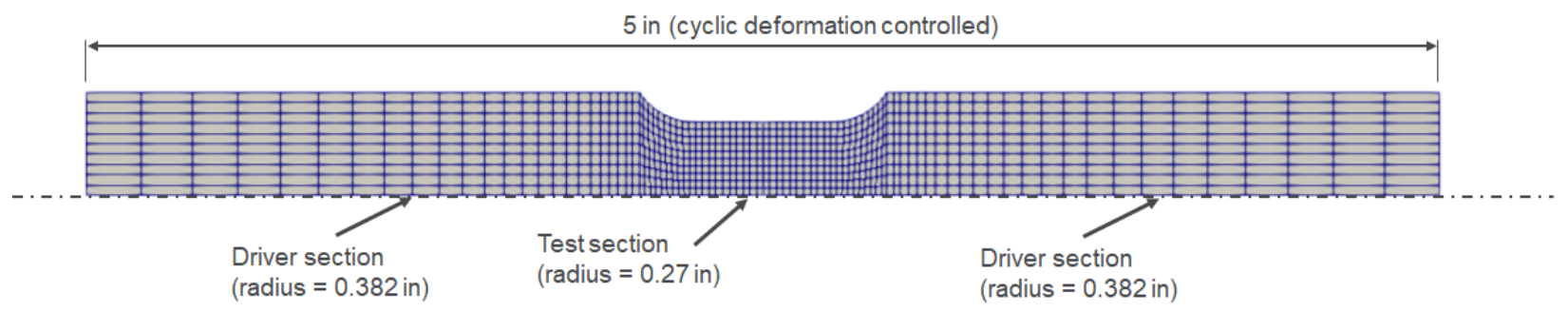

Type-1

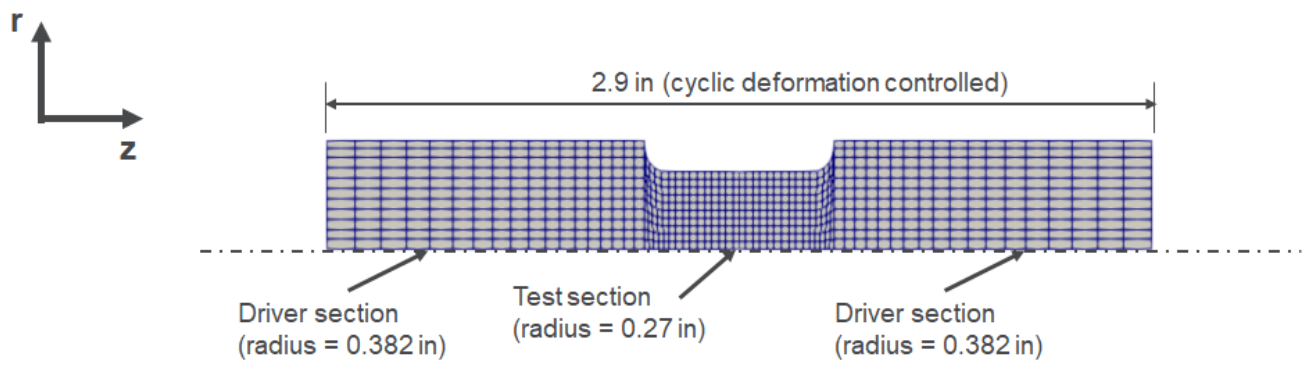

Type-2

Figure 4.16: Axisymmetric finite element models for Type-1 and Type-2 SMT specimens.

We performed two analyses for each SMT tests: 1) inelastic analysis using the Alloy 617 constitutive model provided in [34] to evaluate the elastic follow up and 2) cyclic EPP analysis using the method described in Section 3.1 to determine the EPP cyclic stable strain. We calculated the elastic follow up factor, $Q$ using the tangent definition provided in [33]. Figure 4.17 shows example results from analyses. The contour plots indicate that both $Q$ and the EPP steady cyclic equivalent strain range are maximum at the center of the SMT specimen. The maximum local value of $Q$ during hold is always close to 5 for both Type-1 and Type-2 SMT tests. 
To check the validity of Equation 4.14, we compare the SMT test results with the nominal curves determined above in Figure 4.18. The figure also plots the creep-fatigue test data. The cycles on $\mathrm{X}$-axis is the cycles to failure determined from SMT experiments, i.e. $N^{S M T}\left(\Delta \varepsilon, t_{h}, T, Q\right)$ multiplied by $Q$ which is, according to Equation 4.14, equivalent to cycles to failure without elastic follow up, $N^{c f}\left(\Delta \varepsilon, t_{h}, T\right)$. For the nominal curves plotted in the figure are for $Q=1$. The values of $Q$ in these plots are the maximum values, $Q^{\max }$ computed using the inelastic analysis of the SMT tests and the values of $\Delta \varepsilon$ are the steady cyclic maximum equivalent strain range, $\Delta \varepsilon_{e q}^{\max }$ computed using EPP cyclic analysis. These comparison plots indicate that the experimental cycles to failure is significantly higher than the cycles to failure predicted from nominal curve using $Q^{\max }, \Delta \varepsilon_{e q}^{\max }$, and Equation 4.14 for all the SMT tests. This means either the relationship in Equation 4.14 is overly conservative or the strain range determined from EPP cyclic analysis already accounts for the elastic follow up. This is also a significant change from the results obtained from analyses of the simple two bar model.

So, for a sanity check we performed another comparison in Figure 4.19 but this time using $Q=$ $Q^{a v g}$ and $\Delta \varepsilon=\Delta \varepsilon_{z z}^{a v g}$; where $Q^{a v g}$ is the elastic follow up factor and $\Delta \varepsilon_{z z}^{a v g}$ is the steady cyclic strain range along the loading direction, both averaged over a cross-section near the end of the straight region of the test section. These average values are more representative of what the simple two bar model predicts. The plots in Figure 4.19 confirm this, as the predicted values of cycles to failure are now reasonably close to the experimental cycles to failure data.

Now Figure 4.20 checks whether the local maximum value of the steady cyclic strain range from EPP analysis can adequately account for the effect of elastic follow up, considering the fact that the ASME design philosophy aims to prevent creep-fatigue damage initiation in a structure. The figure plots the SMT test data considering $\Delta \varepsilon=\Delta \varepsilon_{e q}^{\max }$ and $Q=1$. All the plots in the figure indicate that the nominal curves bound the SMT test results, i.e. the predicted cycles to failure values from nominal curves using $\Delta \varepsilon_{e q}^{\max }$ are less than the experimental cycles to failure data. This means the EPP cyclic analysis can account for the elastic follow up and an additional margin is not required, at least for these SMT tests. This fact is also well supported by the p-SMT test results discussed in Section 4.9.

However, all the SMT and p-SMT test data were generated in the high strain range regime. As discussed in Section 4.9, one p-SMT test was run in the low strain range regime but a failure data is not available as the test was stopped after it ran for 37693 cycles, taking close to 9 months. So, there is an uncertainty in EPP cyclic analysis accounting for the elastic follow up effect in the low strain range regime. Considering this the draft rules tell designers to use an appropriate value for $Q$ for piping systems and use $Q=2$ for other structures. This design margin is in addition to the $2 / 20$ margin applied to the nominal curves in constructing the design charts. 

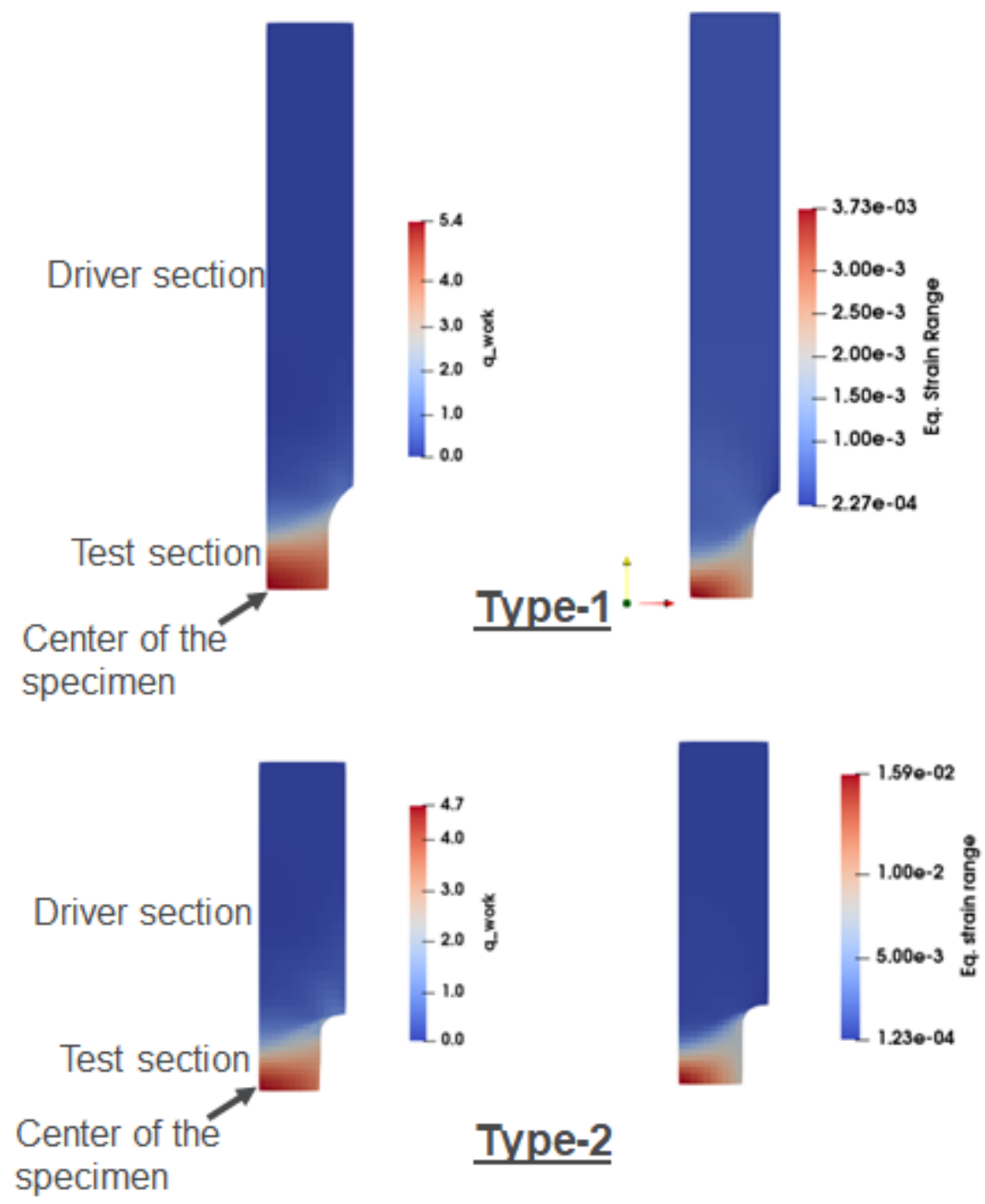

\section{Type-2}

Figure 4.17: Example SMT test simulation results showing the contour plots of elastic follow up factor, $Q$ during hold (determined from inelastic simulation) and steady cyclic equivalent strain range (determined from EPP cyclic analysis). Figures show half of the specimen. 

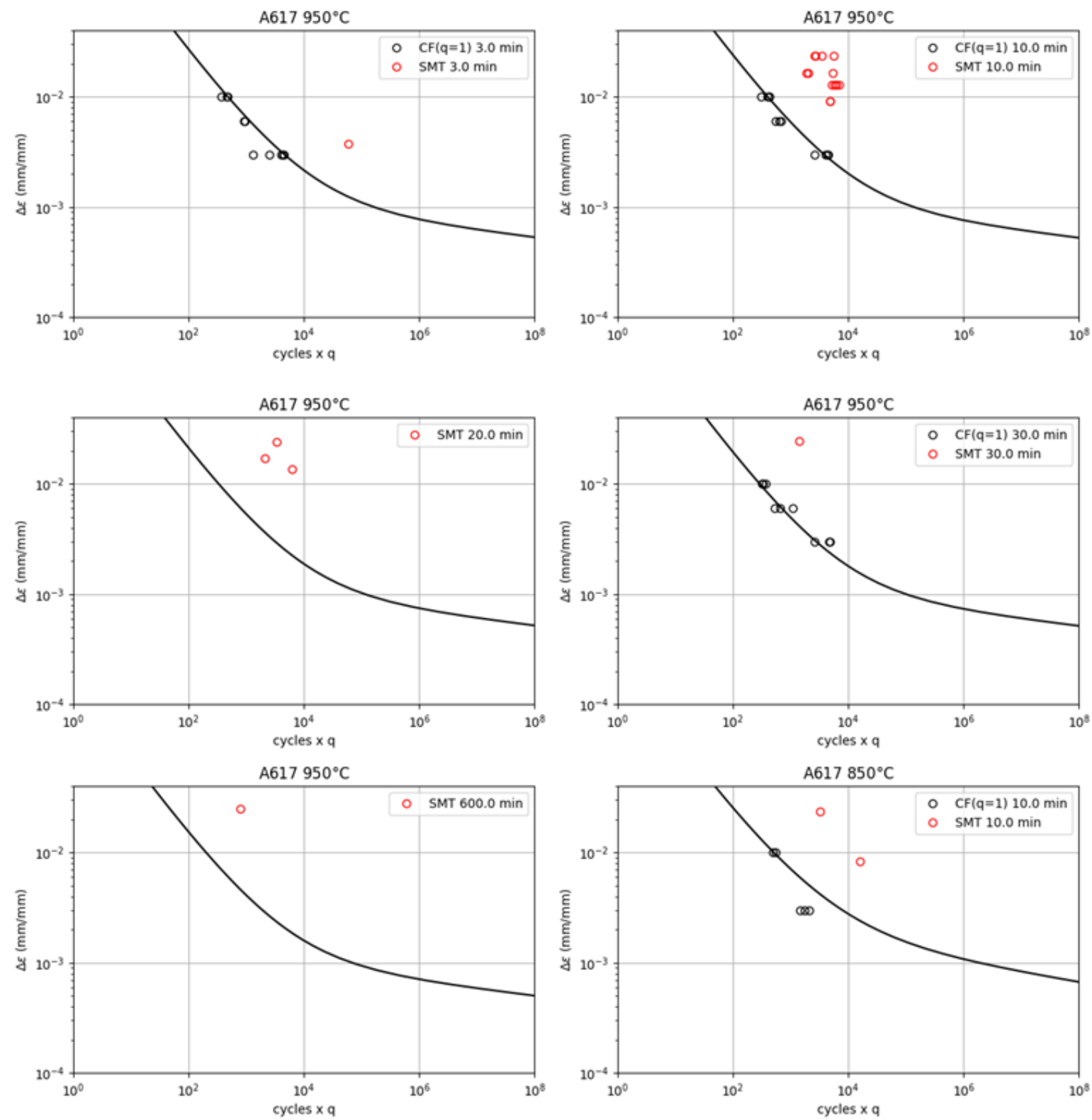

Figure 4.18: Alloy 617 SMT test results (considering $Q=Q^{\max }$ and $\Delta \varepsilon=\Delta \varepsilon_{e q}^{\max }$ ) compared with average approach nominal curves $(Q=1)$ and creep-fatigue test data. SMT test data come from [14]. 

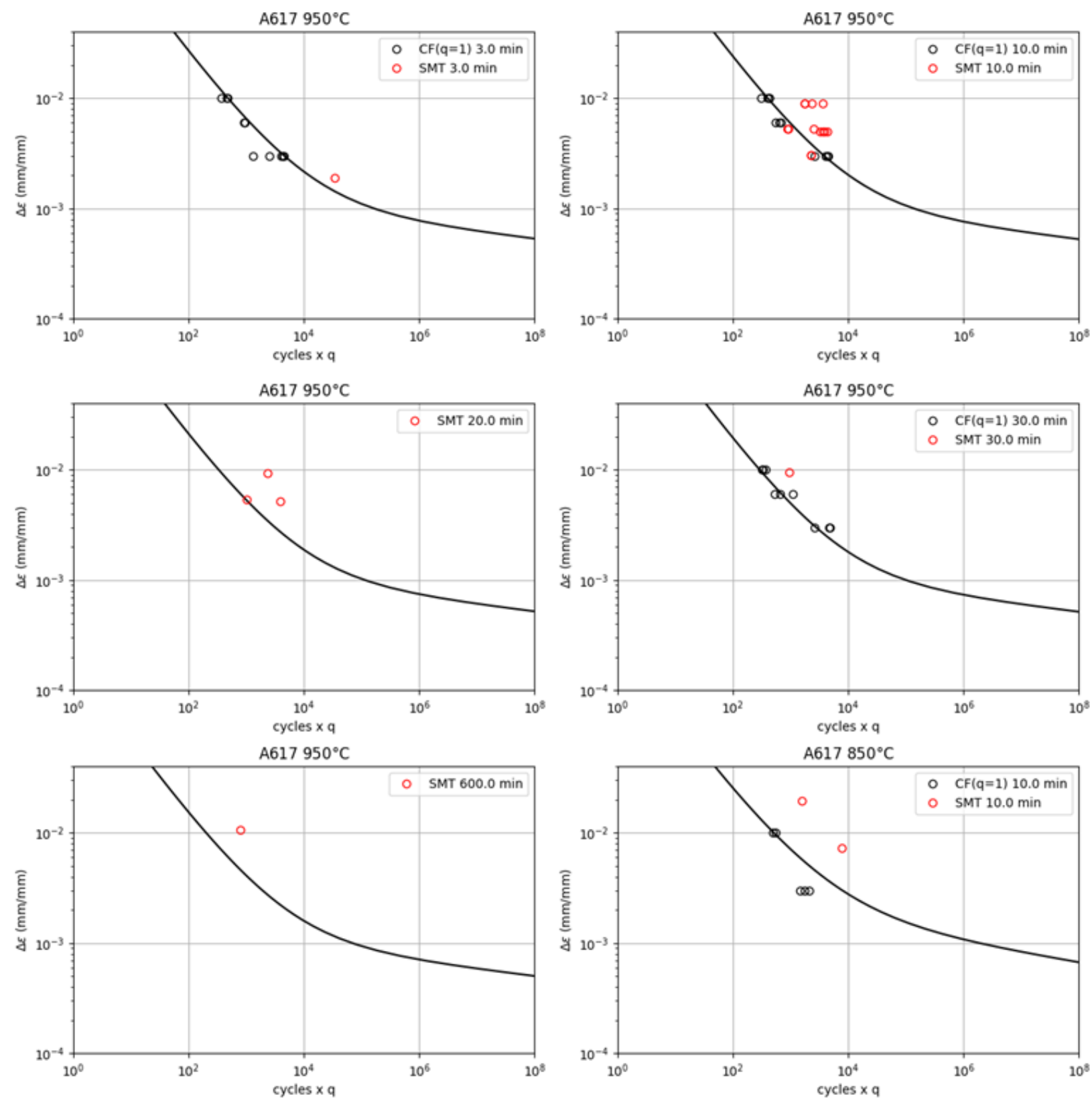

Figure 4.19: Alloy 617 SMT test results (considering $Q=Q^{a v g}$ and $\Delta \varepsilon=\Delta \varepsilon_{z z}^{a v g}$ ) compared with average approach nominal curves $(Q=1)$ and creep-fatigue test data. SMT test data come from [14]. 

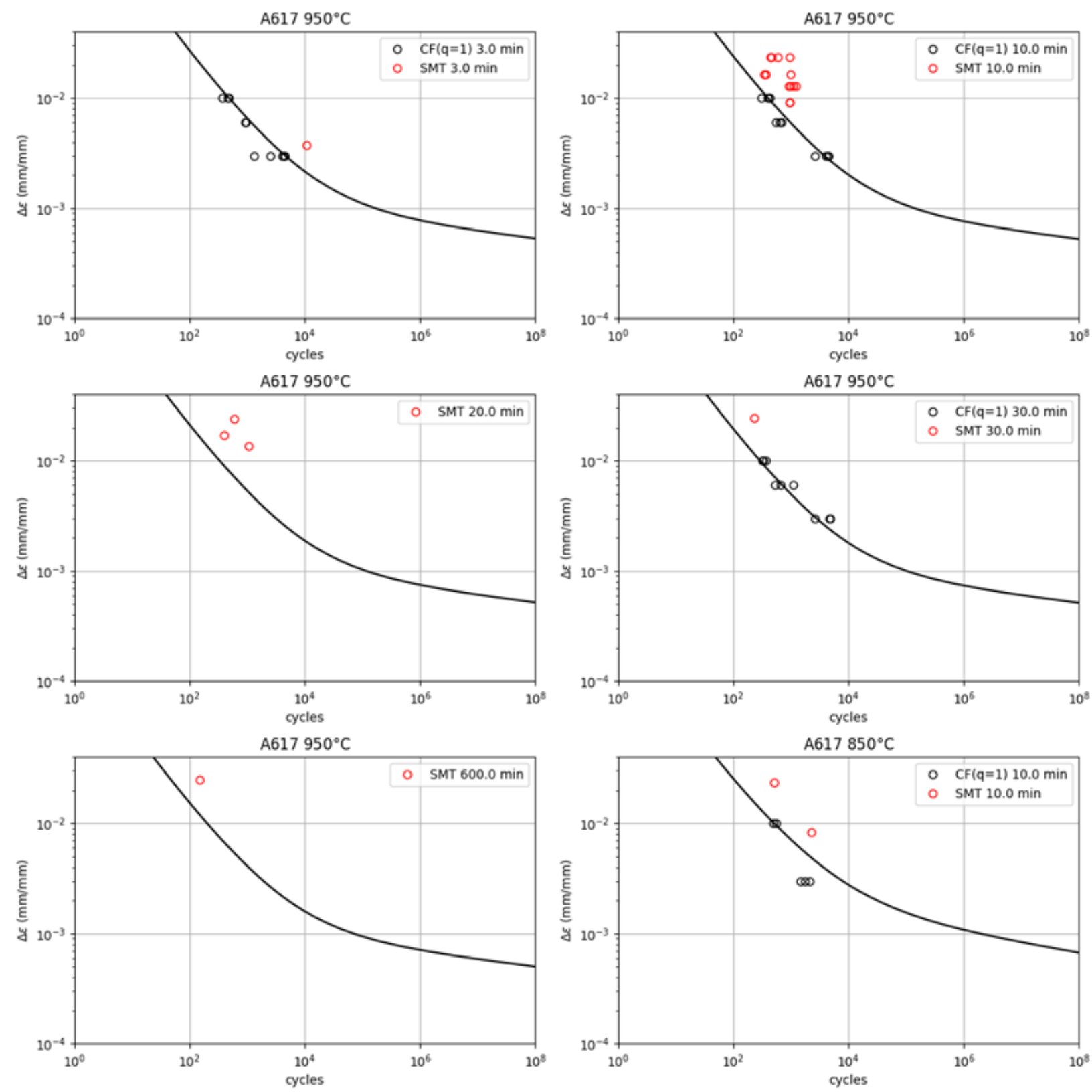

Figure 4.20: Alloy 617 SMT test results (considering $Q=1$ and $\Delta \varepsilon=\Delta \varepsilon_{e q}^{\max }$ ) compared with average approach nominal curves $(Q=1)$ and creep-fatigue test data. SMT test data come from [14]. 


\subsection{Primary load effect}

Structural components in service are nearly always loaded with both primary and secondary stresses. Primary stresses are those that develop to maintain the component in equilibrium with the applied external boundary forces and moments and body forces. These stresses are not self-limiting - once plastic deformation begins it continues unrestricted until force equilibrium is achieved through change of the external boundary conditions or until failure of the component. Applied pressure is a typical example of primary load. Secondary stresses, on the other hand, are not required to maintain equilibrium with the applied loads and therefore are self-limiting. Secondary stresses dissipate as the system deforms without affecting the balance of external forces on the component. Thermal stress is a typical example of secondary load. The load applied in standard strain-controlled creep-fatigue tests is entirely secondary.

The primary load limits in ASME design rules restrict the amount of primary load that can be applied to a component. These limits safeguard a structure against time-independent plastic instability and time-dependent creep rupture caused by primary loads. Primary load can also accelerate the creep-fatigue damage accumulation, especially when it is above a threshold value [31]. For a fixed secondary load, increasing the primary load is found to decrease the component cyclic life [10]. The EPP+SMT creep-fatigue design method therefore must capture this "primary load effect”.

Our previous work [14] describes several approaches to include the primary load effect in the $\mathrm{EPP}+\mathrm{SMT}$ design method. However, the recommendation is to use the increased strain range from EPP analysis due to primary load and combine it with a bounding elastic follow up factor applied to the design allowable cycles. This approach is advantageous over others owing to its simplicity and not requiring any explicit change in the design method. The draft design rules retain this method. As discussed in Section 4.9, the follow up factor recommended in Section 3.6 should adequately account for the primary load effect in EPP+SMT design. Results from p-SMT test, as discussed in Section 4.9, also indicate that the EPP analysis can screen out pressures exceeding the primary load limits before the creep-fatigue damage calculation.

\subsection{Cycle counting procedure}

The goal of the cycle counting procedure is to take the results of the EPP composite cycle analysis and extract a number of cycles, each defined by the number of repetitions, a strain range, a temperature, and a cycle hold to, to use in calculating the creep-fatigue damage. Several alternatives are available based on past work on strain-based fatigue cycle counting approaches. The procedure described here, and used in the sample problems, builds on recent work [27] developing a strainbased cycle counting specifically for high-temperature nuclear reactor components. Additional work on including the subcycle time, along with the strain range, temperature, and number of repetitions, could further improve the procedure described here.

\subsubsection{Cycle counting procedure method applied in this report}

The cycle counting procedure outlined in this section may be used instead of the procedures in HBB-T-1413 and HBB-T-1414 and when it is not possible to directly identify a maximum or minimum in accordance with HBB-T-1413, Step 2, and HBB-T-1414, Step 4. 
This procedure is used to calculate the strain ranges $\Delta \epsilon_{j}$, temperatures $T_{j}$, and corresponding number of cycles $n_{j}$ for fatigue damage calculation per HBB-T-1411. The resulting strain ranges are also used as $\Delta \epsilon_{\max }$ in HBB-T-1432 to start the creep-fatigue damage evaluation.

The procedure is described in the following 4 steps. Figure HBB-T-1415-1 provides a graphical example for a simple 1D strain history in step 1 , and for identifying the strain paths in step 2 . The procedure must be repeated for the entire component to find the critical location for the component design.

Step 1. Construct a temperature-strain history based on the information provided about the Level A, B, and C Service Loadings in the Design Specification. This history should encompass all the repetitions of the Level A, B, and C Service Load conditions in the Design Specification and cover the entire component design life. Tabulate the strain and temperature at sufficient time interval. Number the points in time-temperature-strain history from 1 to $N$

Step 2. Identify strain paths for fatigue damage analysis.

A strain path is a collection of points in the strain history, which are not necessarily sequential. A The identification of strain paths is an iterative procedure that ends when all points in the temperature-strain history have been added to a strain path. For the first iteration the current path is the entire temperature-strain history.

(a) Consider the first point in the current path as the reference point, calculate the equivalent strain range of all the points in the current path using the procedure in HBB-T1413.

(b) Identified strain path $A_{j}$, add the first two points in the current path to path $A_{j}$. If the current path has only two points go to (d)

(c) March through the remaining points in the current path and compare the equivalent strain range at the point $i, \Delta \epsilon_{i}$, and the last point in the identified path $A_{j}, \Delta \epsilon_{A j . l a s t}$

ii. If $\Delta \epsilon_{i} \geq \Delta \epsilon_{A j \text {.last }}$, then add point $i$ to the end of path $A_{j}$. If there are no more points in the current path, then stop and go to (d). If there are additional points, continue to point $i+1$ by repeating step (c).

iii. If $\Delta \epsilon_{i}<\Delta \epsilon_{A j . l a s t}$, create a skipped path $\mathrm{B}_{\mathrm{k}}$, add the point $i$ to both path $A_{j}$ and to the skipped Path $B_{k}$. Add subsequent points $i+1, i+2, \ldots i+n$ to Path $B_{k}$ until the point $i+n$ either generates $\Delta \epsilon_{i+n} \geq \Delta \epsilon_{A j . l a s t}$ or it is last point in the current path. Starting from point $i+n$ go to (1).

(d) At this stage, all the points in the current path are exhausted and the identified path $A_{j}$ is finalized. Repeat steps (a) to (c) for all the skipped paths $B_{k}$ and identify additional paths, $A_{j+1}, A_{j+2} \cdots$

Step 3. Calculate the temperature and strain range for the identified paths. The process has identified a list of strain paths, $A_{j}$, consisting of points from the original strain history from Step 1. Calculate the maximum equivalent strain range using the procedure in HBB-T-1413 while considering the first point in the path as the reference point. Identify the path temperature as the maximum temperature of any of the points included in each path. Call the strain ranges and temperatures for each path $\Delta \epsilon_{j}$ and $T_{j}$. 
Step 4. Group the strain ranges and temperatures from each identified path into bins with the same values of $\Delta \epsilon_{j}$ and $T_{j}$. Count the number of paths in each bin, $N_{j}$. Each path identified by this procedure is one strain reversal or $1 / 2$ of a load cycle. The number of full cycles $n_{j}$ for a bin of common values of $\Delta \epsilon_{j}$ and $T_{j}$ is therefore $1 / 2$ times the number of paths in the bin, i.e. $n_{j}=\frac{1}{2} N_{j}$.

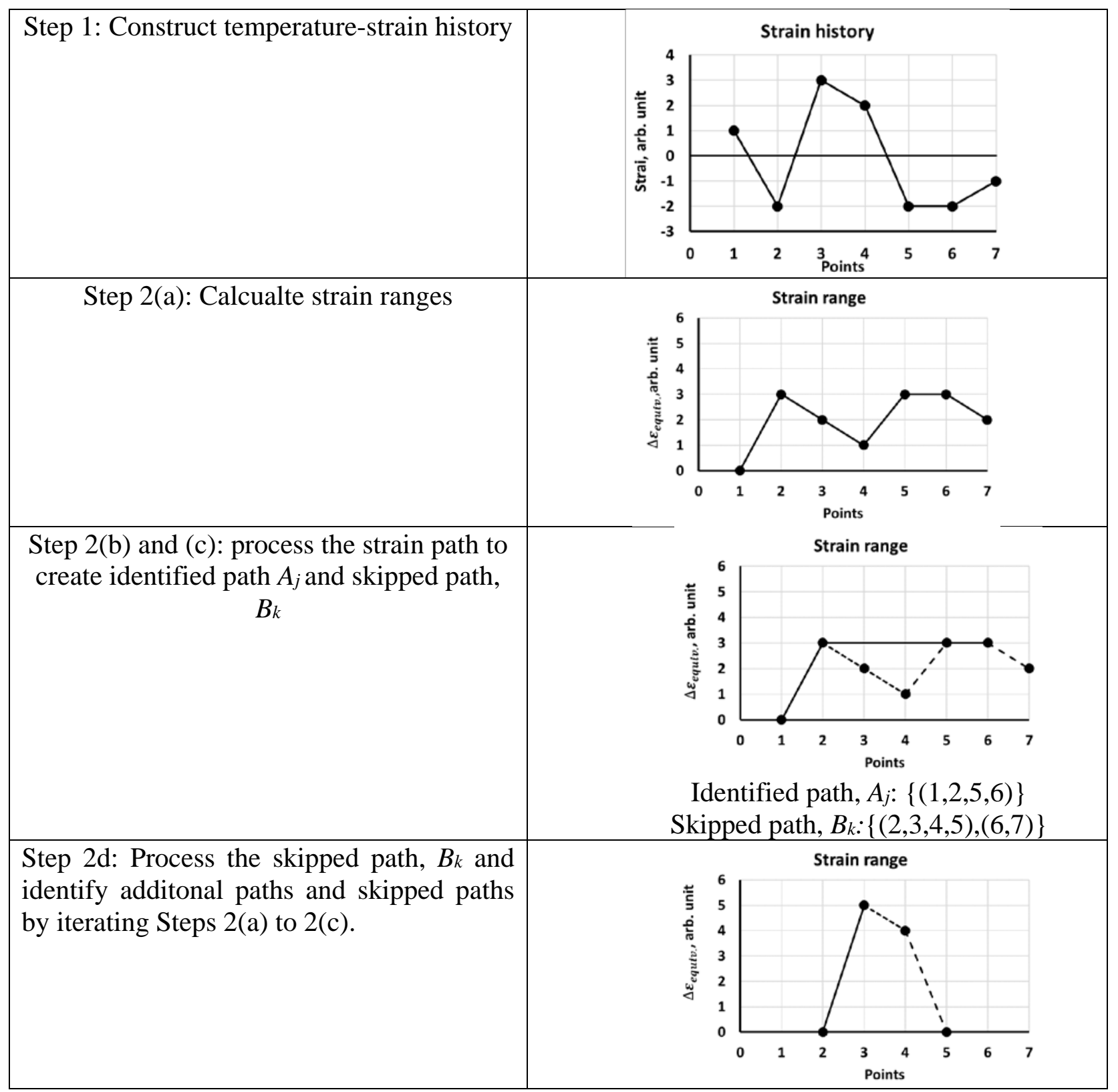




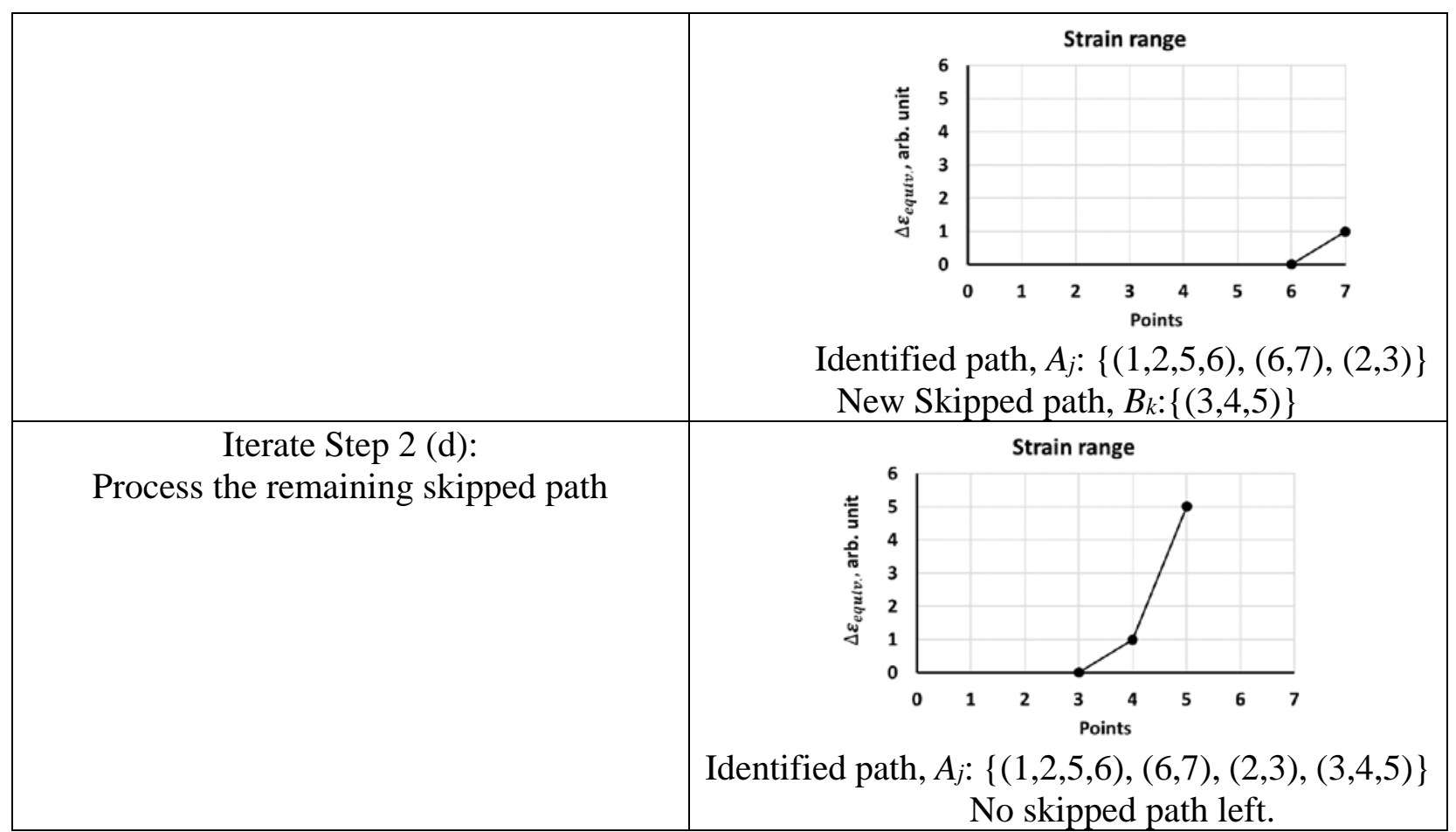

Figure 4.21: Illustrative Example strain path determination.

\subsection{Validation with p-SMT tests}

This section provides validation for the draft design rules and design charts developed in Section 4.5 using the failure data gathered from p-SMT tests in previous ART sponsored works $[8,10]$. The applied loading in the standard creep-fatigue tests and the SMT tests are purely secondary, while the loading in p-SMT tests include both the primary and secondary loads. Figure 4.22 shows the axisymmetric finite element model for the p-SMT tests. The test article is a tubular specimen subjected to constant internal pressure and a deformation controlled loading applied over a test section combined with two stiffer driver sections, each on both sides of the test section. As in the SMT tests, the stiffness difference between the driver and test sections in a p-SMT specimen applies an elastic follow up to the test section. A p-SMT test can be considered a component test as it covers nearly all the possible variables, including primary stresses, secondary stresses, hold times, elastic follow up due to geometric discontinuity, and temperature, that can affect the cyclic creep-fatigue life. The below discusses the results from an EPP cyclic analysis of the p-SMT tests and the comparison between the estimated creep-fatigue lives using EPP+SMT method and the experimental failure data. The discussion also includes comparisons between EPP+SMT and current creep-fatigue design methods. 


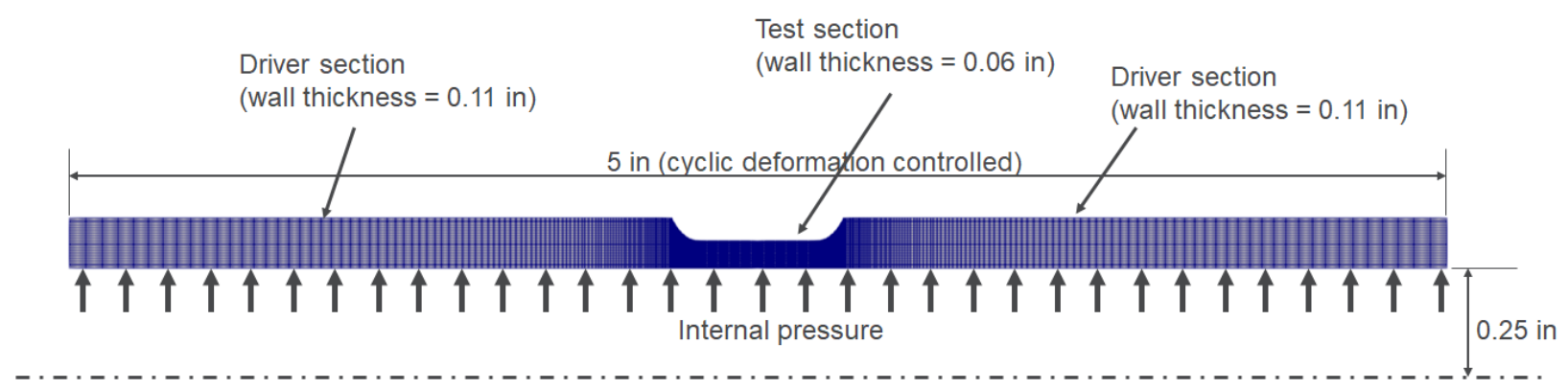

Figure 4.22: Axisymmetric finite element model for p-SMT tests.

Table 4.4 lists the test conditions for different p-SMT tests conducted on Alloy 617. The table also lists the stable cyclic equivalent strain range determined from EPP cyclic analysis, following the procedure in the draft rules. For some of the test conditions the EPP cyclic analysis results in plastic rupture. This means excessive ratcheting with increasing rate from cycle to cycle is observed in EPP analysis, which eventually results in nonconvergence in finite element simulation. Interesting, the applied pressure load in these tests exceeds the ASME primary load design limits. This is an important finding as it indicates the EPP cyclic analysis of EPP+SMT design method can screen out the primary load design limits.

Another important observation from the listed EPP equivalent strain range in Table 4.4 is that the strain range increases with the increase of pressure load when all the other conditions are fixed. Since the EPP+SMT is a strain-based creep-fatigue damage evaluation method, this increase in strain range due to primary load will estimate lower creep-fatigue life when compared with creepfatigue life under secondary load alone.

\begin{tabular}{ccccccc}
\hline ID & $T\left({ }^{\circ} \mathrm{C}\right)$ & $\begin{array}{c}\text { Amplitude, } \\
\pm \delta(\mathrm{mm})\end{array}$ & $\begin{array}{c}\text { Tensile hold } \\
(\mathrm{sec})\end{array}$ & $\begin{array}{c}\text { Compression } \\
\text { hold }(\mathrm{sec})\end{array}$ & $\begin{array}{c}\text { Pressure } \\
(\mathrm{MPa})\end{array}$ & $\begin{array}{c}\text { EPP eq. strain } \\
\text { range }\end{array}$ \\
\hline INC617-P01 & 950 & 0.1143 & 600 & 0 & 0.01 & $3.148 \%$ \\
INC617-P02 & 950 & 0.1143 & 600 & 0 & 1.38 & $3.176 \%$ \\
INC617-P04 & 950 & 0.1143 & 600 & 0 & 3.45 & plastic rupture \\
INC617-P03 & 950 & 0.1143 & 600 & 0 & 5.17 & plastic rupture \\
INC617-P06 & 950 & 0.1143 & 600 & 0 & 5.17 & plastic rupture \\
INC617-P09 & 950 & 0.0762 & 600 & 0 & 5.17 & plastic rupture \\
INC617-P10 & 950 & 0.0254 & 600 & 0 & 1.03 & $0.065 \%$ \\
INC617-P12 & 950 & 0.0635 & 600 & 0 & 0.01 & $1.328 \%$ \\
INC617-P13 & 950 & 0.0635 & 600 & 0 & 1.03 & $1.334 \%$ \\
INC617-P14 & 850 & 0.0762 & 600 & 0 & 2.76 & $1.242 \%$ \\
INC617-P15 & 850 & 0.0762 & 600 & 0 & 0.14 & $1.229 \%$ \\
INC617-P05 & 950 & 0.1143 & 600 & 600 & 0.01 & $3.253 \%$ \\
INC617-P08 & 950 & 0.1143 & 600 & 600 & 3.79 & plastic rupture \\
INC617-P07 & 950 & 0.1143 & 600 & 600 & 5.17 & plastic rupture \\
\hline
\end{tabular}

Table 4.4: Steady cyclic equivalent strain range from EPP analysis of Alloy 617 p-SMT tests under different loading conditions. p-SMT test data come from $[8,10]$. 
Table 4.5 compares the best estimate creep-fatigue lives calculated using EPP+SMT method with the p-SMT tests failure data. The EPP+SMT best estimate life is calculated using the nominal curves constructed using the average extrapolation approach. The table also lists best estimate lives calculated using inelastic analysis method, which is similar to the ASME design by inelastic analysis approach but using average fatigue and creep rupture properties and without applying any margin on stress in creep damage calculation. The inelastic model used in inelastic analysis is from [34]. This inelastic model is under development, eventually to be included to Section III, Division 5 for use in conjunction with the design by inelastic analysis rules.

Table 4.5 indicates the best estimate lives from EPP+SMT method considering $Q=1$ are reasonably close to, but always bounding, the experimental life for p-SMT tests with high amplitude loading condition. For the high amplitude loading tests, the EPP+SMT best estimate lives are also comparable to the life estimated by the inelastic analysis method. There is only one test data available with low amplitude loading - test ID INC617-P10. As listed in Table 4.4, the EPP equivalent strain range for this test is $0.065 \%$ which is significantly less than the strain ranges calculated for all the other tests. The EPP+SMT method estimates very high cyclic life, more than 6 million cycles, for this test, which is also significantly higher than the life estimated by the inelastic analysis. Failure data is not available for this test. The test was stopped after running for 37,693 cycles as it already took close to 9 months. Although a direct comparison between life estimation and failure data cannot be made for this low strain range test, we can still use the available information, i.e. no failure up to 37,693 cycles, to apply a maximum limit, as discussed below, to the number of allowable cycles in the design charts. This ensures the design charts are limited to interpolation over the available test data.

\begin{tabular}{|c|c|c|c|c|c|c|c|c|}
\hline \multirow[b]{2}{*}{ ID } & \multirow[b]{2}{*}{$T\left({ }^{\circ} \mathrm{C}\right)$} & \multirow[b]{2}{*}{$\begin{array}{c}\text { Amplitude, } \\
\pm \delta(\mathrm{mm})\end{array}$} & \multirow{2}{*}{$\begin{array}{c}\text { Tensile } \\
\text { hold } \\
\text { (sec) }\end{array}$} & \multirow{2}{*}{$\begin{array}{l}\text { Comp. } \\
\text { hold } \\
\text { (sec) }\end{array}$} & \multirow[b]{2}{*}{$\begin{array}{c}\text { Pressure } \\
\text { (MPa) }\end{array}$} & \multirow{2}{*}{$\begin{array}{c}\text { Experimental } \\
\text { life } \\
\text { (cycles) }\end{array}$} & \multicolumn{2}{|c|}{$\begin{array}{c}\text { Best estimate life } \\
\text { (cycles) }\end{array}$} \\
\hline & & & & & & & $\begin{array}{c}\text { Inelastic } \\
\text { analysis }\end{array}$ & $\begin{array}{c}E P P+S M T \\
\quad(Q=1)\end{array}$ \\
\hline INC617-P01 & 950 & 0.1143 & 600 & 0 & 0.01 & 220 & 49 & 75 \\
\hline INC617-P02 & 950 & 0.1143 & 600 & 0 & 1.38 & 220 & 49 & 75 \\
\hline INC617-P05 & 950 & 0.1143 & 600 & 600 & 0.01 & 320 & 35 & 63 \\
\hline INC617-P10 & 950 & 0.0254 & 600 & 0 & 1.03 & $>37,693$ & 5,992 & $6,766,814$ \\
\hline INC617-P12 & 950 & 0.0635 & 600 & 0 & 0.01 & 1,360 & 218 & 289 \\
\hline INC617-P13 & 950 & 0.0635 & 600 & 0 & 1.03 & 820 & 225 & 289 \\
\hline INC617-P14 & 850 & 0.0762 & 600 & 0 & 2.76 & 3,440 & 364 & 402 \\
\hline INC617-P15 & 850 & 0.0762 & 600 & 0 & 0.14 & 3,460 & 368 & 404 \\
\hline
\end{tabular}

Table 4.5: Best estimate creep-fatigue life using EPP+SMT method and inelastic analysis method compared with experimental life for Alloy 617 p-SMT tests. p-SMT test data come from $[8,10]$. 
Table 4.6 compares the creep-fatigue design lives of the p-SMT tests between the EPP+SMT method and two current ASME design methods - design by elastic analysis and design by inelastic analysis. The table also lists the experimental lives. Note during the creep-damage calculation both the ASME design by elastic analysis and design by inelastic analysis methods apply a margin on the stress relaxation profile by dividing it by a factor, $K^{\prime}$. The value of $K^{\prime}$ is 0.9 for design by elastic analysis method and 0.67 for design by inelastic analysis method. $K^{\prime}$ has a large impact on creep damage calculation. Table 4.6 therefore also lists design by inelastic analysis life using $K^{\prime}=0.9$. As indicated by Table 4.6 the design by inelastic analysis lives with $K^{\prime}=0.67$ is overly conservative when compared to experimental life. Design lives computed using EPP+SMT method are comparable with design by inelastic analysis method lives for the high amplitude load tests.

The design by elastic analysis method predicts longer lives than other methods for the high amplitude p-SMT tests. This is somewhat unusual because design by elastic analysis typically provides most conservative estimation of life, at least for low strain ranges, as in the INC617-p10 test here, and for long hold times, as in the sample problems discussed in Chapter 5. For the single low amplitude p-SMT tests, INC617-p10, the EPP+SMT method provides the least conservative estimation. The estimated life is 10,000 cycles when $Q=1$. Note the actual estimated EPP+SMT design life is 47,319 cycles when no limitation is applied to the design charts. As discussed above, failure data is not available for this test while the specimen did not fail up to 37,693 cycles. Considering this along with the available creep-fatigue and SMT test data in the low strain range, we recommend to limit the design chart to 10,000 cycles until more high cycle data become available or an appropriate mechanistic extrapolation method is developed.

Note Table 4.6 also lists EPP+SMT design lives based on $Q=2$. The basis for recommending $Q=2$ is discussed in Section 4.6. The EPP+SMT design life based on $Q=2$ is 5,000 cycles for INC617p10 test which is significantly higher than the life estimated by current ASME design by elastic analysis (90 cycles) and design by inelastic analysis (190 cycles). This indicates the EPP+SMT method reduces the over conservatism of the current methods for low strain range loading conditions, typical for structural components in nuclear service.

\begin{tabular}{|c|c|c|c|c|c|c|c|c|c|c|c|}
\hline \multirow[b]{3}{*}{ ID } & \multirow{3}{*}{$\begin{array}{c}T \\
\left({ }^{\circ} \mathrm{C}\right) \\
\end{array}$} & \multirow{3}{*}{$\begin{array}{l}\text { Ampl., } \\
\pm \delta(\mathrm{mm}) \\
\end{array}$} & \multirow{3}{*}{$\begin{array}{l}\text { Ten. } \\
\text { hold } \\
\text { (sec) }\end{array}$} & \multirow{3}{*}{$\begin{array}{c}\text { Comp. } \\
\text { hold } \\
\text { (sec) }\end{array}$} & \multirow{3}{*}{$\begin{array}{c}P \\
(M P a) \\
\end{array}$} & \multirow{3}{*}{$\begin{array}{c}\text { Expt. life } \\
\text { (cycles) }\end{array}$} & \multicolumn{5}{|c|}{ Design life (cycles) } \\
\hline & & & & & & & \multirow{2}{*}{$\begin{array}{l}\text { Elastic } \\
\text { analysis }\end{array}$} & \multicolumn{2}{|c|}{ Inelastic analysis } & \multicolumn{2}{|c|}{$E P P+S M T$} \\
\hline & & & & & & & & $K^{\prime}=0.67$ & $K^{\prime}=0.9$ & $Q=1$ & $Q=2$ \\
\hline INC617-P01 & 950 & 0.1143 & 600 & 0 & 0.01 & 220 & 8 & 0 & 2 & 3 & 1 \\
\hline INC617-P02 & 950 & 0.1143 & 600 & 0 & 1.38 & 220 & 8 & 0 & 2 & 3 & 1 \\
\hline INC617-P05 & 950 & 0.1143 & 600 & 600 & 0.01 & 320 & 6 & 0 & 1 & 3 & 1 \\
\hline INC617-P10 & 950 & 0.0254 & 600 & 0 & 1.03 & $>37,693$ & 90 & 190 & 1,053 & $\begin{array}{r}>10,000 \\
(47,319 *)\end{array}$ & $\begin{array}{c}>5,000 \\
(23,659 *)\end{array}$ \\
\hline INC617-P12 & 950 & 0.0635 & 600 & 0 & 0.0 & 1,360 & 23 & 3 & 14 & 14 & 7 \\
\hline INC617-P13 & 950 & 0.0635 & 600 & 0 & 1.0 & 820 & 22 & 3 & 13 & 14 & 7 \\
\hline INC617-P14 & 850 & 0.0762 & 600 & 0 & 2.76 & 3,440 & 73 & 2 & 19 & 20 & 10 \\
\hline INC617-P15 & 850 & 0.0762 & 600 & 0 & 0.14 & 3,460 & 83 & 2 & 19 & 20 & 10 \\
\hline
\end{tabular}

\# ASME Section III, Division 5 design by inelastic analysis rules use $K^{\prime}=0.67$.

* Life without considering the 10,000 cycles limit in the EPP+SMT design charts.

Table 4.6: Creep-fatigue design life compared between design by elastic analysis, design by inelastic analysis, and EPP+SMT method for Alloy 617 p-SMT tests. p-SMT test data come from $[8,10]$. 



\section{Comparison with current ASME methods}

This chapter compares the EPP+SMT method (based on the draft rules in Chapter 2 and the selected options for several subprocedures in Chapter 4) with current creep-fatigue design methods - Section III, Division 5 design by elastic analysis and design by inelastic analysis - by analyzing several representative high temperature nuclear reactor components. The first sample problem is an Alloy 617 flat head vessel. For this problem the creep-fatigue design methods are compared for several different loading conditions. The second problem is an Alloy 617 hot gas duct in a high temperature gas-cooled reactor. The first two problems use the Alloy 617 design charts constructed in Chapter 4 to compute EPP+SMT creep-fatigue design life of the components. All the relevant material data for thermal and structural analyses and creep-fatigue evaluation come from [29]. The design by inelastic analysis method uses an inelastic material model to represent the constitutive response of Alloy 617. The model comes from [34].

The chapter includes a third sample problem - a Grade 91 heat recovery steam generator outlet header. To compute the EPP+SMT creep-fatigue design life this problem uses the Grade 91 EPP+SMT design charts provided below. The inelastic material model for Grade 91 to use in design by inelastic method comes from [3]. All other relevant material data come from [3].

\subsection{Sample problem-1: A flat head vessel}

Figure 5.1 illustrates the problem. The vessel is subjected to a constant internal pressure, $P_{\text {inner }}=$ $P$, a through thickness temperature gradient, $\Delta T$. The inner surface temperature, $T_{i n n e r}$ cycles between $T_{\max }-\Delta T$ and $T_{\max }$, while the outer surface temperature, $T_{\text {outer }}$ stays constant at $T_{\max }-$ $\Delta T$. The temperature cycle for $T_{\text {inner }}$ includes a $1 \mathrm{hr}$ heat up from $T_{\max }-\Delta T$ to $T_{\max }$ followed by a hold, $t_{\text {hold }}$ at $T_{\max }$ and a $1 \mathrm{hr}$ cool down to $T_{\max }-\Delta T$. Table 5.1 lists the values of $T_{\max }$, $\Delta T, P, t_{\text {hold }}$ considered for different loading conditions. Table 5.1 also lists the creep-fatigue design lives of the flat head vessel evaluated by different design methods. Additionally, the table lists the EPP steady cyclic equivalent strain range at the critical location of the structure. As the table indicates, the sample problem considers a broad range of loading conditions, covering both high and low strain range regimes, hold time effect, and primary load effect.

The table lists allowable creep-fatigue cycles from design by inelastic analysis for two values of $K^{\prime}: 0.67$ and 0.9 . $K^{\prime}$ is a safety factor applied to the stress analysis results before creep damage calculation. The ASME Section III, Division 5 rules use 0.67 for $K^{\prime}$ in design by inelastic analysis which, as discussed in Section 4.9, is overly conservative. For EPP+SMT design a value of elastic follow up, $Q$ must be selected. According to the recommendation in the draft design rules, $Q=2$ is considered for the flat head vessel. 
The comparison among different design methods indicates the design by elastic method predict the least number of design allowable cycles. This is expected as the design by elastic analysis method approximates the effect of plasticity and creep based on results from a linear-elastic analysis using numerous conservative assumptions. The comparison indicates the EPP+SMT method is comparable with the design by inelastic analysis method with $K^{\prime}=0.9$ when applied loading generates high strain range. As the strain range decreases, the EPP+SMT method predicts increasingly higher number of allowable cycles than the inelastic analysis method. Note the EPP+SMT estimated creep-fatigue lives are restricted to 5,000 cycles, computed using Equation 4.4. This is based on the 10,000 cycles limit of the design charts and considering $Q=2$ for the flat head vessel.

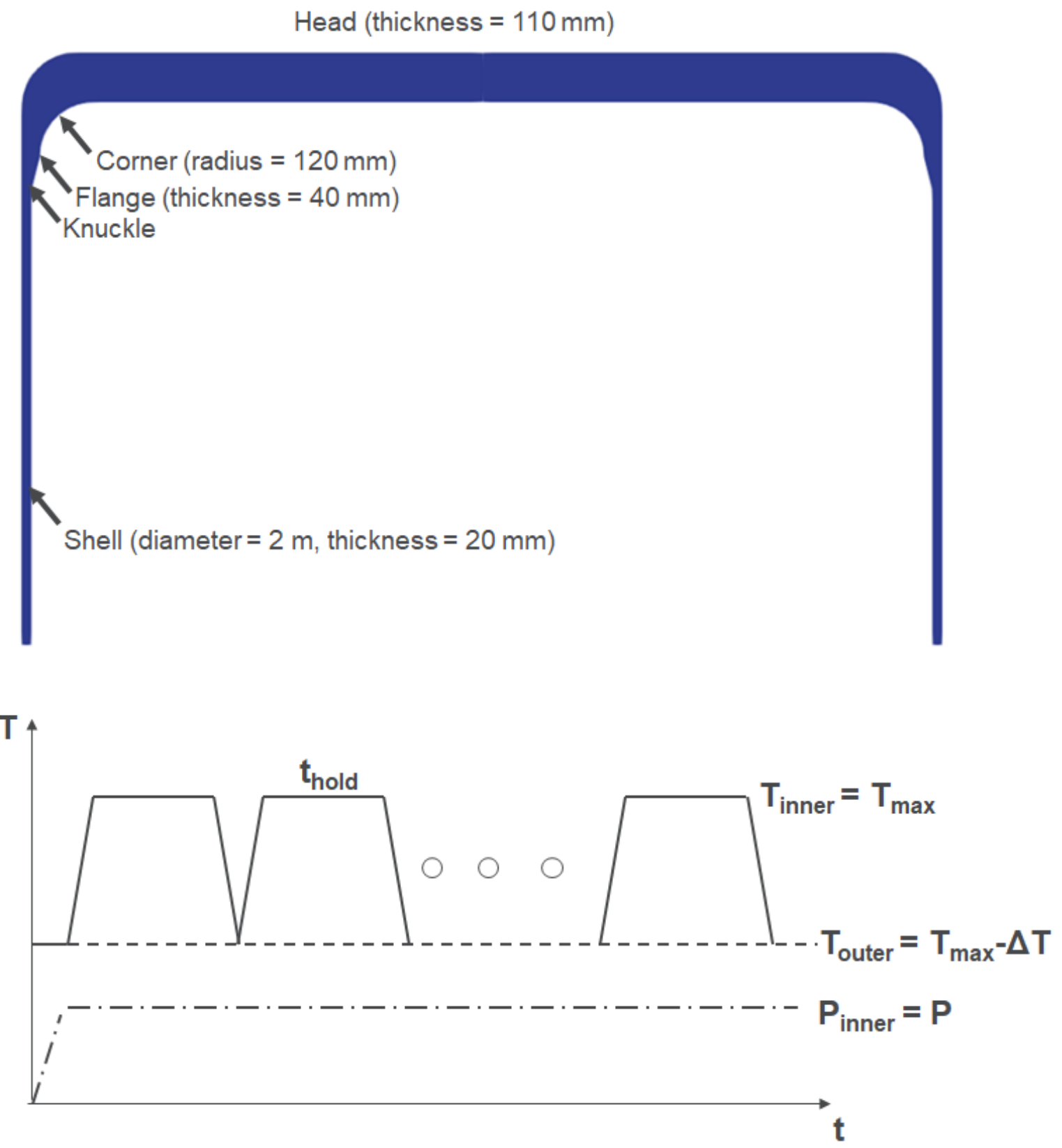

Figure 5.1: Alloy 617 flat head vessel problem. 
Both the design by inelastic analysis and design by elastic analysis methods compute creep and fatigue damage separately and then evaluate their combined effect using a creep-fatigue damage interaction diagram generated from creep-fatigue data. While the methods use strain range from analysis results to compute fatigue damage, creep damage is computed using stresses by comparing those to creep rupture design data and using a time faction rule. The time fraction approach for calculating creep damage might produce over conservative results as it keeps accumulating creep damage even after stresses reach to a complete relaxed state. The EPP+SMT method on the other hand attempts to evaluate the creep-damage directly from experimental data. However, generating creep-fatigue data in the low strain range regime and long hold time is practically impossible as these tests take long time to complete. The extrapolation approaches discussed in Chapter 4 and a new approach discussed in Chapter 3 try to address this issue by extrapolating the high strain range, short hold test data to low strain ranges and long hold times. Once an appropriate extrapolation is developed and can be verified through some mechanics based simulations, e.g. crystal plasticity, the EPP+SMT method could significantly cut down the over conservatism of current design methods. This is in addition to the already established advantage of EPP+SMT method - much simpler design evaluation process than current methods. As discussed in Chapter 4, the current EPP+SMT design charts generated based on the average approach are limited to 10,000 cycles to ensure interpolation over the available test data.

\begin{tabular}{|c|c|c|c|c|c|c|c|c|}
\hline \multirow{3}{*}{$\begin{array}{r}T_{\max } \\
\left({ }^{\circ} \mathrm{C}\right)\end{array}$} & \multirow{3}{*}{$\begin{array}{c}\Delta T \\
\left({ }^{\circ} \mathrm{C}\right)\end{array}$} & \multirow{3}{*}{$\begin{array}{r}P \\
(M P a)\end{array}$} & \multirow{3}{*}{$\begin{array}{r}t_{\text {hold }} \\
(\mathrm{hr})\end{array}$} & \multicolumn{4}{|c|}{ Design life (cycles) } & \multirow{3}{*}{$\begin{array}{r}E P P \text { Eq. } \\
\text { strain range } \\
\text { at critical } \\
\text { location }\end{array}$} \\
\hline & & & & \multirow{2}{*}{$\begin{array}{r}\text { Elastic } \\
\text { analysis }\end{array}$} & \multicolumn{2}{|c|}{ Inelastic analysis $^{\#}$} & \multirow{2}{*}{$\begin{array}{r}E P P+S M T \\
(Q=2)\end{array}$} & \\
\hline & & & & & $K^{\prime}=0.67$ & $K^{\prime}=0.9$ & & \\
\hline 950 & 25 & 0.1 & 1000 & 0 & 2 & 14 & 14 & $0.583 \%$ \\
\hline 950 & 25 & 0.1 & 100 & 0 & 3 & 22 & 21.5 & $0.463 \%$ \\
\hline 950 & 25 & 0.1 & 10 & 2 & 5 & 36 & 57.5 & $0.289 \%$ \\
\hline 950 & 10 & 0.1 & 1000 & 0 & 19 & 91 & 739.5 & $0.122 \%$ \\
\hline 950 & 10 & 0.1 & 100 & 0 & 35 & 187 & $>5,000\left(131,65^{*}\right)$ & $0.063 \%$ \\
\hline 950 & 10 & 0.1 & 10 & 11 & 92 & 408 & $>5,000(320,000 *)$ & $0.038 \%$ \\
\hline 950 & 10 & 0.2 & 10 & 1 & 89 & 364 & $>5,000(320,000 *)$ & $0.038 \%$ \\
\hline 950 & 10 & 0.5 & 10 & 0 & 8 & 24 & $>5,000(185,000 *)$ & $0.040 \%$ \\
\hline 850 & 25 & 0.1 & 1000 & 0 & 0 & 1 & 94.5 & $0.267 \%$ \\
\hline 850 & 25 & 0.1 & 100 & 3 & 0 & 20 & 717 & $0.161 \%$ \\
\hline 850 & 10 & 0.1 & 1000 & 3 & 1 & 84 & $>5000(12,100,000 *)$ & $0.035 \%$ \\
\hline 850 & 10 & 0.1 & 100 & 31 & 16 & 376 & $>5000(12,100,000 *)$ & $0.035 \%$ \\
\hline
\end{tabular}

\# ASME Section III, Division 5 design by inelastic analysis rules use $K^{\prime}=0.67$.

* Life without considering the 10,000 cycles limit in the EPP+SMT design charts.

Table 5.1: Creep-fatigue design life of the A617 flat head vessel under different loading conditions compared for different design methods. 


\subsection{Sample problem-2: A hot gas duct}

Figure 5.2 illustrates the second sample problem. This problem is based on a hot gas duct design in a helium engineering demonstration loop (HENDEL) with an intended use for high temperature gas-cooled reactors [41]. The loading condition and material considered here are different from the original design. Hot helium (He) gas flows through the liner tube while the cold He flows in between the inner and outer tube. The inner tube provides structural support for the hot He gas but without coming into direct contact. The thermal insulation between the liner and inner tubes helps avoid high through thickness temperature gradient for the inner tube under normal operating condition. During an incident of broken thermal insulation between the liner and inner tubes a control system activates the emergency shut down which cools down the hot He temperature to $400^{\circ} \mathrm{C}$ in $10 \mathrm{hr}$.

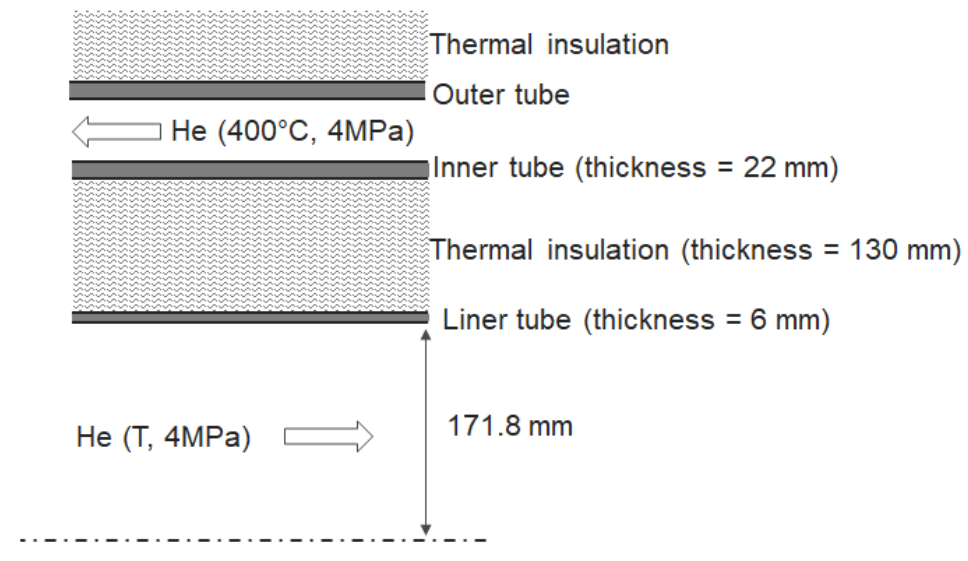

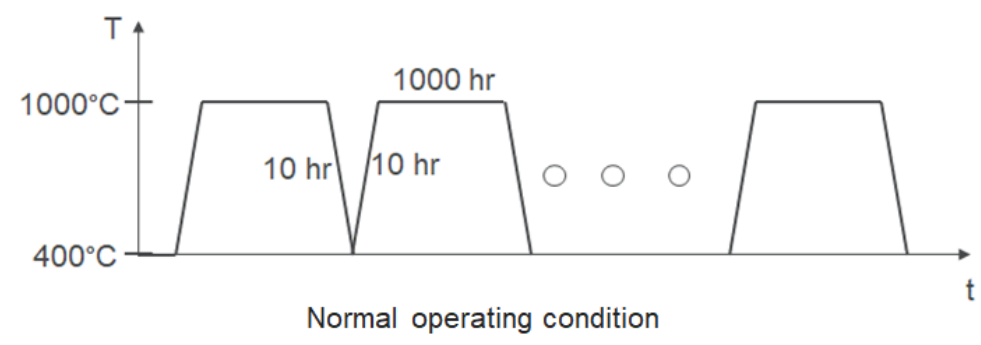

Figure 5.2: Alloy 617 hot gas duct problem.

Figure 5.3 plots the metal temperature of the inner, outer, and mid surface of the inner tube under both normal operating and accidental conditions. These results are from transient heat transfer analyses of the system considering kaowool for the thermal insulation. The convective heat transfer coefficient considered for He is $2000 \mathrm{~W} / \mathrm{m}^{2} \mathrm{~K}$, an approximate value from [12].

The temperature profiles of the inner tube show that there is a negligible through thickness temperature gradient during normal operating condition. The metal temperature is always about $400^{\circ} \mathrm{C}$ which is significantly less than the negligible creep temperature for Alloy 617. Therefore, the tube will not accumulate any creep-fatigue damage under normal operating condition. 

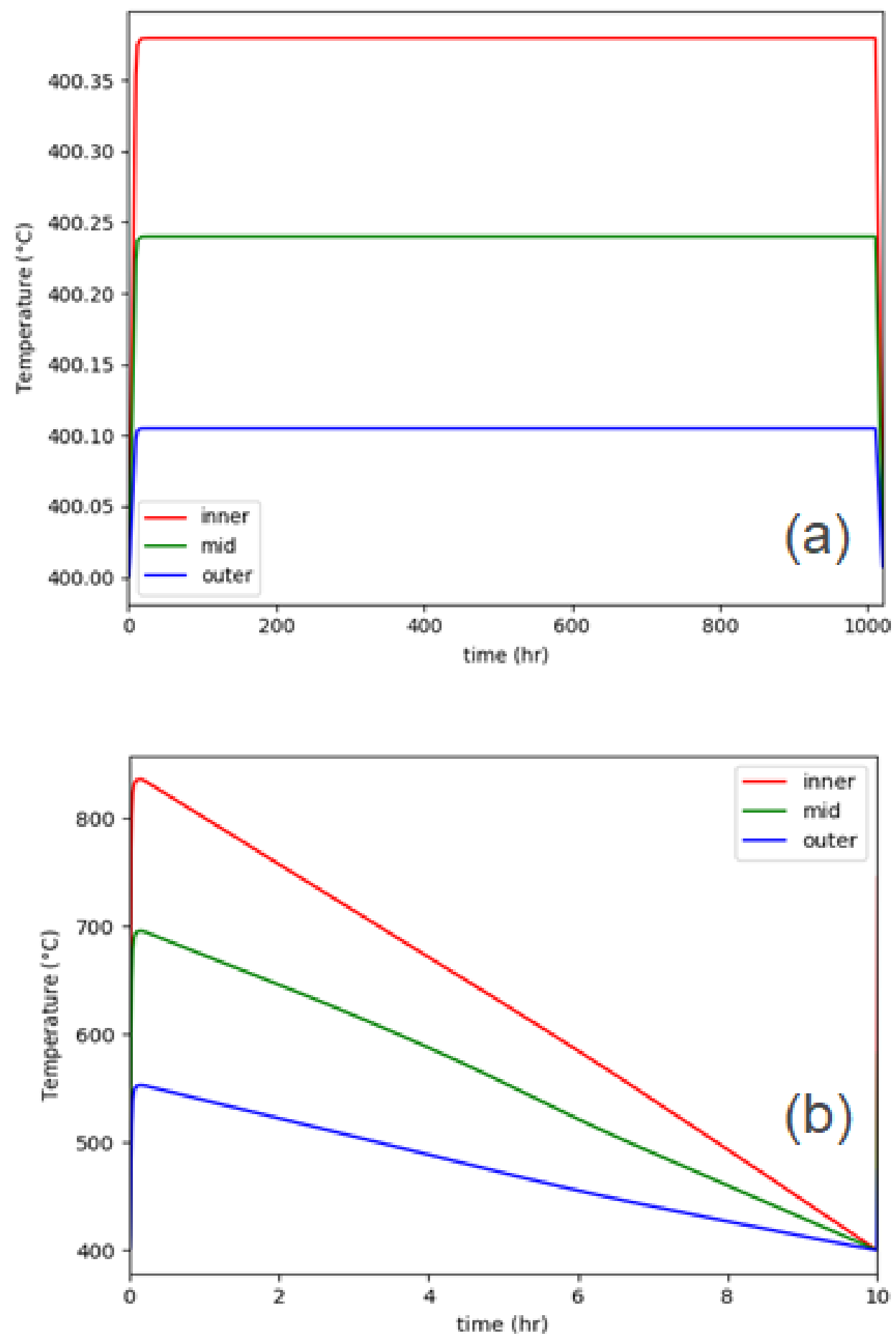

Figure 5.3: Metal temperature at different through thickness locations of the inner tube (a) under normal operating conditions and (b) during an accidental incident as a result of broken thermal insulation between the liner and inner tubes. 
The inner tube, however, will accumulate creep-fatigue damage during an accident. As indicated by the temperature profile in Figure 5.3b the tube will experience high through thickness temperature gradient as well as high the inner surface temperature, exceeding $800^{\circ} \mathrm{C}$. So, the sample problem evaluates how many of this incident can be allowed in service. Table 5.2 lists the allowable number of accidental incidents for the inner tube using different methods. Similar to the observation from the first sample problem, the design by elastic analysis method produces the most conservative estimation for this problem while the allowable number of incidents from design by inelastic analysis and EPP+SMT methods are close.

\begin{tabular}{|c|c|c|}
\hline Method & & Allowable incidents \\
\hline Design by elastic analysis & & 0 \\
\hline \multirow{2}{*}{ Design by inelastic analysis } & $\mathrm{K}^{\prime}=0.67$ & 13 \\
\hline & $\mathrm{K}^{\prime}=0.9$ & 30 \\
\hline \multirow{2}{*}{$\mathrm{EPP}+\mathrm{SMT}$} & $\mathrm{Q}=1$ & 27 \\
\hline & $\mathrm{Q}=2$ & 13 \\
\hline
\end{tabular}

Table 5.2: Allowable accidental incidents for the hot gas duct problem compared for different design methods.

\subsection{Sample problem-3: STP-PT-070 Heat recovery steam generator outlet header}

Figure 5.4 shows an additional sample problem: a representative Heat Recovery Steam Generator (HRSG) steam outlet header. This problem was defined and analyzed in an ASME report examining creep-fatigue design guidelines for non-nuclear components [42]. Further work at ASME on modernizing the Section I and Section VIII high temperature design rules continues to use the component as a reference problem [43]. This problem is useful in evaluating the new EPP+SMT design methods as it is well-studied with other creep-fatigue evaluation approaches, including the current Section III, Division 5 design by elastic analysis and design by inelastic analysis rules, and because it is representative of actual, operating, non-nuclear components under creep-fatigue critical loading conditions.

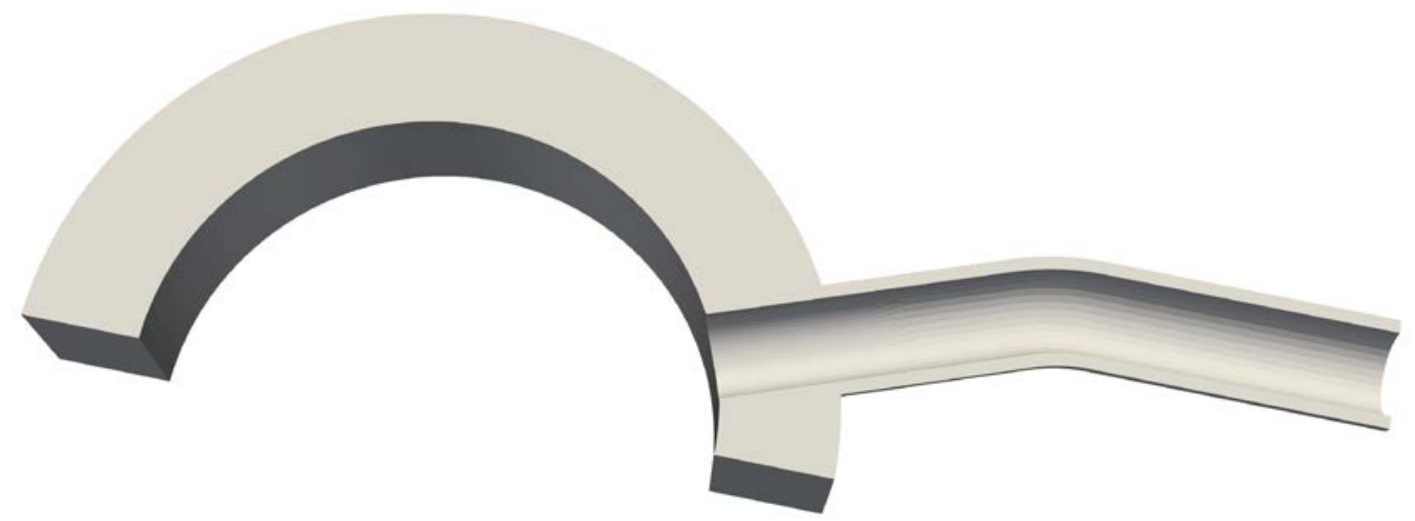

Figure 5.4: HRSG outlet header model. The model is half symmetric both out of the page (tube) and for the header (larger pipe section). 
The header is constructed from Grade 91 steel. Therefore, to evaluate the problem using the new design approach requires an EPP+SMT design chart of the type discussed in Chapter 4. Figure 5.5 shows a chart for Grade 91, based on creep-fatigue and SMT test data collected at Oak Ridge National Laboratory. The process for developing this chart from the test data is basically the same as for the A617 design charts discussed in detail above. The cutoff at 10,000 cycles, aimed at limiting the uncertainty in the method for untested high cycle creep-fatigue, may need to be adjusted based on the differences between the A617 and Grade 91 test database.

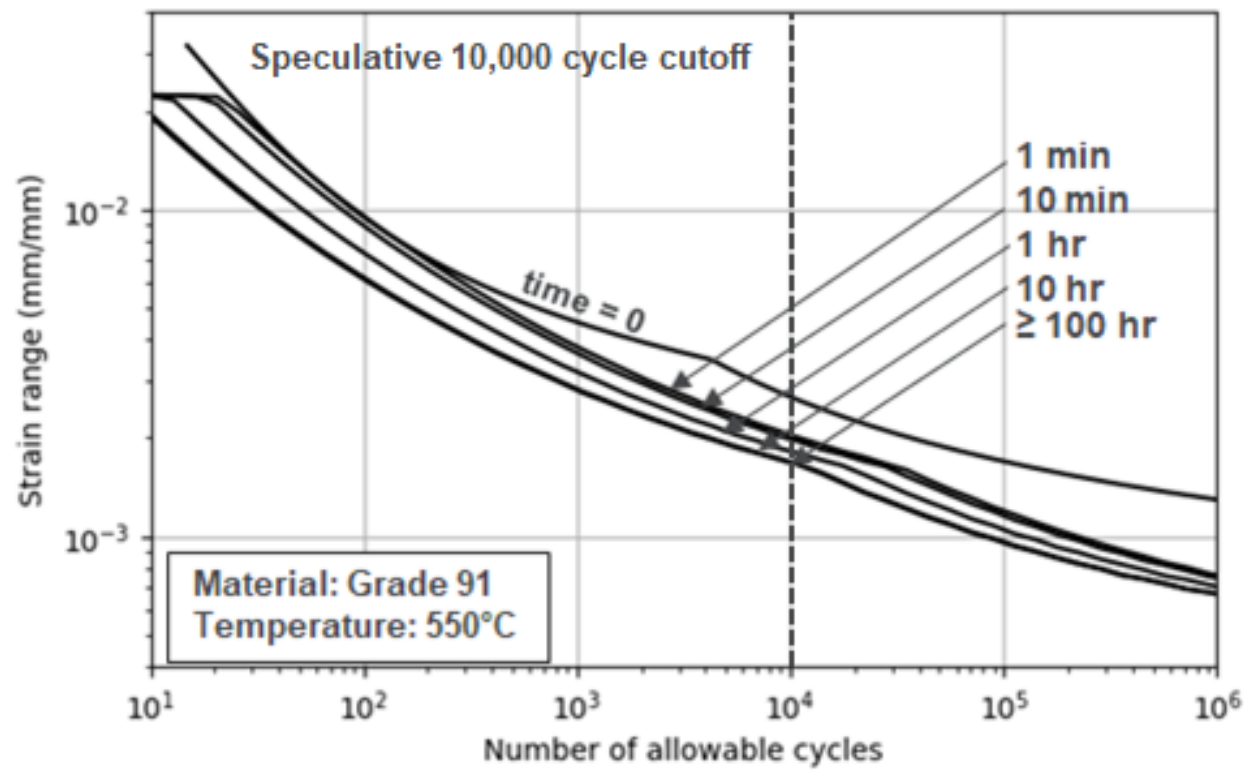

Figure 5.5: Design EPP+SMT chart for Grade 91 at $550^{\circ} \mathrm{C}$, based on ORNL test data.

Figure 5.6 defines a design load cycle for the component. This loading is not the same set of conditions used in the Section I/VIII analyses, but rather one designed to be more representative of high temperature reactor components operating for longer periods of steady operation (instead of typical HRSG cycles). The loading consists of a time-dependent internal pressure on both the header and tube as well as a time-dependent inner fluid temperature, transmitted to the metal via convective heat transfer. The outside of the header is treated as perfectly insulated. Symmetry conditions represent the $1 / 2$ header pipe and $1 / 2$ tube not in the model. The back face of the pipe section cannot deform axially and the remaining two surfaces (front of the pipe and top of the tube) are constrained to remain plane, but can expand and contract freely beyond that constraint. The loading cycle period is about 10,000 hours and the maximum metal temperature in the component resulting from the thermal loads is about $550^{\circ} \mathrm{C}$. Therefore, we use these conditions to index into the EPP+SMT design chart in Figure 5.5. 


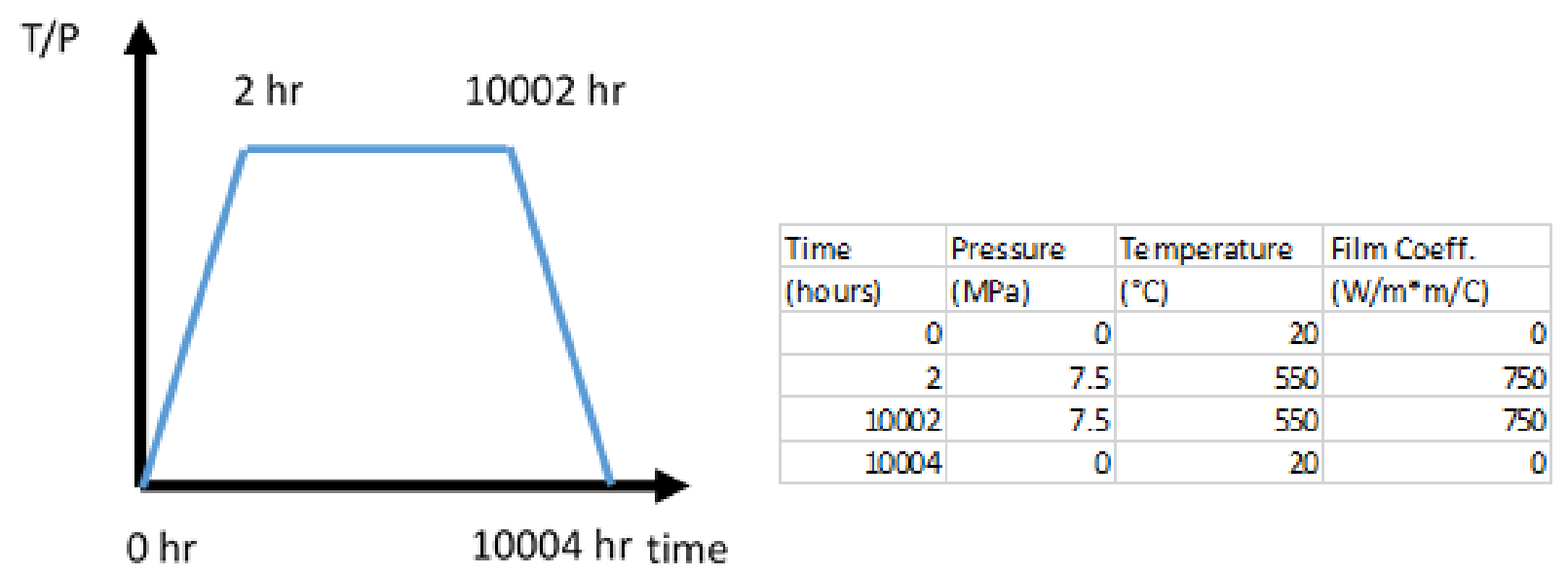

Figure 5.6: Loading conditions for the sample problem.

Table 5.3 compares the maximum permissible creep-fatigue design life of this component and loading using three different design methods:

1. The design by elastic analysis rules in Section III, Division 5, Subsection HB, Subpart B, Appendix HBB-T using the 2021 edition of the ASME Boiler and Pressure Vessel Code.

2. The design by inelastic analysis rules in Section III, Division 5, Subsection HB, Subpart B, Appendix HBB-T.

3. The EPP+SMT design rules described in this report, using the design chart in Figure 5.5.

\begin{tabular}{cc}
\hline Method & Allowable cycles \\
\hline Design by elastic analysis & 1 \\
Design by inelastic analysis & 100 \\
EPP+SMT & $>5,000$ \\
\hline
\end{tabular}

Table 5.3: Allowable design cycles for the three different creep-fatigue design methods.

The table demonstrates the three design methods produce vastly different allowable cyclic lives. For the EPP+SMT approach the maximum allowable number of cycles exceeds the 10,000 limit, the inelastic method allows only 100 cycles, and the elastic method only a single repetition. Because we use $Q=2$, this means the maximum allowable cycles is 5,000 i.e. 10,000/2. The large difference in the allowable cyclic life arise from three main factors:

1. The general conservatism in the design by elastic analysis method. Differences between the maximum design life for around one to two orders of magnitude between the design by elastic analysis and design by inelastic analysis method are common for many problems. This reflects the numerous conservative assumptions in the elastic method for approximating the effects of plasticity and creep on the component based only on a linear-elastic stress analysis. 
2. The explicit safety factor, $K^{\prime}$, in the design by inelastic analysis method. Both the design by elastic analysis and design by inelastic analysis methods increase the stresses from the modified analysis results by dividing by a safety factor $K^{\prime}$ before computing damage. Because creep damage tends relate to stress via a power law, this increased stress leads to a greatly decreased life, compared to the original stresses. Table 5.4 compares the design by inelastic analysis cyclic life of the component for three values of $K^{\prime}: 0.67$, corresponding to the actual ASME design by inelastic analysis rules, 0.9, used for design by elastic analysis, and 1.0. This factor has a large influence on the predicted life.

3. Differences in how the methods calculate stress relaxation damage. For this problem, and many other representative problems, the creep damage dominates the creep-fatigue damage calculation for both the current ASME methods. These approaches both calculate damage using a stress-based, time-fraction approximation. By contrast, the new method uses a conservative, bounding strain range and strain-based creep-fatigue curves. Though of course strain and stress are linked, this notionally means that the EPP-SMT approach is independent of the stress and the current methods are independent of the strain. This fundamental difference, essentially in how the approaches extrapolate test data to the high cycle regime, can translate to large differences in the component creep-fatigue design life.

\begin{tabular}{cc}
\hline$K^{\prime}$ & Allowable cycles \\
\hline 0.67 & 100 \\
0.9 & 330 \\
1.0 & 466
\end{tabular}

Table 5.4: Allowable design life for design by inelastic analysis for different values of $K^{\prime}$.

This sample problem illustrates the potential promise of the EPP+SMT design method: it could result in vastly increased allowable creep-fatigue life compared to current methods. Given that creep-fatigue is likely to control the design life of many key advanced reactor components, this could directly lead to large cost-savings for plant designers and vendors. However, the large differences between the EPP+SMT and current design methods warrants further validation of the new approach, to ensure that it conservative predicts creep-fatigue life for low strain range/long hold time conditions. 



\section{Walk-through sample problem with multiple load cycles}

All the sample problems discussed in Chapter 5 consider single load case. This chapter considers an additional sample problem to show how to handle multiple load cases in EPP+SMT design process. The sample problem also walks through the step-by-step procedure in the draft design rules (Chapter 2 plus the selected options for several subprocedures in Chapter 4).

\subsection{Problem description and load definition}

Figure 6.1 show the problem. It is an Alloy 617 flat head vessel with He flowing inside the vessel and air flowing outside the vessel. Air temperature and pressure are constant at $550^{\circ} \mathrm{C}$ and 0.2 $\mathrm{MPa}$, respectively. He pressure is also constant at $0.3 \mathrm{MPa}$. He temperature changes following the loading conditions provided in Table 6.1. The loading conditions includes a Service Level A load a and two Service Level B loads $b_{1}$ and $b_{2}$. Load $a$ includes a $10 \mathrm{hr}$ start-up and a $10 \mathrm{hr}$ shut-down transients plus a $1,000 \mathrm{hr}$ long normal steady operation. Both loads $b_{1}$ and $b_{2}$ are fluctuations from normal steady operation. The design life of the vessel is $5100 \mathrm{hr}$ which include 5 repetitions of load $a$ and 1 repetition of both load $b_{1}$ and $b_{2}$.

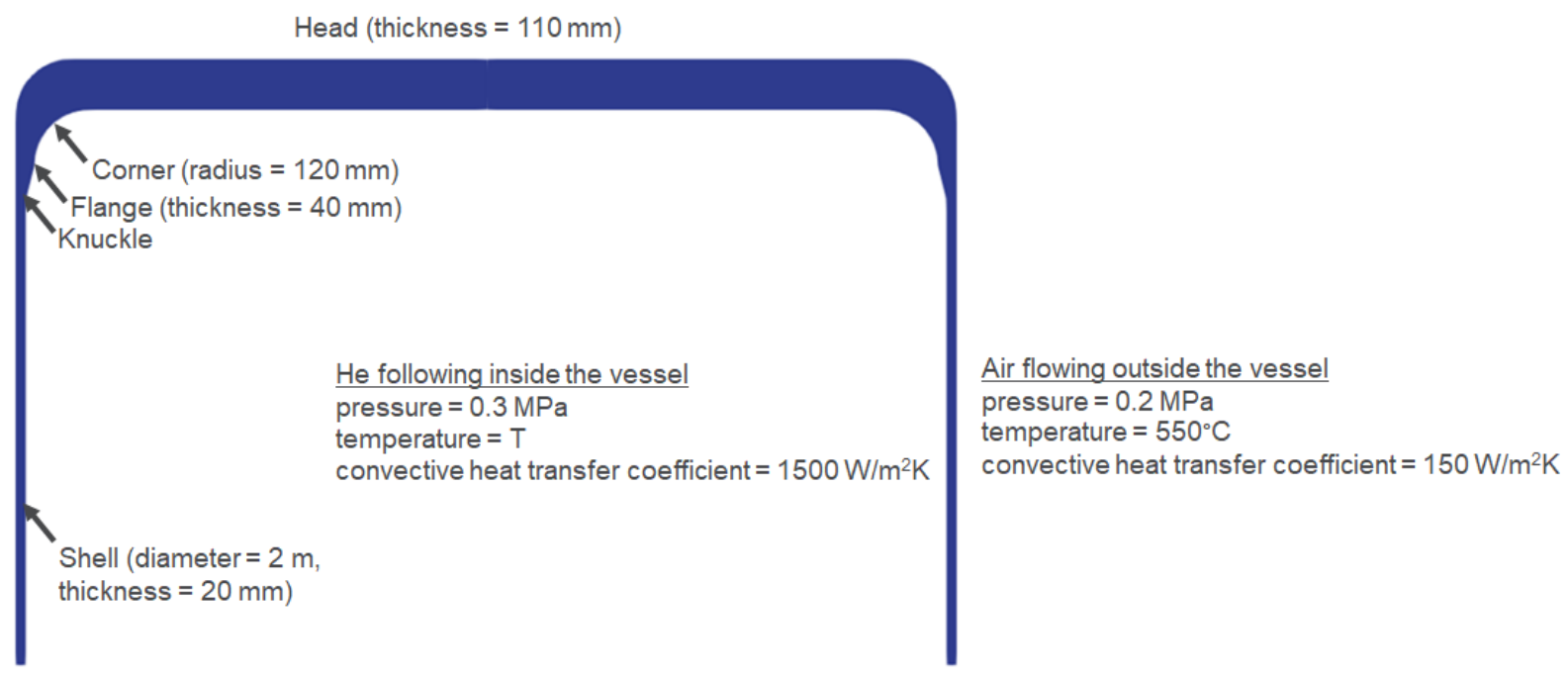

Figure 6.1: Alloy 617 flat head vessel.

\begin{tabular}{lccc} 
& Load a & Load b1 & Load b2 \\
\hline Service level & $\mathrm{A}$ & $\mathrm{B}$ & $\mathrm{B}$ \\
Cold temperature & $550^{\circ} \mathrm{C}$ & $900^{\circ} \mathrm{C}$ & $900^{\circ} \mathrm{C}$ \\
Hot temperature & $900^{\circ} \mathrm{C}$ & $935^{\circ} \mathrm{C}$ & $970^{\circ} \mathrm{C}$ \\
Heat up/cool down time & $10 \mathrm{hr}$ & $1 \mathrm{hr}$ & $1 \mathrm{hr}$ \\
Hold at hot temperature & $1000 \mathrm{hr}$ & $8 \mathrm{hr}$ & $8 \mathrm{hr}$ \\
Total repetitions & 5 & 1 & 1 \\
\hline
\end{tabular}

Table 6.1: He temperature, $T$ inside the vessel under different loading condition. 


\subsection{Composite cycles}

Table 6.2 lists all the composite cycles generated following Equation 1 in draft design rules. Figure 6.2 shows the temperature profiles for He inside the vessel for different composite cycle types.

\begin{tabular}{ccc}
\hline $\begin{array}{c}\text { Composite } \\
\text { cycle type, } i\end{array}$ & $\begin{array}{c}\text { Service } \\
\text { Loads }\end{array}$ & $\begin{array}{c}\text { Number of } \\
\text { repetitions, } n^{i}\end{array}$ \\
\hline 1 & $a$ & 3 \\
2 & $a+b_{1}$ & 1 \\
3 & $a+b_{2}$ & 1 \\
\hline
\end{tabular}

Table 6.2: Service loads and their repetitions considered in composite cycles.
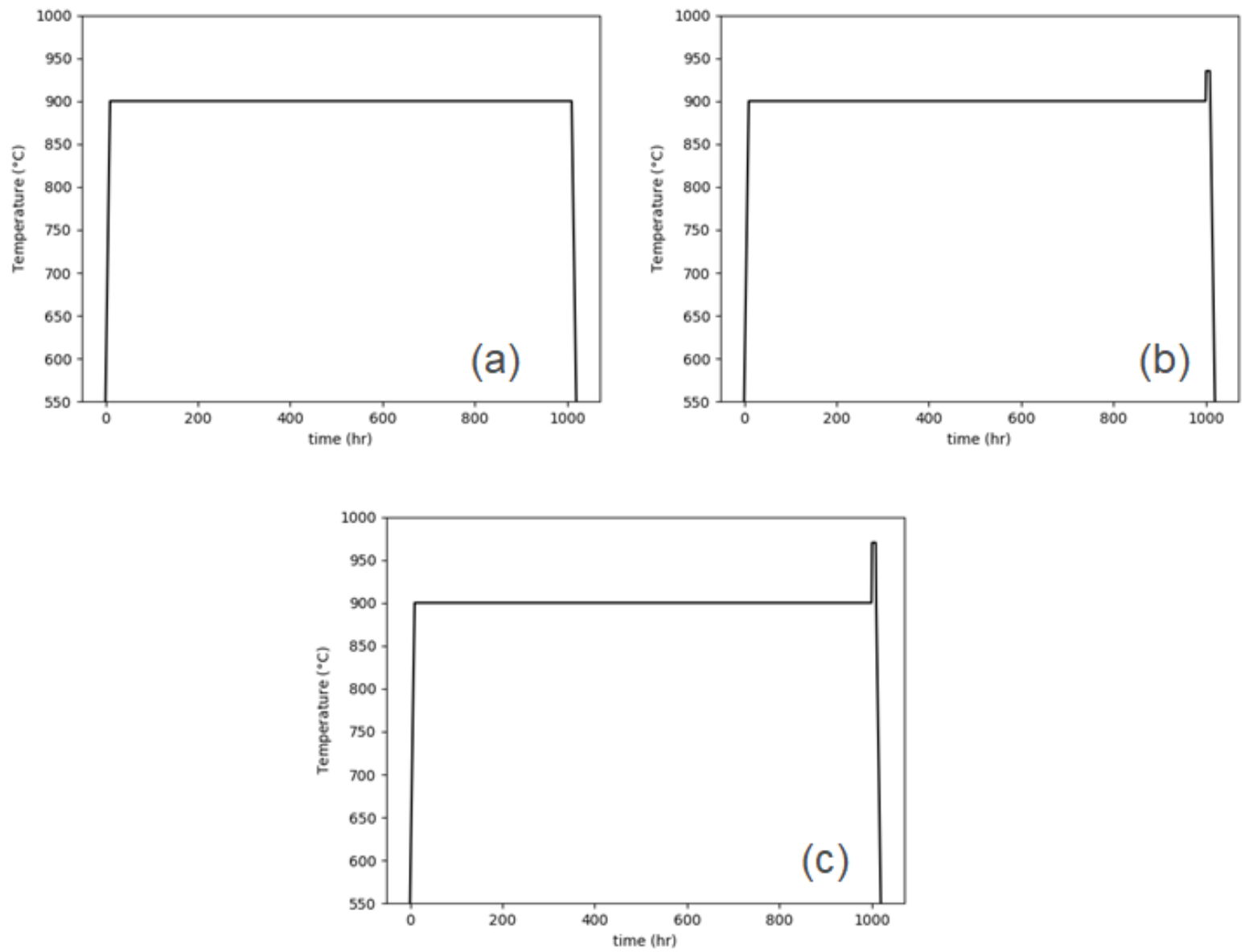

Figure 6.2: He temperature profiles under different composite cycles. (a) composite cycle type-1, (b) composite cycle type-2, and (c) composite cycle type-3. 


\subsection{Cyclic EPP analysis}

For each composite cycle type defined above a cyclic coupled transient thermal-structural finite element analysis is performed until a steady cyclic condition is achieved. In these calculations the constitutive response of Alloy 617 is represented using an elastic-perfectly plastic material model with a temperature dependent pseudoyield stress. As defined in the draft rules, the pseudoyield stress is the lesser of the yield strength and a stress determined from the isochronous stress-strain curves for a $0.2 \%$ offset in strain from the elastic slope for a time equal to the composite cycle period. Figure 6.2 indicates the period for all three types of composite cycles is 1,020 hr. The steady cyclic solution from EPP analysis are used for creep-fatigue evaluation as discussed below.

\subsection{Creep-fatigue evaluation}

Creep-fatigue evaluation starts with the steady cyclic strain and temperature history from the cyclic EPP analysis. From the strain and temperature history, a list of strain ranges, $\Delta \epsilon_{j}^{i}$, temperatures, $T_{j}^{i}$, and corresponding number of cycles, $N_{j}^{i}$ are calculated using the cycle counting procedure provided in the draft rules. In the next step, $N_{j, k}^{i}$ is determined for each individual cycle: $N_{j, k}^{i}=1$ for a full cycle and $N_{j, k}^{i}=0.5$ for a half cycle. A time, $t_{j, k}^{i}$ must be also assigned to each individual full or half cycle. The total of the assigned times must be greater than or equal to the composite cycle period. As a conservative approach, we assign the composite cycle period to the maximum strain range full cycle. Using $\left(\Delta \epsilon_{j}^{i}, T_{j}^{i}, t_{j, k}^{i}\right)$ an allowable number of cycle, $N_{d}$ is then determined from the design charts for each individual cycle. The total creep-fatigue damage is then calculated using Equation 4.4. The total creep-fatigue damage must be less than or equal to 1 at all points in the structure for the design to pass. Table 6.3 summarizes the creep-fatigue damage evaluation at a critical location of the flat head vessel. The design passes the creep-fatigue evaluation as the total creep-fatigue damage is less than 1.

\begin{tabular}{ccccccccc}
\hline $\begin{array}{c}\text { Composite } \\
\text { cycle } i\end{array}$ & $\Delta \epsilon_{j}^{i}$ & $T_{j}^{i}$ & $t_{j, k}^{i}$ & $N_{j, k}^{i}$ & $N_{d}\left(\Delta \epsilon_{j}^{i}, T_{j}^{i}, t_{j, k}^{i}\right)$ & $Q$ & $n^{i}$ & $\frac{Q * n_{i} * N_{j, k}^{i}}{N_{d}\left(\Delta \epsilon_{j}^{i}, T_{j}^{i}, t_{j, k}^{i}\right)}$ \\
\hline 1 & 0.00813 & 867 & 1020 & 1 & 13 & 2 & 3 & 0.4615 \\
\hline \multirow{2}{*}{2} & 0.00937 & 899 & 1020 & 1 & 11 & 2 & 1 & 0.1818 \\
& 0.00074 & 883 & 0 & 0.5 & 10,000 & 2 & 1 & 0.0001 \\
\hline \multirow{2}{*}{3} & 0.01186 & 930 & 1020 & 1 & 8 & 2 & 1 & 0.2500 \\
& 0.00185 & 898 & 0 & 0.5 & 6,737 & 2 & 1 & 0.0001 \\
\hline \multicolumn{7}{c}{ Total creep-fatigue damage, $D=0.8935<1$} \\
\hline
\end{tabular}

Table 6.3: Summary of creep-fatigue evaluation at a critical location of the flat head vessel. 



\section{Conclusions}

The report develops a complete set of draft design rules for creep-fatigue evaluation of high temperature nuclear components using an integrated EPP analysis and SMT approach. The description of the design method includes a discussion of alternative options for key design steps, along with a complete, step-by-step description and technical justification of one particular set of alternative options. The report develops EPP+SMT design charts for Alloy 617 at temperatures between $800^{\circ} \mathrm{C}$ and $950^{\circ} \mathrm{C}$. To construct the design charts from high strain range, short hold creep-fatigue test data the report investigates three extrapolation approaches -1) direct extrapolation, 2) classical, and 3) average of direct extrapolation and classical. While all the approaches predict the creepfatigue test data in the high strain range regime equally well, only the average approach reasonably captures the few available intermediate strain range (in the transition between high strain range and low strain range regimes) tests for different Class A materials. The design charts are therefore constructed using the average extrapolation approach. The design charts are, however, limited to 10,000 cycles for Alloy 617 to restrict the charts to interpolation over the available test data.

Results from EPP analysis of the SMT and p-SMT tests indicate that the steady cyclic EPP strain range can capture the effect of elastic follow up on the creep-fatigue cyclic life. Considering the lack of SMT failure data in the low strain range regime, however, the draft rules let the designer determine an appropriate value for the elastic follow up factor, $Q$, for piping systems and recommends using $Q=2$ for other structures.

The report uses the p-SMT failure data to validate the design rules. The EPP+SMT method conservatively estimates the design life of p-SMT specimens when compared with the experimental failure data. When compared with current creep-fatigue design methods, the EPP+SMT method provides the least conservative estimate of design life for the low strain range p-SMT test.

The report also compares the EPP+SMT methods with current creep-fatigue design methods for several representative high temperature nuclear components. The comparison shows that the EPP+SMT method can significantly reduce the over-conservatism in current methods.

Finally, the report provides a sample problem with multiple load cases walking through the proposed design rules. This sample problem could be used to educate reactor designers and other potential users of the EPP+SMT design method on the process of executing the design method.

The design results described here are complete in that they can be fully-executed to design Alloy 617 components operating in the creep-regime. The report identifies several aspects of the method that could be further optimized:

- The various alternative options should be down-selected to develop a final design method to propose to ASME as a nuclear Code Case. Additional testing or analysis could be used to aid in the selection process. Alternatively, several of the best options could be integrated into the proposed Code Case, allowing the designer to select from a choice of methods depending on the required accuracy and level of analysis. 
- The method for constructing the design curves should be rationalized with the goal of removing the 10,000 cycle limitation. The work-based method discussed in Chapter 3 could provide a method for accomplishing this task.

- An improved, prescriptive cycle counting procedures that accounts for the cycle time should be developed and tested.

- Validation testing, ideally against component tests, should be completed to support the adoption of the new design method by the ASME, regulators, and the reactor designer community.

Additionally, the method needs to be extended to the remaining ASME Class A materials. The primary challenge will be formulating design curves. For recently-studied materials like Grade 91 and $316 \mathrm{H}$ current and historical creep-fatigue data can be used to set the EPP+SMT design charts, and the curves validated by a limited amount of SMT testing. For the other materials additional, dedicated cyclic tests may be required, unless data can be identified from historical sources. As with Alloy 617, component validation testing should be an additional long-term goal. 


\section{Acknowledgements}

This research was sponsored by the US Department of Energy (DOE), under Contract No. DEAC07-05ID14517 with Idaho National Laboratory (INL), managed and operated by Battelle Energy Alliance, under Contract No. DE-AC02-06CH11357 with Argonne National Laboratory, managed and operated by UChicago Argonne LLC, and under contract DE-AC05-00OR22725 with Oak Ridge National Laboratory, managed and operated by UT-Battelle LLC. Programmatic direction was provided by the Office of Nuclear Reactor Deployment of the DOE Office of Nuclear Energy.

The authors gratefully acknowledge the support provided by Sue Lesica, Federal Advanced Materials Lead, Advanced Reactor Technologies (ART) Program, Diana Li, Federal Program Manager, ART Gas-Cooled Reactors (GCR) Campaign, and Gerhard Strydom of INL, National Technical Director, ART GCR Campaign. 



\section{Bibliography}

[1] Jetter, R. I. (1998). An Alternate Approach to Evaluation of Creep-Fatigue Damage for High Temperature Structural Design Criteria. ASME-PUBLICATIONS-PVP, 365, 199206.

[2] Sham, T. L., Jetter, R. I., \& Wang, Y. (2016). Elevated temperature cyclic service evaluation based on elastic-perfectly plastic analysis and integrated creep-fatigue damage. In Pressure Vessels and Piping Conference (Vol. 50367, p. V01BT01A022). American Society of Mechanical Engineers.

[3] American Society of Mechanical Engineers. Section III, Division 5. In ASME Boiler and Pressure Vessel Code. 2019.

[4] American Society of Mechanical Engineers. Code Case N-862. In ASME Boiler and Pressure Vessel Code. 2017

[5] Messner, M. C., Sham, T. L., Wang, Y., \& Jetter, R. I. (2018). Evaluation of methods to determine strain ranges for use in SMT design curves (No. ANL-ART-138). Argonne National Lab.(ANL), Argonne, IL (United States).

[6] Wang, Y., Messner, M. C., Sham, T. L. (2018). Report on the FY18 Uniaxial Material Model Testing and Key Feature Test Articles Testing of Grade 91 (No. ORNL/TM2018/885). Oak Ridge National Lab.(ORNL), Oak Ridge, TN (United States).

[7] Wang, Y., Jetter, R. I., Messner, M. C., Sham, T. L. (2018). Report on FY18 Testing Results in Support of Integrated EPP-SMT Design Methods Development (No. ORNL/TM2018/887). Oak Ridge National Lab.(ORNL), Oak Ridge, TN (United States).

[8] Wang, Y., Jetter, R. I., Messner, M. C., \& Sham, S. (2019). Report on FY19 Testing in Support of Integrated EPP-SMT Design Methods Development (No. ORNL/TM2019/1224). Oak Ridge National Lab.(ORNL), Oak Ridge, TN (United States).

[9] Wang, Y., Jetter, R. I., \& Sham, T. L. (2016). Preliminary Test Results in Support of Integrated EPP and SMT Design Methods Development. ORNL/TM-2016/76, Oak Ridge National Laboratory, Oak Ridge, TN.

[10] Wang, Y., Hou, P., Jetter, R. I., \& Sham, S. (2020). Report on FY2020 Test Results in Support of the Development of EPP Plus SMT Design Method(No. ORNL/TM2020/1620). Oak Ridge National Lab.(ORNL), Oak Ridge, TN (United States).

[11] Wang, Y., Jetter, B., Messner, M. C., \& Sham, T. L. (2019). Development of Simplified Model Test Methods for Creep-Fatigue Evaluation. In Pressure Vessels and Piping Conference (Vol. 58929, p. V001T01A065). American Society of Mechanical Engineers.

[12] Wang, Y., Hou, P., Jetter, R. I., \& Sham, S. (2020). Report on FY 2020 Testing in Support of the Development and Extension of ASME Code Rules for Grade 91 (No. ORNL/TM2020/1613). Oak Ridge National Lab.(ORNL), Oak Ridge, TN (United States).

[13] Wang, Y., Hou, P., Jetter, R. I., \& Sham, S. (2017). Report on FY17 testing in support of integrated EPP-SMT design methods development. (No. ORNL/TM-2017/351). Oak Ridge National Lab.(ORNL), Oak Ridge, TN (United States).. 
[14] Barua, B., Messner, M. C., Sham, T. L., Jetter, R. I., \& Wang, Y. (2020). Preliminary description of a new creep-fatigue design method that reduces over conservatism and simplifies the high temperature design process (No. ANL-ART-194). Argonne National Lab.(ANL), Argonne, IL (United States).

[15] Messner, M. C., Jetter, R. I., Wang, Y., \& Sham, T. L. (2019). Initial Development of an Improved Creep-Fatigue Design Method that Avoids the Separate Evaluation of Creep and Fatigue Damage and Eliminates the Requirement for Stress Classification (No. ANLART-168). Argonne National Lab.(ANL), Argonne, IL (United States).

[16] Messner, M. C., \& Sham, T. L. (2019). Development of a multiaxial deformation measure and creep-fatigue damage summation for multiple load cycle types in support of an improved creep-fatigue design method (No. ANL-ART-164). Argonne National Lab.(ANL), Argonne, IL (United States).

[17] Carter, P. (1985). Bounding theorems for creep-plasticity. International journal of solids and structures, 21(6), 527-543.

[18] Carter, P. (2005). Analysis of cyclic creep and rupture. Part 1: Bounding theorems and cyclic reference stresses. International journal of pressure vessels and piping, 82(1), 1526.

[19] Carter, P. (2005). Analysis of cyclic creep and rupture. Part 2: Calculation of cyclic reference stresses and ratcheting interaction diagrams. International journal of pressure vessels and piping, 82(1), 27-33.

[20] Carter, P., Jetter, R. I., \& Sham, T. L. (2012). Application of elastic-perfectly plastic cyclic analysis to assessment of creep strain. In Pressure Vessels and Piping Conference (Vol. 55003, pp. 749-760). American Society of Mechanical Engineers.

[21] American Society of Mechanical Engineers. Code Case N-862. In ASME Boiler and Pressure Vessel Code. 2017

[22] Messner, M. C., Jetter, R. I., \& Sham, T. L. (2020). A High Temperature Primary Load Design Method Based on Elastic Perfectly-Plastic and Simplified Inelastic Analysis. In Pressure Vessels and Piping Conference (Vol. 83815, p. V001T01A068). American Society of Mechanical Engineers.

[23] Frederick, C. \& P. Armstrong. (1966). Convergent internal stresses and steady cyclic states of stress. The Journal of Strain Analysis for Engineering Design, 1(2), 154-159.

[24] Hayhurst, D. R. (1972). Creep of metals under multi-axial states of stress. Journal of the Mechanics and Physics of Solids, 20, 381-390.

[25] Chubb, E. J. \& Bolton, C. J. (1980). Stress state dependence of creep deformation and fracture in AISI type 316 stainless steel. In International conference on engineering aspects of creep, (London), 39-48.

[26] Huddleston, R. L. (1985). An Improved Multiaxial Creep-Rupture Strength Criterion. Journal of Pressure Vessel Technology, 107(November), 421-429.

[27] Rovinelli, A., Messner, M. C., \& Sham, T. L. (2021). “A comprehensive comparison between different multiaxial cycle counting procedure,” In Pressure Vessels and Piping Conference (PVP2021-62067). American Society of Mechanical Engineers 
[28] Coffin, L. F. (1976). The Concept of Frequency Separation Methods in Life Prediction for Time-Dependent Fatigue. In ASME-MPC Symposium on Creep-Fatigue Interaction (MPC-3) (pp. 346-363).

[29] American Society of Mechanical Engineers. Code Case N-898. In ASME Boiler and Pressure Vessel Code. 2019.

[30] Kato, S., Furukawa, T., \& Yoshida, E. (2009). Material test data of Mod. 9Cr-1Mo steel (1) (No. JAEA-DATA/CODE--2008-030). Japan Atomic Energy Agency.

[31] Brinkman, C. R., Strizak, J. P., \& Booker, M. K. (1978). Use of Strain-Range Partitioning for Predicting Time-Dependent, Strain-Controlled Cyclic Lifetimes of Uniaxial Specimens of 2 1/4 Cr-1 Mo Steel, Type 316 Stainless Steel, and Hastelloy X (No. ORNL-5396). Oak Ridge National Lab.(ORNL), Oak Ridge, TN (United States).

[32] Spindler, M. W. (2006). An improved method to calculate the creep-fatigue endurance of type $316 \mathrm{H}$ stainless steel. Materials for advanced power engineering.

[33] Messner, M. C., Jetter, B., \& Sham, T. L. (2019). A Method for Directly Assessing Elastic Follow Up in 3D Finite Element Calculations. In Pressure Vessels and Piping Conference (Vol. 58929, p. V001T01A064). American Society of Mechanical Engineers.

[34] Messner, M. C., \& Sham, T. L. (2021). Reference constitutive model for Alloy 617 and $316 \mathrm{H}$ stainless steel for use with the ASME Division 5 design by inelastic analysis rules (No. ANL-ART-225). Argonne National Lab.(ANL), Argonne, IL (United States).

[35] Kobashi, K. I., \& Udoguchi, T. (1986). Stress and strain behaviors under uniaxial elastic follow-up. Bulletin of JSME, 29(257), 3672-3678.

[36] Wang, Y., Smith, D. J., \& Truman, C. E. (2013). Inelastic deformation and elastic followup. In Pressure Vessels and Piping Conference (Vol. 55638, p. V01AT01A049). American Society of Mechanical Engineers.

[37] Smith, D. J., \& Shirahatti, A. M. (2015). The effects of long-range residual stress, elastic follow-up and applied load on creep crack incubation and material toughness. The Journal of Strain Analysis for Engineering Design, 50(7), 455-469.

[38] Zhao, Z. Z., Wu, X. Y., \& Chen, X. (2015). Structural Integrity and Creep-fatigue Assessment by ASME-NH for Hydrogenation Equipment at $454^{\circ} \mathrm{C}$. Procedia Engineering, 130, 414-422.

[39] Messner, M. C., Phan, V. T., \& Sham, T. L. (2019). Evaluating and modeling rate sensitivity in advanced reactor structural materials: 316H, Gr. 91, and A617. International Journal of Pressure Vessels and Piping, 178, 103997.

[40] Hishida, M., Kunitomi, K., Ioka, I., Umenishi, K., Tanaka, T., Shimomura, H., \& Sanokawa, K. (1984). Thermal performance test of the hot gas ducts of HENDEL. Nuclear engineering and design, 83(1), 91-103.

[41] Liu, Q., Wang, L., Mitsuishi, A., Shibahara, M., \& Fukuda, K. (2017). Transient heat transfer for helium gas flowing over a horizontal cylinder in a narrow channel. Experimental Heat Transfer, 30(4), 341-354. 
[42] "Design Guidance for the Effects of Creep, Fatigue, \& Creep-Fatigue Interaction with Design-By-Analysis and Nondestructive Inspection Acceptance Criteria.” Technical report, American Society of Mechanical Engineers International, ASME-STP-070, 2014.

[43] Mann, A. et al. (2021). Comparison of Candidate Steady Loading Elevated Temperature Design-by-Analysis Methods. In Pressure Vessels and Piping Conference (PVP202163905). American Society of Mechanical Engineers.

[44] Penny, R. K., \& Marriott, D. L. (2012). Design for creep. Springer Science \& Business Media.

[45] Dasgupta, A., Oyan, C., Barker, D., \& Pecht, M. (1992). Solder creep-fatigue analysis by an energy-partitioning approach.

[46] Jeong, C. Y., et al. (2007). Normalized creep-fatigue life prediction model based on the energy dissipation during hold time. Materials Science and Engineering: A., 460, 195-203.

[47] Massiot, G., \& Munier, C. (2004, May). A review of creep fatigue failure models in solder material-simplified use of a continuous damage mechanical approach. In 5th International Conference on Thermal and Mechanical Simulation and Experiments in Microelectronics and Microsystems, 2004. EuroSimE 2004. Proceedings of the (pp. 465-472). IEEE.

[48] He, M., Huang, B., Zhu, C., Chen, Y., \& Li, N. (2018). Energy dissipation-based method for fatigue life prediction of rock salt. Rock Mechanics and Rock Engineering, 51(5), 14471455.

[49] Wang, C., \& Brown, M. (1996). Life prediction techniques for variable amplitude multiaxial fatigue-Part 1: Theories. Journal of engineering materials and technology, 118(3), 367-370.

[50] Wang, C., \& Brown, M. (1996). Life prediction techniques for variable amplitude multiaxial fatigue-Part 2: Comparison with experimental results. Journal of engineering materials and technology, 118(3), 371-374. 



\section{Argonne}

\section{Applied Materials Division}

Argonne National Laboratory

9700 South Cass Avenue, Bldg. 212

Argonne, IL 60439

www.anl.gov

Argonne National Laboratory is a U.S. Department of Energy laboratory managed by UChicago Argonne, LLC 